\title{
Sleep, depression and antidepressants
}

Citation for published version (APA):

van Bemmel, A. L. (1993). Sleep, depression and antidepressants. [Doctoral Thesis, Maastricht University]. Scorpio. https://doi.org/10.26481/dis.19931124ab

Document status and date:

Published: 01/01/1993

DOI:

10.26481/dis.19931124ab

Document Version:

Publisher's PDF, also known as Version of record

\section{Please check the document version of this publication:}

- A submitted manuscript is the version of the article upon submission and before peer-review. There can be important differences between the submitted version and the official published version of record.

People interested in the research are advised to contact the author for the final version of the publication, or visit the DOI to the publisher's website.

- The final author version and the galley proof are versions of the publication after peer review.

- The final published version features the final layout of the paper including the volume, issue and page numbers.

Link to publication

\footnotetext{
General rights rights.

- You may freely distribute the URL identifying the publication in the public portal. please follow below link for the End User Agreement:

www.umlib.nl/taverne-license

Take down policy

If you believe that this document breaches copyright please contact us at:

repository@maastrichtuniversity.nl

providing details and we will investigate your claim.
}

Copyright and moral rights for the publications made accessible in the public portal are retained by the authors and/or other copyright owners and it is a condition of accessing publications that users recognise and abide by the legal requirements associated with these

- Users may download and print one copy of any publication from the public portal for the purpose of private study or research.

- You may not further distribute the material or use it for any profit-making activity or commercial gain

If the publication is distributed under the terms of Article $25 \mathrm{fa}$ of the Dutch Copyright Act, indicated by the "Taverne" license above, 



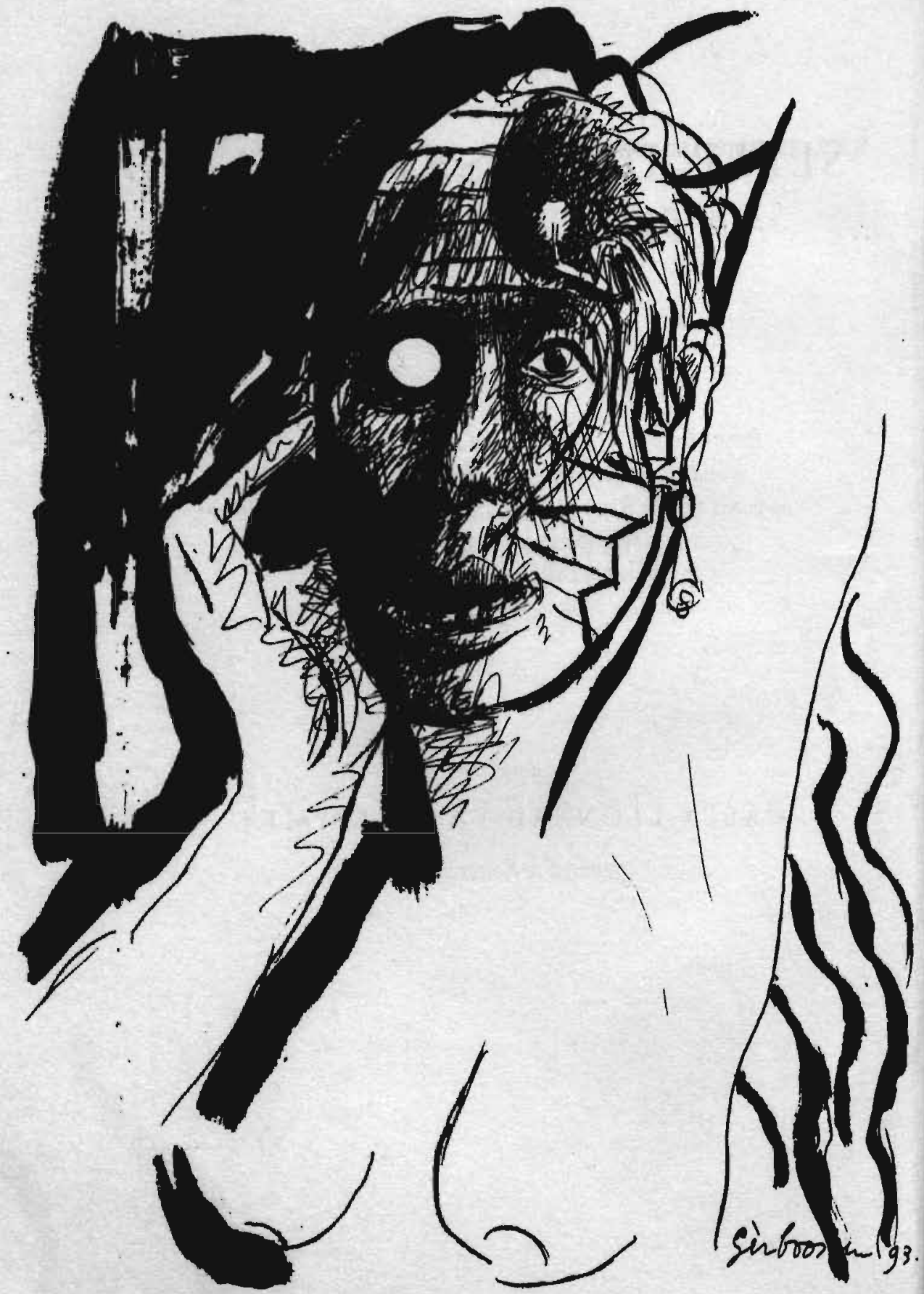




\section{SLEEP, DEPRESSION AND ANTIDEPRESSANTS}

Proefscbrift ter verkrijging van de graad van doctor aan de Rijksuniversiteit Limburg te Maastricht, op gezag van de Rector Magnificus, Prof. dr. H. Philipsen, volgens bet besluit van het College van Dekanen, in bet openbaar te verdedigen op woensdag, 24 november 1993 om 16.00 uur

door

ALEX LEONARD VAN BEMMEL

geboren te Rotterdam 
PROMOTORES :

Prof. dr. R.H. van den Hoofdakker (Rijksuniversiteit Groningen)

Prof. dr. M.M.W. Richartz

CO-PROMOTOR:

dr. D.G.M. Beersma (Rijksuniversiteit Groningen)

BEOORDE LING S COMM ISSIE:

Prof. dr. J.J.C.B. Bremer (voorzitter)

Prof. dr. A.A. Borbély (Universität Zürich)

Prof. dr. R.J. van den Bosch (Rijksuniversiteit Groningen)

Prof. dr. F. Spaans

Prof. dr. H.A.J. Struijker Boudier

\section{CIP-GEGEVENS KONINKLIJKE BIBLIOTHEEK, DEN HAAG}

Bemmel, Alex Leonard van

SLEEP, DEPRESSION AND ANTIDEPRESSANTS /

Alex Leonard van Bemmel. - Maastricht : Scorpio

Proefschrift Maastricht.-Met lit. opg.-Met een samenvatting in het Nederlands.

ISBN 90-71630-15-3

Trefw.: Sleep antidepressants.

The printing of this thesis was financially supported by the BWOOKP Foundation; and by Lundbeck B.V. and Searle B.V., The Netherlands. 
Keine geringe Kunst ist schlafen:

es thut schon Noth, den ganzen Tag darauf hin zu wachen.

(Also SPRACH ZaraTHuStRa, Friedrich Nietzsche)

Each day I live seems endless, and I suffer through endless nights.

When I lie down, I long for morning; when I get up, I long for evening; all day I toss and turn.

(THE BOOK OF JOB, translated by Stephen Mitchell) 


\section{CONTENTS}

$\begin{array}{lll}\text { Chapter } 1 \text { Introduction } & 9\end{array}$

1.1. Sleep and depression 10

1.2. The influence of antidepressant drugs on sleep 12

1.3. The importance of the influence of antidepressant drugs on sleep for the alleviation of depression $\quad 17$

$\begin{array}{ll}\text { 1.4. Theoretical approaches } & 18\end{array}$

1.4.1. The REM sleep pressure hypothesis $\quad 19$

1.4.2. The acetylcholine-monoaminergic balance model, and the hypothesis of a common pathophysiological mechanism underlying both REM sleep disturbance and depression

1.4.3. The two-process model of sleep regulation, and the S-defiency and non-REM sleep hypotheses

1.5. Concluding remarks 30

1.6. Clinical studies of this thesis 31

$\begin{array}{ll}\text { 1.7. } & \text { References } \\ & 32\end{array}$

Chapter 2 Effects of trazodone on EEG sleep and clinical state in major depression

Chapter 3 Changes in EEG power density of non-REM sleep in depressed patients during treatment with trazodone

Chapter 4 Changes in sleep polygraphic variables and clinical state in depressed patients during treatment with citalopram 
Chapter 5 Changes in EEG power density of non-REM sleep in depressed patients during treatment with citalopram

Chapter $6 \quad$ Epilogue

Summary

Samenvatting

Appendix

Power spectra in non-REM sleep of each subject separately treated with citalopram

List of abbreviations

Dankwoord

Curriculum vitae

List of publications 
CHAPTER 1

\section{Introduction}

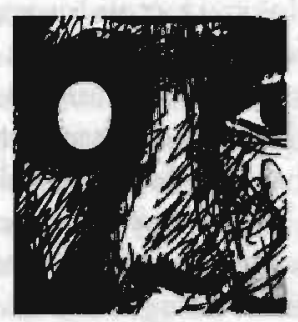


Depression has been a topic of research for many years. All the evidence indicates that causation of depression is multifactorial; the disorder has many causes, with an amalgam of genetic make-up, early environmental, biological factors, and recent social stresses (Paykel, 1989). However, scientific research has not yet reached definite conclusions on the etiology, pathogenesis, course or treatment of this complex disorder (Keller, 1989).

It is now widely recognized that in some patients biological factors play an important role (Klerman, 1984). This view is supported by several clinical observations, i.e. the iatrogenetic induction of depression by some medications and by exogenous hormones, the therapeutic response to antidepressant drugs, electroconvulsive therapy, manipulations of sleep, and light therapy. Furthermore, in different fields of research some support for the existence of biological disturbances has been obtained, such as in studies of monoamine neurotransmission, genetic factors, biological rhythms, and sleep physiology. Nevertheless, the precise biological factors concerning the etiology, pathogenesis and recovery of depression remain unknown. It seems very unlikely that there is just one biological factor or disturbance involved.

During the past decades the role of sleep dysregulation in depression has aroused great interest in the search for biological abnormalities in depression (Gillin and Borbély, 1985). The therapeutic benefits of non-pharmacological sleep manipulations in depressives suggest that sleep changes are of importance for the recovery of depression. Drugs with antidepressant properties bring about remarkable changes in sleep. The major topic of this thesis is the relationship between changes in sleep and in clinical state in depressed patients during treatment with an antidepressant drug. Four studies are presented concerning the effects of antidepressant drugs on sleep in depressives and their possible significance for the amelioration of depressive symptomatology. Before the studies are presented I will describe the empirical and conceptual backgrounds of the effects of antidepressant drugs on sleep in this introductory chapter.

\subsection{SLEEP AND DEPRESSION}

Sleep disturbances have been considered as cardinal symptoms of depression for as long as this disorder has been described. Clinical descriptions going back as far as the ancient Greeks have included disturbed sleep as part of the syndrome of melancholia (Jackson, 1986). According to contemporary diagnostic criteria for mental disorders (DSM-III-R; APA, 1987) severe sleep complaints form 
a prominent part of the symptomatology of depression'. Approximately $90 \%$ of the patients suffering from a depression report complaints of initiating and maintaining sleep as well as early awakening and remaining awake (ISCD, 1990). So profound is the insomnia of these patients that many experience the disturbance primarily as a sleep disorder (Goodwin and Jamison, 1990).

The systematic examination of sleep in depressed patients began in the $1950 \mathrm{~s}$ almost immediately after the introduction of modern polygraphic techniques for electrophysiological recording of sleep-related events (see review by Gillin, 1983a), i.e. by means of electro-encephalography (EEG), electro-oculography (EOG) and electro-myography (EMG). Sleep disturbances of depressives have been registrated objectively by means of polysomnography (EEG, EOG and EMG), for many years now (see reviews by Gillin et al., 1984; Reynolds and Kupfer, 1987). Compared to healthy controls, subjects with a depression display: prolonged sleep latency, frequent awakenings, early sleep termination, increase of rapid eye movement sleep (REMS) in the first part of sleep, short REMS latency, diminished production of non-REMS stages 3 and 4 (slow wave sleep or sws), and large variability in non-REMS-REMS cycle duration. None of these changes appears to be pathognomonic of depression (Wehr, 1990).

Recently, an extensive review has appeared of the literature on sleep in psychiatric disorders with an evaluation of the polysomnographic data by statistical meta-analysis (Benca et al., 1992; 177 studies concerning 7151 patients and controls). A striking result was that depressive disorders differed significantly from controls for the majority of the sleep variables. The median values of REMS latency, total time asleep, sws (minutes and percentage from total time asleep) were lower, and REMS (percent) values higher, in depressive disorders than in all other diagnostic categories. However, the statistical differences between depressive disorders and other psychiatric categories were far less obvious; no sleep variable reliably distinguished depressive disorders from other psychiatric disorders. A shortened REMS latency, for example, also occurred in subjects with narcolepsy, and sometimes in schizophrenia, borderline disorder, and eating disorders; reduction of sws was seen in alcoholism and insomnia. The authors suggest that the sleep disturbances in depressive disorders are more profound and widespread than in other diagnostic categories, but are not specific for depression.

Because sleep disturbances are so strongly associated with the depressive state, an obvious question is whether these disturbances play a role in the pathogenesis and recovery of depression. It is now widely recognized that a number of sleep manipulations ameliorate symptoms of depression (see reviews by Gillin, 1983b; Leibenluft and Wehr, 1992). These include total and partial

\footnotetext{
'i.c. major depressive episode as (single or recurrent) episode of a major depression, or of a bipolar disorder.
} 
sleep deprivation, selective deprivation of REMS, and phase shifting of the sleepwake cycle. Total and partial sleep deprivation induce an immediate improvement in about $60 \%$ of depressed subjects, which is often reversed by recovery sleep (i.e. subsequent sleep). The therapeutic effects of selective REMS deprivation on depression occur in about $50 \%$. These effects have a slower onset $(3$ weeks) but last longer. If total sleep deprivation is combined with antidepressant medication, which started on the day prior to the sleep deprivation, this sometimes resulted in the absence of relapse after the recovery sleep (Elsenga and Van den Hoofdakker, 1983; Kasper et al., 1990). It has also been reported that the response to sleep deprivation has some predictive value for the response to regular antidepressant treatment (see for ref.: Leibenluft and Wehr 1992).

Another fact worth mentioning in this context is that antidepressant drugs bring about remarkable changes in sleep polygraphic variables. This subject will be discussed more extensively in the remainder of this chapter.

In summary, the reported findings that manipulations of sleep have clinical benefits in some patients together with the influence of antidepressant drugs upon sleep suggest that sleep changes are not merely epiphenomena of depression. Changes in sleep physiological processes might, therefore, be intimately involved in the pathogenesis and recovery of depression (Gillin and Borbély, 1985; Van den Hoofdakker and Beersma, 1988; Wehr, 1990).

One way to elucidate the link between sleep and depression is to examine whether the influence of antidepressant drugs on sleep is related to clinical changes of depressives during treatment. For that purpose the remainder of this chapter deals with a review concerning the effects of antidepressants on sleep and their importance for the alleviation of depression. Four hypotheses about sleep and depression will form the conceptual framework. The chapter ends with a short description of the studies presented in the next chapters.

\subsection{THE INFLUENCE OF ANTIDEPRESSANT DRUGS ON SLEEP}

Studies on the effects of antidepressant drugs (ADs) upon sleep polygraphic - variables in man are listed in Table 1.

The results of these studies can be subdivided in effects on REMS, on non-REMS and on sleep continuity. The effects on REMS characteristics have been investigated more frequently and systematically than those on the other sleep polygraphic variables. They will be summarized first. 
Table 1. Summary of the significant effects of antidepressant drugs (in alphabetical order) upon REMS, REMS latency (REMSL), intermittent wakefulness (SO), non-REMS stages ( $\mathrm{S} 1$ and $\mathrm{S} 2=$ non-REMS stages 1 and 2; sws= slow wave sleep, non-REMS stages $3 \& 4$ ), sleep latency (SL), and total time asleep (TTA) in healthy (H) and depressed (D) subjects. Dosage: $50=$ one dose or a fixed dosage schedule; $50-200=$ increasing dosage schedule; $75 ; 150=$ two different dosages, one time. Treatment: - = decrease in duration; $0=$ no change in duration; + = increase in duration; $\#=$ because of almost completely abolished REMS no REMS latency detectable. Withdrawal: $\mathrm{R}=$ rebound increase of REMS or rebound decrease of REMS latency; $M=$ maintenance of treatment level or partial return to pretreatment level. It should be noted that the different studies of this review are not completely comparable. The studies may differ, among others, with respect to treatment duration, dosage regimen, and subject characteristics. Moreover, the studies can differ concerning polysomnographic methods. Comparisons between the studies must, therefore, be made with caution.

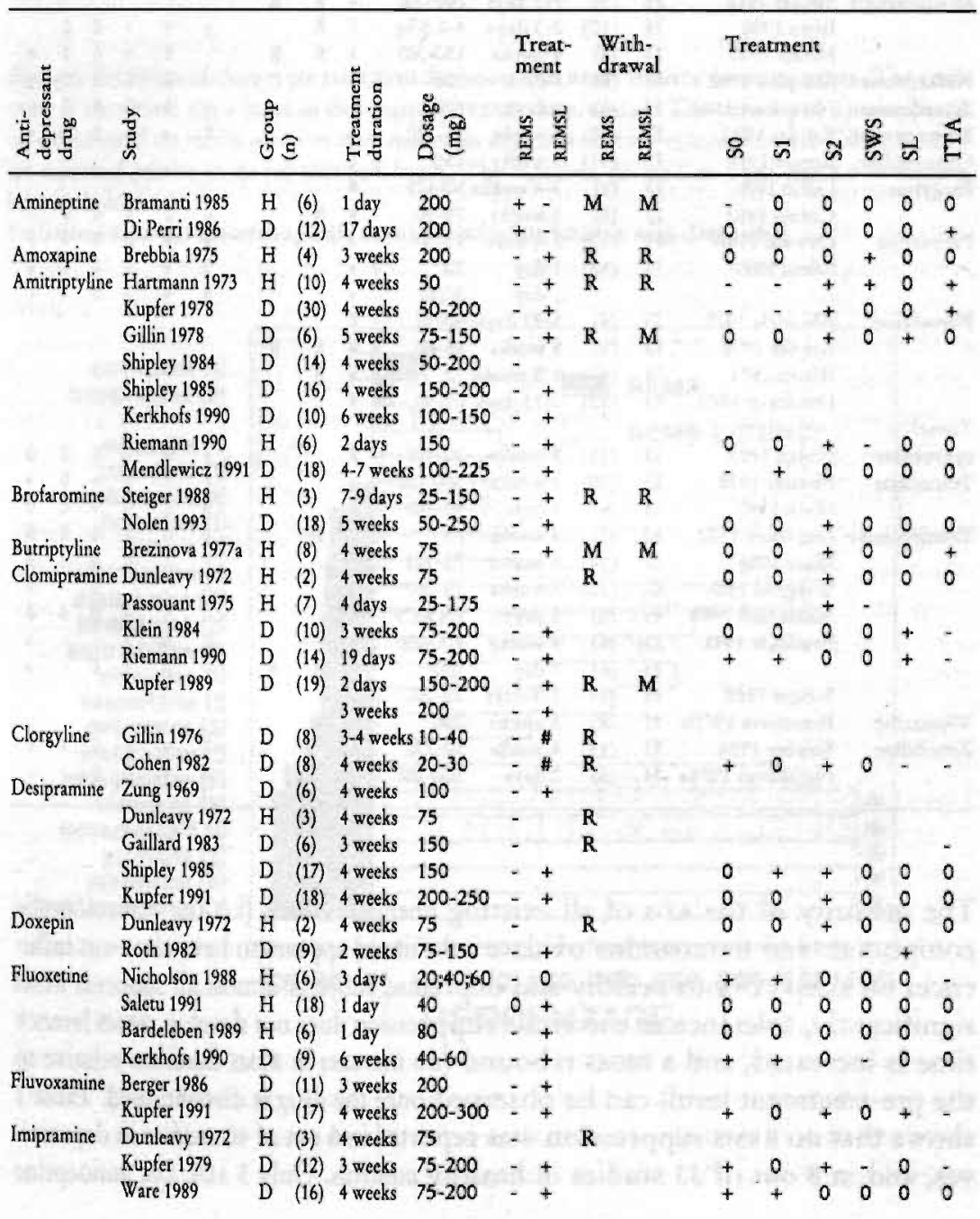




\begin{tabular}{|c|c|c|c|c|c|c|c|c|c|c|c|c|c|c|c|}
\hline \multirow{2}{*}{ 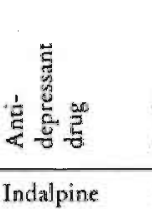 } & \multirow{2}{*}{$\begin{array}{l}\text { ڤं } \\
\text { Nicholson } 1986\end{array}$} & \multicolumn{2}{|c|}{$\stackrel{\circ}{0} \mathrm{~B}$} & \multirow{2}{*}{ 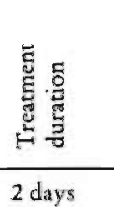 } & \multirow{2}{*}{$\frac{{ }_{0}}{25.50}$} & 弯 & 苔 & $\sum_{\check{\omega}}^{\infty}$ & 葡 & in & tmen & N & 8 & $\vec{n}$ & $\stackrel{S}{E}$ \\
\hline & & $\mathrm{H}$ & (6) & & & - & + & & & + & + & 0 & 0 & 0 & - \\
\hline Iprindole & Dunleavy 1972 & $\mathrm{H}$ & (3) & 4 weeks & 75 & 0 & & M & & & & & & & \\
\hline Isocarboxazid & Wyatr 1969 & $\mathrm{D}$ & (2) & 2 weeks & $30-60$ & $"$ & & & & & & & & & \\
\hline Maprotiline & Nicholson 1986a & $\mathrm{H}$ & (6) & 2 days & $75 ; 150$ & - & & & & & & & & & \\
\hline \multirow[t]{4}{*}{ Mianserin } & Morgan 1980 & $\mathrm{H}$ & (12) & 1 day & 30 & $=$ & + & & & & & & & & \\
\hline & Mendlewicz 1985 & $\mathrm{D}$ & $(10)$ & 4 weeks & 60 & 0 & + & & & - & 0 & + & 0 & 0 & 0 \\
\hline & Nicholson 1986b & $\mathrm{H}$ & (6) & 2 days & $20 ; 40$ & 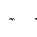 & + & & & & & & & & \\
\hline & Maeda 1990 & $\mathrm{HI}$ & (6) & 1 week & 20 & - & + & & $M$ & 0 & 0 & 0 & 0 & 0 & 0 \\
\hline \multirow[t]{3}{*}{ Moclobemide } & Steiger 1988 & $\mathrm{H}$ & (3) & $7-9$ days & $100-300$ & $\cdots$ & +1 & $\mathrm{R}$ & $\mathrm{R}$ & & & & & & \\
\hline & Blois 1990 & $\mathrm{H}$ & $(10)$ & $2-3$ days & $4-6.5 / \mathrm{kg}$ & - & 0 & $\mathrm{R}$ & & + & + & + & 0 & 0 & - \\
\hline & Monti 1990 & $\mathrm{D}$ & (8) & 4 weeks & $150-300$ & - & + & $\mathrm{R}$ & $\mathrm{R}$ & . & 0 & + & 0 & 0 & + \\
\hline Nefazodone & Sharpley 1992 & $\mathrm{H}$ & (8) & 7 days & 200 & + & 0 & & & - & 0 & 0 & 0 & 0 & + \\
\hline Nomifensine & Nicholson 1986 & $\mathrm{H}$ & (6) & 2 days & 100 & - & + & & & + & 0 & 0 & 0 & 0 & - \\
\hline Nortriptyline & Kupfer 1982 & $\mathrm{D}$ & $(20)$ & 4 weeks & $25-1100$ & - & + & & & 0 & + & + & 0 & 0 & 4. \\
\hline Oxaprotiline & Berger 1986 & $\mathrm{D}$ & (11) & 3 weeks & 150 & $\star$ & + & & & & & & & & \\
\hline \multirow[t]{2}{*}{ Pargyline } & Gillin 1976 & $\mathbb{D}$ & $(8)$ & 344 weeks & $50-125$ & - & \# & & & & & & & & \\
\hline & Cohen 1982 & $\mathbb{D}$ & $(8)$ & 4 weeks & $75-90$ & 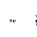 & $\#$ & $R$ & & 0 & 0 & + & 0 & 0 & - \\
\hline \multirow[t]{3}{*}{ Paroxetine } & Oswald 1986 & $\mathrm{H}$ & (12) & $2-4$ days & $15-30$ & 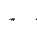 & + & & & + & 0 & 0 & + & + & . \\
\hline & Saletu 1991 & $\mathrm{H}$ & (18) & I day & 20 & 0 & + & & & 0 & + & + & 0 & + & 0 \\
\hline & & & & I day & $30 ; 40$ & - & + & & & + & + & + & 0 & + & . \\
\hline \multirow[t]{4}{*}{ Phenelzine } & Akindele 1970 & $\mathbb{D}$ & $(4)$ & $5-22$ days & $60-90$ & - & $\#$ & & & & & & & & \\
\hline & Kupfer 1972 & $\mathbb{D}$ & (9) & 5 weeks & $45-60$ & $\cdots$ & $\#$ & $\mathrm{R}$ & $\mathrm{R}$ & & & & & & \\
\hline & Wyate 1971 & $\mathrm{D}$ & (6) & $4-8$ weeks & 875 & - & $\#$ & $\mathrm{R}$ & & & & & & & \\
\hline & Dunleavy 1973 & D & (22) & 1-15 days & $60-90$ & $*$ & \# & & & & & & & & \\
\hline \multirow{3}{*}{$\begin{array}{l}\text { Tranyl- } \\
\text { cypromine } \\
\text { Trazodone }\end{array}$} & Nolen 1993 & $\mathrm{D}$ & (13) & 5 weeks & $20-100$ & - & \# & & & + & 0 & 0 & 0 & 0 & 0 \\
\hline & Mouret 1988 & $\mathrm{D}$ & (10) & 4 weeks & $100-600$ & 0 & + & & & - & - & + & + & 0 & + \\
\hline & Ware 1990 & $\mathrm{H}$ & (6) & 4 days & $50-200$ & 0 & + & & & 0 & 0 & 0 & + & 0 & 0 \\
\hline \multirow[t]{7}{*}{ Trimipramine } & Dunleavy 1972 & $\mathrm{H}$ & (2) & 4 weeks & 75 & 0 & & $M$ & & 0 & 0 & + & 0 & 0 & 0 \\
\hline & Ware 1986 & $\mathrm{D}$ & (14) & 4 weeks & $75-200$ & 0 & & & & - & - & 0 & 0 & - & + \\
\hline & Wiegand $19: 86$ & $\mathrm{D}$ & (10) & 3 weeks & $75-200$ & + & + & & & - & & & 0 & “ & + \\
\hline & Nicholson 1989 & $\mathrm{H}$ & (6) & 3 days & $25 ; 50 ; 75$ & - & 0 & & & 0 & 0 & + & 0 & 0 & 0 \\
\hline & Feuillade 1992 & $\mathrm{D}$ & (6) & 4 weeks & $100-200$ & 0 & + & & & 0 & + & + & - & * & + \\
\hline & & $\mathrm{H}$ & (6) & 1 day & 100 & - & + & $\mathrm{R}$ & $\mathrm{R}$ & 0 & 0 & + & 0 & - & + \\
\hline & Steiger 1988 & $\mathrm{H}$ & (1) & $7-9$ days & $25-200$ & 0 & 0 & & & & & & & & \\
\hline Viloxazine & Brezinova $1977 \mathrm{~b}$ & $\mathrm{H}$ & $(8)$ & 3 weeks & 200 & - & & $\mathrm{R}$ & & & & & & & \\
\hline \multirow[t]{2}{*}{ Zimelidine } & Shipley 1984 & $\mathrm{D}$ & (13) & 4 weeks & $50-250$ & - & + & & & 0 & + & + & 0 & + & 0 \\
\hline & Nicholson $1986 \mathrm{a}$ & $\mathrm{H}$ & (6) & 2 days & $100-200$ & 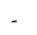 & + & & & + & + & 0 & 0 & + & - \\
\hline
\end{tabular}

The majority of the ADs of all existing chemical classes (i.e. the various cyclic compounds and monoamine oxidase inhibitors) appears to have clear-cut influences on sleep of both healthy and depressed subjects: almost all suppress REMS significantly, tolerance to this REMS suppression does not develop, REMS latency time is increased, and a RIMS rebound (an increase in REMS duration relative to the pre-treatment level) can be observed once the drug is discontinued. Table 1 shows that no REMS suppression was reported in 6 out of 40 studies in depressives, and in 8 out of 33 studies in healthy controls. Only 3 ADs, i.e., amineptine 
(Bramanti et al., 1985; Di Perri et al., 1986), nefazodone (Sharpley et al., 1992), and trimipramine (Wiegand et al., 1986) are reported to increase REMS.

The studies of the effects of ADs on sleep in depressives differ from those in healthy subjects with respect to several important aspects. 'The majority of the studies in healthy subjects focus on effects over periods encompassing only very few days. Since it takes several weeks before the therapeutic effects of ADs become apparent, the studies which deal only with the acute effects on sleep in healthy subjects are considered irrelevant in this context and are excluded from the following analysis. Figure 1 shows the results of the estimated long-term changes, per AD, of REMS and REMS latency in depressives.

Tigure 1. The estimated changes per AD of REMS duration and REMS latency in depressives. The rank order of the various $A D S$ is based on their degree of KEMS suppression. The values per $A D$ are based on the means of the results of one or more studies in depressives (for references: see Table 1), and are expressed relative to the pre-treatment levels. The number of studies used per $\mathrm{AD}$ is shown between brackets.

* = because REMS was almost completely abolished, no FEMs latency was detectable.

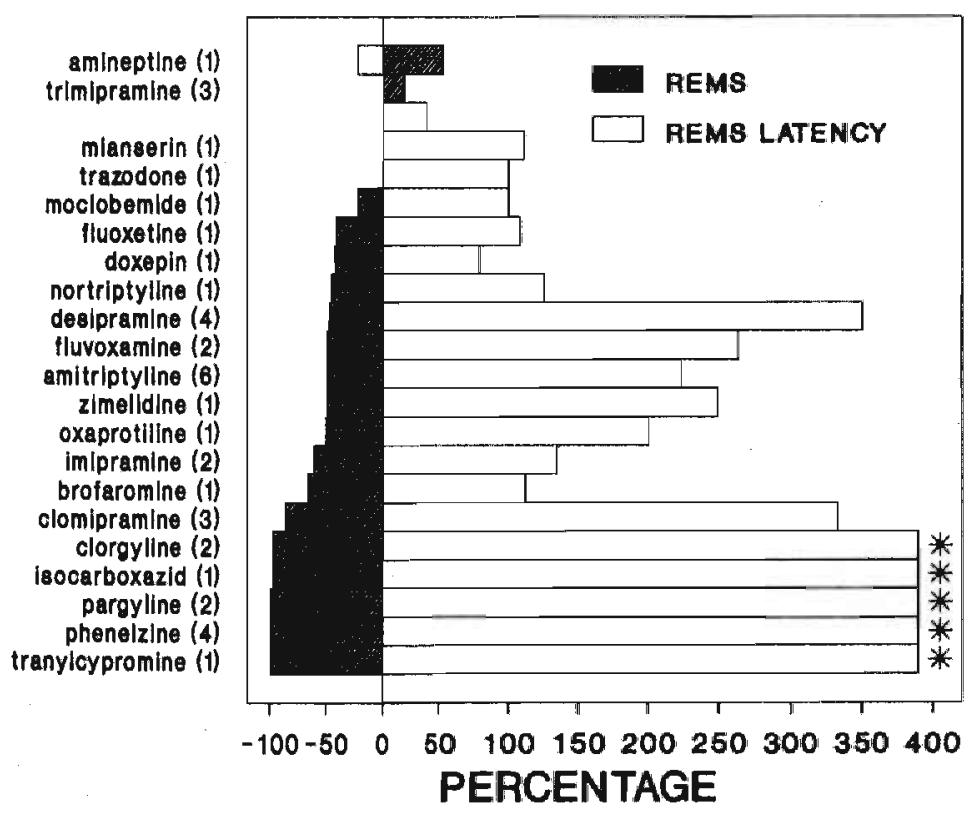


The classical monoamine oxidase inhibitors (MAOIs; i.e. clorgyline, isocarboxazid, pargyline, phenelzine and tranylcypromine) may completely abolish the signs of REMS in the first 1-3 weeks of treatment. During continued medication for up to 2 months their REMS suppressing effects remain (Akindele et al., 1970; Wyatt et al., 1969; 1971). Upon discontinuation of these compounds REMS may show a rebound of more than $250 \%$ compared to baseline levels, persisting for days or even weeks. In contrast to the classical MaOls the new reversible selective MAOIs (i.e. moclobemide and brofaromine) are reported to have a smaller REMS suppressant effect (Monti et al., 1990; Nolen et al., 1993). From Fig. 1 it can be seen that most of the various cyclic ADs suppress REMS and induce a lenghthening of the REMS latency to varying degrees. Most of them already do so after acute administration (see reviews by Chen, 1979; Scherschlicht et al., 1982; Vogel et al., 1990; Van Bemmel, 1990; Havermans and Van Bemmel, 1991).

In contrast to studies of REMS changes, the effects of ADs on the duration of the various stages of non-REMS and on sleep continuity (i.e. intermittent wakefulness, sleep latency, total time asleep) have been investigated less systematically. A general pattern in the effects on these sleep polygraphic variables in both healthy subjects and depressives cannot yet be detected. Because of the aforementioned differences between the studies in healthy and depressive subjects, only the data on non-REMS and sleep continuity in depressives are summarized in Figure 2.

Non-REMS stage 2 is reported to increase in $65 \%$ of the studies, while $83 \%$ show no significant change in sws duration. $65 \%$ of the studies report no change of sleep latency and $43 \%$ no change of total time asleep.

While most ADs, of all existing chemical classes, influence REMs in a comparable way, their effects on non-REMS and sleep continuity are much more variable. Recently, it was reported in healthy subjects that the latter variability could be associated with the chemical profile of ADs (Nicholson and Pascoe, 1991; Saletu et al., 1991). The acute effects of ADs with mainly noradrenergic (NA) uptake inhibition appear to induce sedation, whereas ADs with mainly serotonergic (5HT) uptake inhibition increase both nocturnal wakefulness and alertness during the day. Inspired by these observations the effects of ADs with mainly 5-HT uptake inhibition on sleep polygraphic variables of depressives were compared with those of ADs with mainly NA uptake inhibition (Berger et al., 1986; Kerkhofs et al., 1990; Kupfer et al., 1991). It was found that both 5-HT and NA uptake inhibitors suppressed REMS. In contrast to the NA uptake inhibitors the 5-HT uptake inhibitors produced more sleep discontinuity by increasing wakefulness. 
Figure 2. Changes of non-REMS stages, sleep latency and total time asleep during treatmeat with ADS, as reported in 23 studies in depressives (for references: see Table 1). Only the studies which reported results of all the sleep variables involved are used in the figure, i.e. 3 studies are excluded. The majority of the studies shows no significant changes in the duration of the non-REMS stage 1, sleep latency and total time asleep, but shows a significant increase of non-REMs stage 2. In only 4 out of 23 studies a change in 5 ws was found: three with a decrease and one with an increase.

SO = intermittent wakefulness; 1 and $S 2=$ non-REMS stages 1 and 2; sws $=$ slow wave sleep (nonREMS stages 3 \& $r$ ); SI = sleep latency; T T'TA = total time asleep.

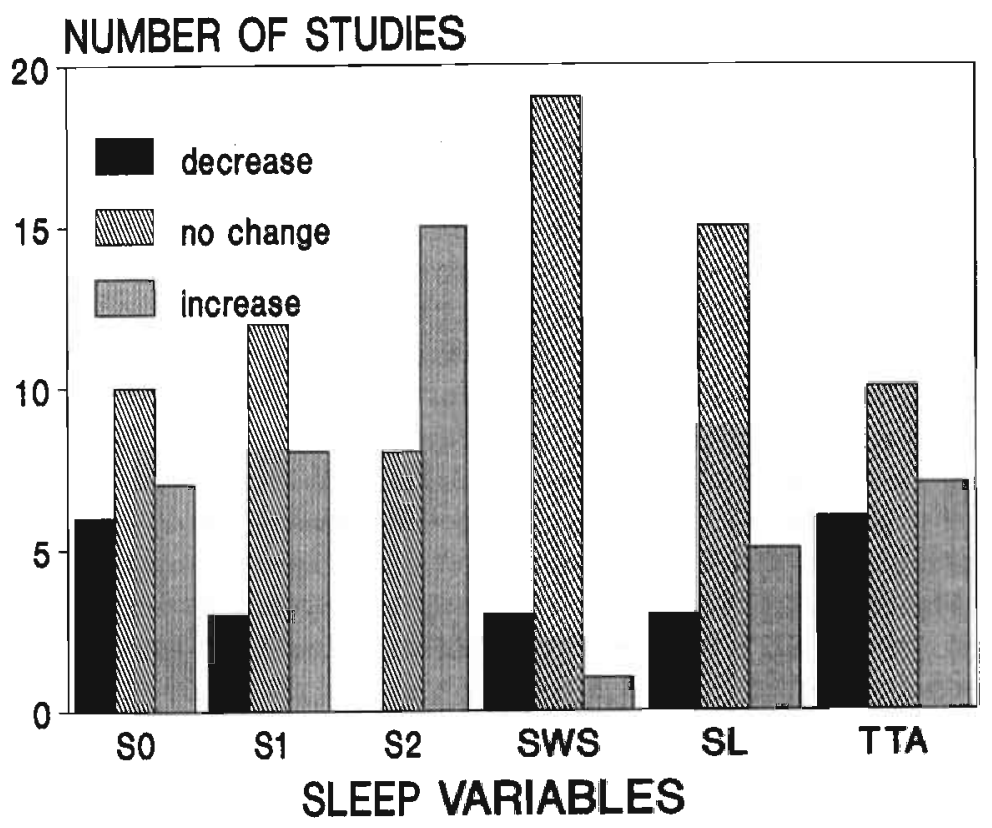

\subsection{THE IMPORTANCE OF THE INFLUENCE OF ADS ON SLEEP FOR THE ALLEVIA- TION OF DEPRESSION}

Drugs which alleviate depression appear to influence REMS variables rather consistently, whereas their influence on non-REMS and sleep continuity variables is much less evident and uniform. The question is whether changes in sleep polygraphic variables, during treatment with $\mathrm{ADS}$, have clinical significance.

Only a minority of the studies on the effects of ADs on sleep in depressives has focussed on the relationship between changes in sleep polygraphic variables 
and clinical response. The results of early reports suggest that in patients who respond to classical MAOIs the clinical improvement coincides with the onset of maximal REMS suppression (Wyatt et al., 1971; Dunleavy and Oswald, 1973). In studies with the $\mathrm{AD}$ amitriptyline it was found that the depressive patients who improved after 5 weeks showed a higher degree of REMS suppression at the start of the treatment (Gillin et al., 1978; Kupfer et al., 1981). However, in a retrospective study over a 5-7-week treatment period with amitriptyline a relationship between changes in REMS and clinical response could not be found (Mendlewicz et al., 1991). Moreover, improvement of depression after 19 days of treatment with the AD clomipramine did not correlate with the amount of initial REMS reduction (Riemann and Berger, 1990).

A shortened baseline REMS latency has been proposed to be predictive of poor treatment outcome (Kupfer et al., 1981). Rush et al. (1989) reported, however, that a short pre-treatment REMS latency predicted a good treatment response in depressed outpatients after a 6-week treatment with either amitriptyline or desipramine. In contrast, Reynolds et al. (1991) reported that a prolonged baseline REMS latency was significantly associated with clinical improvement in elderly depressed patients treated with nortriptyline.

There are very few reports on the therapeutic significance of changes in nonREMS or sleep continuity (Kupfer et al., 1978; Kupfer et al., 1982; Ware et al., 1989). The differences in drug properties with respect to their impact on these sleep polygraphic variables are, so far, not clearly related to antidepressant efficacy (Mendelson, 1987). In the studies (Berger et al., 1986; Kerkhofs et al., 1990; Kupfer et al., 1991), mentioned earlier, in which the effects of ADs with mainly 5-HT inhibition were compared with those of drugs whith mainly NA inhibition, no differences were found in therapeutic response, notwithstanding their different effects on sleep continuity.

In summary, the clinical significance of the relationship between changes in sleep polygraphic variables and changes in depressive symptomatology during treatment with ADs is far from clear.

\subsection{THEORETICAL APPROACHES}

In this paragraph four hypotheses are reviewed, in which sleep physiology plays a role in the pathogenesis of depression and the mechanisms underlying the effects of antidepressive treatment. 


\subsubsection{The REMS pressure hypothesis}

The REMS pressure hypothesis is based on the assumption that strong initial and sustained REMS suppression is the key mechanism underlying treatment response (Vogel et al., 1975; 1977; 1980). The origin of the interest in the role of REMS abnormalities in psychopathology is closely related to the discovery of REMS (Wehr and Sack, 1988). In the early 1950s Aserinsky and Kleitman (1953) observed the periodic alternations of sleep with and sleep without the occurrence of rapid eye movements throughout the night. Awakenings induced during REMS yielded accounts of dreams in 90 to 95 percent of the cases, and those during non-REMS yielded reports of dreams in only 5 to 10 percent. Furthermore, REMS deprivation appeared to lead to a REMS debt which was compensated for during recovery sleep. These observations inspired intensive research into the psychological and physiological functions of REMS (see reviews by Dement, 1972; Hartmann, 1973).

The finding that most dreams are reported after awakening from REMS, coupled with the opinion (inspired by psychoanalytic theory) that dreaming represents an important mental function, led to the assumption that a shortage of REMS would impair mental functioning, and could even lead to mental disorders (Dement, 1960; Fisher and Dement, 1963; Snyder, 1963). Supposed similarities between psychotic symptoms and dreams suggested that a psychosis was an intrusion of dreams into wakefulness (Gillin and Wyatt, 1975). It was predicted that REMS deprivation would induce psychotic symptoms, and indeed one subject developed psychotic symptoms while participating in a sleep depriwation protocol (Kleitman, 1963). In all later studies, however, no psychopathology was observed (Kales et al., 1964; Snyder, 1963; Mendelson, 1987).

At about that time, Snyder (1969) proposed the REMS deprivation hypothesis of the pathogenesis of depression; a shortened REMS latency, in particular observed in the severest phase of depression would result from prior deprivation of REMS in the early phase of depression. Longitudinal data from later phases are not necessarily consistent with this (see for references: Gillin, 1983a).

Summarizing, today it seems unlikely that REMS deprivation has serious psychopathological consequences. In fact, REMS deprivation may even be beneficial for the treatment of depression. In the late 1960s, Vogel and his colleagues reported that several lines of evidence were consistent with the hypothesis that REMS plays an important role in the pathogenesis and the treatment of depression (summarized in: Vogel, 1975). Firstly, ADs produce substantial, persistent suppression of REMS, much more than drugs without antidepressant properties; secondly, electroconvulsive shock therapy has been reported to decrease REMS; thirdly, reserpine, which induces depression, substantially increases REMS; and, fourthly, prolonged REMS deprivation of animals produces behavioral changes 
opposite to the behavioral characteristics of human depression, i.e., REMS deprived animals become hypersexual, hyperactive, and hyperphagic, while depressed humans typically lose libido, display psychomotor retardation, and are anorectic.

Several pilor tests of the hypothesis yielded promising results (Vogel, 1968; Vogel and Traub, 1968a; 1968b; 1968c). Five out of nine patients improved substantially during REMS deprivation; one patient improved slightly. Subsequently, a double-blind, cross-over study (Vogel et al., 1975) was conducted in 34 patients with endogenous and 18 patients with reactive depression, all hospitalized. REMS deprivation was applied to one group of depressives, while another group was awakened from non-REMS with the same frequency. After three weeks REMS deprivation was also applied to this latter group. During selective sleep deprivation treatment each subject was awakened from REMS or non-REMS on consecutive nights until the subject reached 30 awakenings per night or until six consecutive nights of selective sleep deprivation had taken place, whichever came first. The subject then had a single night of uninterrupted sleep (recovery night) after which the same deprivation procedure was repeated. The entire treatment lasted several weeks. Clinical improvement occurred during REMS deprivation in about $50 \%$ of the endogenously depressed patients. The reactively depressed patients did not improve. During nonREMS deprivation none of the patients showed improvement. Eleven patients who had not responded to REMS deprivation received a treatment with imipramine; only one improved sufficiently to be discharged.

The authors (Vogel et al., 1975) concluded that their results indicate that substantial REMS reduction is antidepressant and that the antidepressant mechanism of ADs might reside in their capacity to reduce REMS substantially. From a further analysis with the same data Vogel et al. (1977) reported a positive and significant correlation between improvement of depression and REMS pressure. This pressure was defined as the percentage of REMS in the first recovery night devided by the mean REMS percentage of the last two baseline nights. In the authors" view this correlation indicates that REMS pressure is the manifestation of a process mediating the antidepressant effects of REMS deprivation. The antidepressant effects of repeated REMS deprivations have not yet been replicated. The complicated and laborious procedure required is probably the reason for this.

In 1990, Vogel et al. presented an extensive review of the literature on the influence of drugs on REMS in animals and humans, including subjects with endogenous depression (from 1962 to $1989 ; 215$ studies). The literature on the therapeutic efficacy of ADs is also included in that study. The authors reviewed the REMS effects of amine precursors, antidepressants, antihistamines, antipsychotics, barbiturates, benzodiazepines, other hypnotics, drugs affecting cholinergic and noradrenergic neurotransmission, ethanol, lithium and narcotics. The REMS 
effects were evaluated with criteria derived from the properties of selective REMS deprivation by arousals (so called: arousal-type REMS deprivation or ATRSD). Firstly, an initial reduction of REMS duration of more than $50 \%$ of the pre-treatment level is required; secondly, this reduction of REMS must persist for several weeks; and, thirdly, immediacely upon cessation of the drug a REMS rebound must occur.

The authors elaborately examined which drugs fulfill these properties of ATRSD. They found that drugs that produce AT-RSD also improve endogenous depression. The influence of non-ADs on REMS proved never to fulfill the criteria for AT-RSD. The antidepressant efficacy of drugs that produced AT-RSD appeared not to be related to certain chemical classes. It was further concluded that the dose threshold for antidepressant efficacy appeared to be the threshold at which substantial ReMS suppression is produced.

A few remarks should, however, be made. Firstly, not all ADs have been studied sufficiently to be certain of their influence on REMS; secondly, although the majority of efficacious ADs produced AT-RSD, not all did so (i.e. amineptine, iprindole, trazodone, and trimipramine), which means that AT-RSD cannot be the exclusive mechanism of action underlying drug induced improvement; thirdly, in their evaluation Vogel et al. also included studies in animals and non-depressed subjects; and, fourthly, most importantly, they could not find studies in which the relationship between drug induced AT-RSD and antidepressant effect was examined directly.

Recently, interesting data were obtained in an animal model for depression, which could support the REMS pressure hypothesis (Adrien et al., 1991; Adrien, 1992). In this so-called learned helplessness model, rats are exposed to inescapable electric footshocks which result in severe retardation in subsequent learning to escape or avoid shock in a different situation. During the initial period after the induction of helplessness in rats transient sleep impairments of paradoxical sleep (PS) were found, in particular shortened PS latencies and increased PS amounts (Adrien et al., 1991). These changes are very similar to the sleep abnormalities observed in depressed patients. Subsequently, in another study (Adrien, 1992) it was observed that repetitive selective deprivation of PS could abolish the behavioral deficits of the learned helplessness syndrome.

In summary, the therapeutic effect of REMS deprivation by arousals and the effects of the majority of ADs upon REMS suggest that strong initial and sustained REMS suppression might be a central factor, without being the only factor involved in the mechanisms underlying treatment response. 


\subsubsection{The acetylcholine-monoaminergic balance model, and the hypothesis of a common pathophysiological mechanism underlying both REMS disturbance and depression}

A second and related hypothesis to be mentioned in the context of this thesis is based on the acetylcholine-monoaminergic (ACh-MA) balance model of sleep cycle control in cats. It has been observed that neuronal activity in the medial reticular nucleus in the pons increased during the transition from non-REMS to REMS, while that in the locus coeruleus decreased. Acetylcholine (Ach) was supposed to be the neurotransmitter of the first cell group and noradrenaline (NA) that of the second (McCarley and Hobson, 1975). On the basis of several experiments Hobson et al. (1975) proposed that the NA cells are auto-inhibitory and also inhibit activity in the Ach system, whereas the Ach sytem is self-excitatory and also stimulares the NA system. In this way, neuronal activity would alternate between one cell group and the other. Ach activity promotes the occurrence of REMS and NA activity suppresses REMS, and non-REMS-REMS cyclicity results.

'Throughout the years, further animal experiments prompted the investigators to modify the model drastically (Hobson et al., 1986). Firstly, a role was attributed to the 5-HT activity in the suppression of REMS; secondly, wakefulness was added as a third state, besides REMS and non-REMs; and, thirdly, it was concluded that the two neurochemically distinct neuronal populations are not strictly localized in neuroanatomically seperate cell groups, but are spread over many areas of the brain. Despite these alterations the essence of the model has remained the same: the assumption that the alternation between non-REMS and REMS is regulated by an interaction between ACh and MA (NA \& 5-HT) neurons. Figure 3 shows the schematic representation of the model.

In $1982 \mathrm{McC}$ arley suggested that these neuronal mechanisms in the regulation of the non-REMS-REMS cycle would also play a role in mood regulation. He proposed the hypothesis of a common pathophysiological mechanism underlying both REMS disturbance and depression. A depressive state is supposed to be the expression of a relatively decreased MA activity in combination with a relatively increased Ach activity. According to this hypothesis both the disturbance of mood and of sleep are manifestations of a disturbed ACh-MA balance. The increase of REMS at the beginning of sleep in depressives would be caused by insufficient suppression of REMS by the MA system. In other words, short REMS latency in depression could reflect an increased ratio of Ach versus MA activity.

To date, the role of the ACh side of REMS regulation is probably better supported than the MA side (see reviews by Gillin and Shiromani, 1990; Dubé, 1993). As initially proposed by Janowsky et al. (1972) in the cholinergic supersensitivity hypothesis of mood disorders, depression is associated with a relative 
Figure 3. Schematic representation of the ACh-MA balance model. The assumed neurochemical identity of the REMS-inhibitory neuronal populations is listed in the left box, and that of the REMS-promoting populations is indicated in the right box. During waking the cell populations with NA and 5-HT activity inhibit those with Ach activity. Over the course of the sleep cycle, the inhibitory MA (norepinephrine \& serotonin) influences diminish because of negative (inhibitory) feedback: when pontine reticular formation neurons are released from inhibition, they become active and, using $A c h$, generate the events of REMS (after McCarley, 1982).

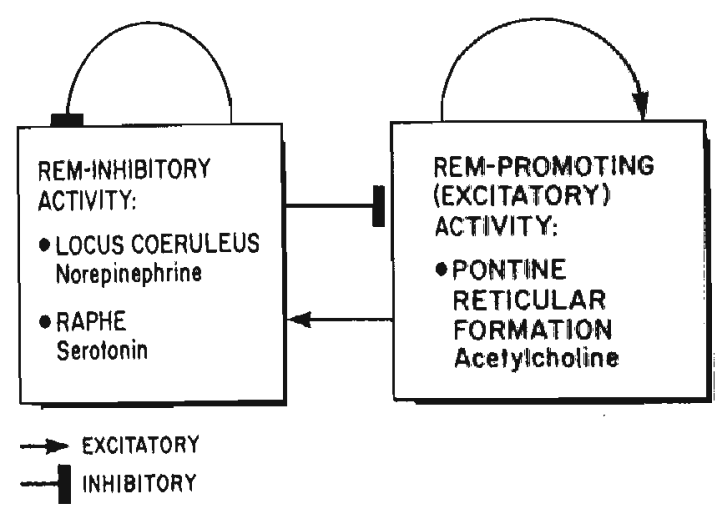

increase in Ach sensitivity, and mania with decreased sensitivity. As applied to sleep in depression, the hypothesis postulates that shortened REMS latency is another manifestation of Ach supersensitivity. In support of heightened ACh sensitivity in depression, the administration of Ach agonists such as arecoline leads to a more rapid appearance of REMS in depressed patients than in controls (Sitaram et al., 1980; 1982). However, Berger et al. (1983) did not find a differential effect of the Ach agonist physostigmine in depressed parients, in part because of the awakenings induced by physostigmine.

Recently, it has been shown that the cholinomimetic drug RS 86 (a spiropiperidyl derivate), given orally before bedtime, results in sleep with shortened REMS latency in depressives (Berger et al., 1985). The same group was able to show that RS 86 provoked REMS onset periods (REMS latency $\leq 25 \mathrm{~min}$ ) in 14 of 16 depressed patients (Berger et al., 1985; 1989). Subjects with personality disorders or an eating disorder, even with a concomittant major depression, showed REMS induction by RS 86 comparable to that in healthy controls and were clearly distinguishable from depressed subjects (Lauer et al., 1988; Berger et al.,1989). In contrast to the original study with arecoline (Sitaram et al., 1982), Berger et al. (1989) did not find a positive effect in depressive patients in remission. In another study Berger et al. (1991) could not demonstrate a significant difference in RS 86-induced sleep onset REMS periods between patients with schizophrenic disorders and patients with depression. The pronounced 
shortening of REMS latency in the schizophrenic patients mainly occurred in the subjects with a chronic course of the disorder or a secondary depression.

Although there are differences between these studies with respect to applied methods, they do support the hypothesis that patients with depression show enhanced REMS response to ACh agonists. Because the underlying mechanism of the amplified response to cholinergic stimuli in depressives is unknown, the interpretation of the role of ACh mechanisms, in terms of REMS dysregulation remains largely speculative at this time (Gillin and Shiromani, 1990).

Despite the seemingly simple regulatory scheme of the Ach-MA imbalance model, still no clear picture exists of the neurophysiological mechanisms involved (Steriade and McCarley, 1990). Although many studies have been published on the effects of various drugs and endogenous substances on the sleep of animals and man (see reviews by Jouvet, 1977; Mendelson, 1987; Borbély and Tobler, 1989; Gaillard, 1990), the interpretation in terms of neurophysiological processes is very difficult. To date, no single neurotransmitter, neuromodulator or neurohormone has been identified as being responsible for the generation and maintenance of REMS or non-REMS. Instead, multiple factors and systems appear to be involved in the regulation of these sleep states. Therefore, the disturbances in sleep in depressed patients cannot, according to present knowledge, be derived simply from, for example, a global abnormality in brain MA or ACh function (Fernstrom and Pastel, 1989; Mendelson, 1991).

Although it is unlikely that there is only one neurotransmitter system involved, several lines of evidence suggest that the 5-HT system in particular may play an important role in sleep regulation as well as in the pathogenesis and recovery of depression.

The involvement of the 5-HT system in sleep has been suggested for more than 20 years (Jouvet, 1969). There is renewed evidence from animal studies that the 5-HT system is involved in sleep regulation, albeit in a complex way (Cespuglio et al., 1992). Furthermore, reduction of REMS is a feature of most drugs which alter 5-HT-mediated transmission (Nicholson and Pascoe, 1988).

In some types of depression it has been proposed that there is 5-HT underactivity and that therapeutic actions of ADs are due to reversal of this deficiency (Assberg et al., 1984; Van Praag, 1986). The 5-HT metabolism in depressive disorders is reviewed by Van Praag (1980; 1982), Meltzer and Lowy (1987) and Brown et al. (1991). The results suggest that the metabolism of this amine is altered in some patients with depression. Recently, results from electrophysiological single-cell recording studies in animals strongly suggest that most, if not all, types of antidepressant treatments (i.e. MAOIs, tricyclic ADs, 5-HT uptake inhibitors, electroconvulsive shock treatment, and possibly sleep deprivation), share an enhancement of 5-HT neurotransmission, although each of these inter- 
ventions achieve this enhancement through different mechanisms (Blier et al., 1987). Blier et al. conclude that intensification of 5 -HT-function appears to be a common element of antidepressant treatments. They allso suggest that this modification may only be one link in a chain of several events leading to an antidepressant response.

In summary, the results from fundamental animal research suggest that the balance between Ach and MA systems is involved in sleep cycle control. However, present empirical knowledge from pharmacological sleep research has not provided an explanation of the effects of ADs on sleep in depressives in the context of the Ach-Ma balance model. Therefore, the hypothesis of a common pathophysiological mechanism underlying both REMS disturbance and depression still lacks a sound empirical pharmacological basis.

\subsubsection{The two-process model of sleep regulation, and the S-defi- ciency and non-REMS hypotheses}

The third theoretical approach to explain the effects of ADs on depression in sleep physiological terms is based on the two-process model of sleep regulation (Borbély, 1982; Daan et al.,1984). The central assumption is that two separate processes underlie the regulation of the sleep-wake cycle, a homeostatic process $\mathrm{S}$ and a circadian process $\mathrm{C}$ (see Fig. 4).

Figure 4. The two process model of sleep regulation (modified from Daan et al., 1984). Wf = waking; $S=$ sleep. For explanation see text.

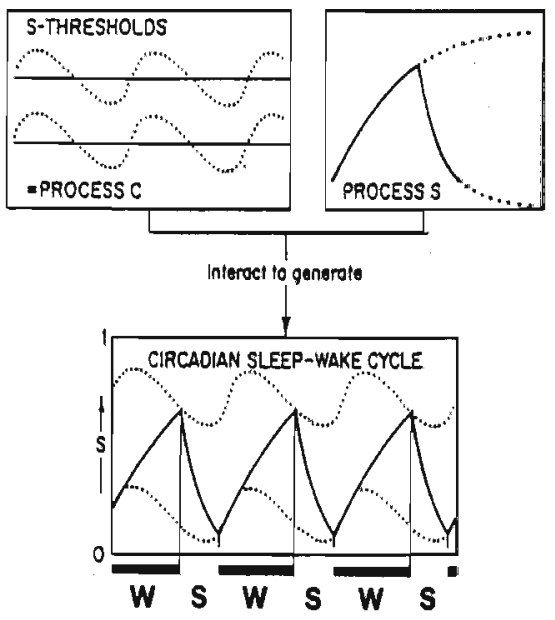


Process S reflects sleep need, and its level declines and rises exponentially during sleep and during waking, respectively. The value of process $S$ is supposed to be exclusively dependent on the history of sleep and wakefulness; in other words, the level of $\mathrm{S}$ is fully determined by the duration of prior wakefulness and thus is supposed to reflect sleep need or sleep debt, c.q. sleep intensity. Process $C$, which varies over the 24-hour period, is supposed to be independent of sleep and waking, but exclusively determined by the biological clock located in the suprachiasmatic nuclei in the hypothalamus. Process $C$ sets thresholds to process $S$ : it interacts with process $S$ so as to control both the time of sleep onset and of sleep termination. Process $S$ is assumed to be reflected in the EEG power of non-REMS, assessed by spectral analysis. Borbély et al. (1981) demonstrated in normal subjects that the power of the sleep EEG shows a continuous slowly declining course across subsequent non-REM-REMS cycles. Since most of the power is present in the low frequency bands $(1-4 \mathrm{~Hz})$, total power values largely reflect the power in slow wave sleep (i.e. slow wave activity, $\mathrm{SWA}^{2}$ ) (see Fig.5).

The focus of quantitative elaboration of the two-process model has been largely the dynamics of $S$ and the shape of $C$. The rise rate of process $S$ was obtained by interpolating the EEG power values at the beginning and the end of normal sleep periods and the beginning of sleep after sleep deprivation. In addition, naps were scheduled in the course of the day in order to obtain intermediate data points (Dijk et al., 1987a). The shape and phase-position of Process C were estimated on the basis of data from sleep timing experiments (Daan et al., 1984).

The two-process model of sleep regulation has proven to be very successful in predicting the energy of the EEG signal, as a function of the duration of the preceding waking period, in both humans and in various animal species (see review by Borbély and Achermann, 1992). The longer the duration of prior wakefulness, the higher the EEG power in non-REMS. Moreover, it is possible to quantitatively predict within one night the non-REMS power increase after temporary suppression of SWA (Dijk et al., 1987b). Clearly, non-REMS power is subject to homeostatic control. The neurophysiological mechanisms underlying this homeostasis are unknown at the moment.

Based on the two-process model of sleep regulation an S-deficiency hypothesis of depression was formulated (Borbély and Wirz-Justice, 1982; Borbély, 1987). This postulates that during the waking period of depressive patients process $S$ does not rise to the level which is attained in non-depressive subjects. Thus the

'It should be noted thar SWA is not idencical with swS which is a substate of non-REMS defined by arbitrary criteria (Borbély, 1987). 
Figure 5. Sleep states and EEG power density plots of a healthy subject. Sleep states (top) are plotted for 30-s epochs. Power density of the various frequency bands is plotted for 1-min segments. The non-REMS-REMS cycles are delimited by vertical lines (after Borbély et al., 1982; 1986).

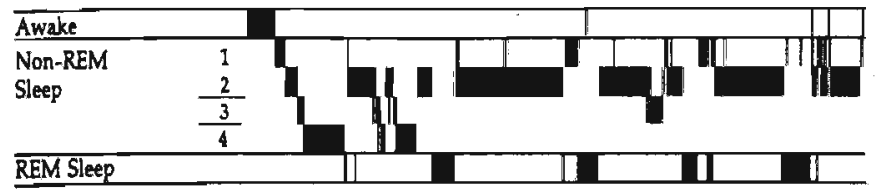

$1-4$

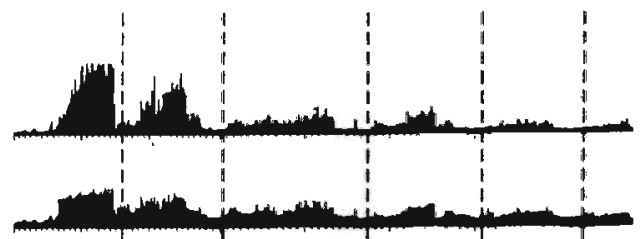

8- $12 \mathrm{~Hz}$

$12-16 \mathrm{~Hz}$

Rapid Waves

$16-25 \mathrm{~Hz}$

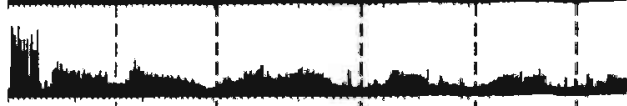

Time of Day

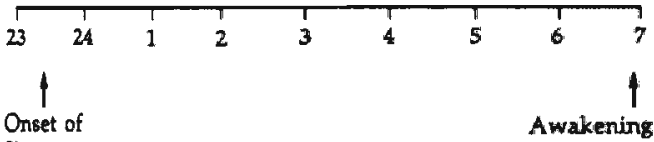

Sileep

build-up of process $S$ is supposed to be deficient, which results in a low level of $S$ at the beginning of sleep. It is further assumed that the level of $S$ is of causal importance for depression (see Fig. 6). 
Figure 6. Diagram of the S-deficiency hypothesis of depression. A lower level of S corresponds with a more depressed mood. The improvement by total sleep deprivation is related to the increase of the level of $\mathrm{S}$. The upper and lower S-thresholds are indicated by $\mathrm{H}$ and $\mathrm{L}$ respectively (modified from Borbély and Wirz-Justice, 1982).

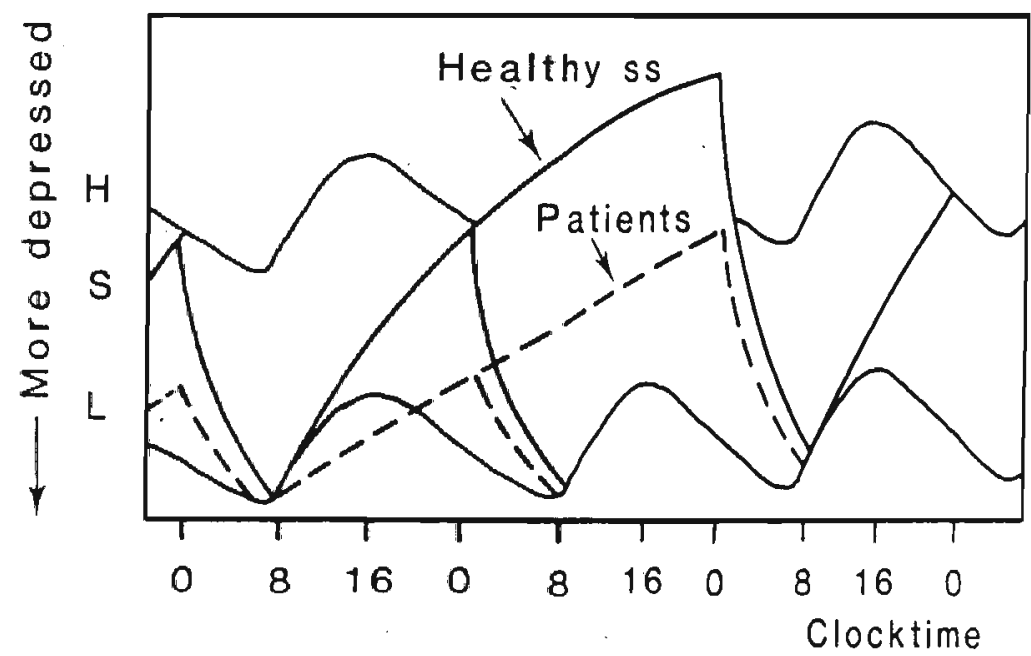

At first sight this so called S-deficiency hypothesis offers an explanation for the sleep characteristics of depressed patients. Since the level of process $S$ determines the duration and intensity of sleep, a low level must lead to shorter and shallower sleep. The hypothesis also suggests an explanation of the therapeutic effect of sleep deprivation: sleep deprivation results in an increased level of process $\mathrm{S}$ and, therefore, in a decrease of depressive symptomatology. After recovery sleep process $\mathrm{S}$ becomes deficient again and depression becomes worse.

At the moment, evidence concerning the S-deficiency hypothesis of depression and therapeutic sleep deprivation is inconsistent. In a theoretical study, Beersma et al. (1985) used the two-process model to simulate the sleep disturbances in depression. They concluded that classical features, such as reduced sleep time and impairment of sleep continuity, could best be simulated by introducing "noise" in process $\mathrm{C}$, rather than by lowering the build-up of process S. Two empirical studies have shown that EEG power density of non-REMS was abnormally low in depressives (Borbély et al., 1984; Kupfer et al., 1984). However, two other studies (Mendelson et al.,1987; Van den Hoofdakker et al., 1986) provided no evidence of differences in total EEG power production between healthy and depressed subjects, even though conventional sleep polygraphic variables showed reduced sws in the depressives. Van den Hoofdakker 
et al. (1986) only observed an altered distribution of EEG power over the night in depressives. Compared to healthy subjects the depressives produced relatively lesS EEG power in non-REMS during the first hours of sleep and relarively more power during the later hours.

The prediction of the S-deficiency hypothesis that augmentation of process $\mathrm{S}$ is responsible for the therapeutic effect of sleep deprivation was also not supported. The improvement of depression after one night's total sleep deprivation appeared not to correlate with the increase of power production during recovery sleep relative to the production in baseline (Van den Hoofdakker and Beersma, 1986; 1992).

Recently, several studies using spectral analysis of the sleep EEG have been reported, which are noteworthy concerning the possible role of non-REMs in depression. Beersma et al. (1990) deprived a group of nine healthy volunteers from REMS by arousing them when REMS occurred during the first 5 hours of the night. During the rest of the night sleep was undisturbed. In a control condition non-REMS was interrupted just as often and during the same 5-hour interval. The REMS deprivation condition resulted in a REMS rebound and, surprisingly, in a reduction of the non-REMS EEG power during the undisturbed part of the night, despite the fact that non-REMS had not been disturbed experimentally. The authors concluded that these results strongly suggest that a high pressure for REMS suppresses the intensity of non-REMS. Dijk et al. (1991) studied the effect of the $A D$ clomipramine on sleep in chipmunks (a day-animal with a circadian sleep-wake rhythm comparable to that of humans). They found that under clomipramine the amount of REMS and the EEG power of nonREMS were considerably decreased. So, just as during non-pharmacologically induced REMS deprivation, under clomipramine too, both REMS and the intensity of non-REMS are suppressed.

These observations have led to the assumption that the antidepressant effects of ADs might be due to the suppression of non-REMS power rather than suppression of REMS (Beersma and Van den Hoofdakker, 1992). The authors argue further that this explanation (the so-called non-REMS hypothesis) is in agreement with the majority of the data on the antidepressant effects of non-pharmacological sleep manipulations, such as total and partial sleep deprivation and REMS deprivation. They all share the non-REMS intensity suppressing element, either acutely or cumulatively.

In summary, the two-process model of sleep regulation and the related hypotheses based on it offer a theoretical framework for the explanation of the processes underlying antidepressive treatment effects. They predict that therapeutic effects must be expected from suppression of non-REMS intensity. 


\subsection{CONCLUDING REMARKS}

The evidence that manipulations of sleep have clinical benefits in some depressed patients and the remarkable influence of most ADs upon sleep suggest that sleep changes are not merely epiphenomena of depression. Changes in sleep physiologicall processes might, therefore, be intimately involved in the pathogenesis, and the manipulations of these changes might be of crucial importance for the recovery from depression. Although an increasing number of findings provides arguments to consider the study of sleep as a source of insight into the physiological background of mood disturbance and antidepressive interventions, the empirical foundations of the prevailing models are still weak (Van den Hoofdakker and Beersma, 1988).

The best documented effects of most efficacious ADs on sleep polygraphic variables in man are REMS suppression and lengthening of REMS latency, irrespective of their pharmacological profile. It is clear, as shown earlier, that some ADs do not share these REMS suppressing properties. Nevertheless, the therapeutic effect of selective REMS deprivation by arousals and the effects of most efficacious ADS on REMS suggest that strong initial and sustained REMS pressure is a prerequisite for the improvement of depression. The reports on a direct relationship between changes of REMS produced by ADs and clinical response are scarce and contradictory. Further clinical sleep research is therefore needed to elucidate the therapeutic importance of the effects of ADs on REMS during treatment.

A significant therapeutic role for changes of REMS is also postulated by the ACh-MA balance model and its related hypothesis of a common pathophysiological mechanism underlying both REMS disturbance and depression. However, the latter hypothesis cannot be tested clinically, because the Ach-MA balance cannot be measured directly in man in the relevant brain structures. Indirect evidence may be expected from clinical sleep research with ADs modifying the ACh and MA neurotransmitter systems specifically. As was shown earlier, ADs which modify the 5-HT system specifically could be relevant in this respect.

The hypotheses, based on the two-process model of sleep regulation, predict that the suppression of EEG power in non-REMS rather than the suppression of REMS is of therapeutic importance. These hypotheses have not been tested during treatment with ADs.

In summary, considering the empirical facts on the influence of ADs on sleep, and the prevailing conceptual backgrounds on the link between sleep and depression, further studies on the effects of ADs on REMS as well as on nonREMS power in depressives are highly needed. In such studies the relationship 
between changes in sleep and in clinical state must be measured over a clinically significant treatment period.

\subsection{CLINICAL ST'UDIES OF THIS THESIS}

Two studies were performed. One with the AD trazodone (chapters 2 and 3), the other with the AD citalopram (chapters 4 and 5 ). The clinical change of subjects suffering from a major depression was compared to the changes in sleep variables obtained by visual scoring and by spectral analysis of the non-REMS EEG during treatment. The studies have the same single blind design: a medication period of 5 weeks is preceded and followed by one-week placebo treatment. The sleep recordings were analyzed in successive 30-s epochs according to the scoring rules of Rechtschaffen and Kales (1968). Fast Fourier transformation ${ }^{3}$ was performed in such a way as to enable spectral-analytical evaluation according to Borbély et al. (1981).

The AD trazodone was chosen, because it had been reported earlier (Mouret et al., 1988) that this AD did not suppress REMS in depressives, whereas REMS latency, sws and sleep efficiency were increased. The effects of trazodone on sleep thus seemed to question the significance of REMS suppression in the pharmacological alleviation of depression. The aim of our study (chapter 2) was to contribute to this controversial issue by comparing the changes in sleep polygraphic variables and antidepressant effects of trazodone more precisely. In chapter 3 the influence of trazodone on EEG power density of non-RIMS is presented and discussed.

The AD citalopram was chosen for the second study because this compound is one of the most selective 5-HT inhibitors currently available, and its metabolites are also 5-HT specific. No human sleep data were yet known from studies in depressives. In chapter 4 the effects of citalopram on sleep polygraphic variables and depression are examined, and in chapter 5 the influence of citalopram on EEG power density of non-REMS is presented and discussed.

\footnotetext{
'Fast Fourier transformation (FFI) is a mathematical procedure by which a vime series of $\mathbf{n}$ datapoints which are sampled at equal intervals, i.e. a digitized LEG signal, is decomposed in sine- and cosine-functions of varying amplitude and frequency. In generali the highest frequency considered is the Nyquist frequency which corresponds to a period of two sampling intervals. The frequency resolution used is $1 / n^{*} d$, where $d$ is the sampling interwal; thes $n^{*} d$ is the duration of the whole time series. The power in a frequency bin represents the contribution of this frequency bin to the total power of the signal. Although the central prerequisite for 1 FT, i.e. stationarity of the signal, is not met by the sleep EEG, this probiem can be solved adequately by separately analyzing many short epochs (for instance 4 seconds) which then are considered "quasi"-stationary. Data reduction can be achieved by calculating an average spectrum over a certain time interval, and by averaging over adjacent frequencies (cited from Dijk, 1988).
} 


\subsection{REFERENCES}

Adrien, J., C. Dugovic and P. Martin. Sleep-wakefulness patterns in the helpless rat. Physiol. Behav. 49:257-262, 1991 .

Adrien, J. Antidepressant-like effects of paradoxical sleep deprivation in the learned helplessness paradigm. J. Sleep Res. 1 [Suppl.1]: 2, 1992.

Akindele, M.O., J.I. Evans and I. Oswald. Monoamine oxidase inhibitors, sleep and mood. Electroencephalogr. Clin. Neurophysiol. 29:47-56, 1970.

APA, American Psychiatric Association: diagnostic and statistical manual of mental disorders (DSM-IIL-R), 3rd revised edn., APA, Washington DC, 1987.

Äsberg, M.L., L. Bertilsson, B. Martisson, G.P. Scilla-Tomba, P. Thoren and L. Traskman-Bendz. CSF monoamine metabolites in melancholia. Acta Psychiatr. Scand. 69:201-219, 1984.

Aserinsky, E. and N. K leitman. Regularly occurring periods of eye motility and concurrent phenomena during sleep. Science 18: 273-274, 1953.

Bardeleben, U.V., A. Steiger and F. Holsboer. Effects of fluoxetine upon pharmacocndocrine and sleep EEG parameters in normal controls. Int. Clin. Psychopharmacol. 4: 1-5, 1989.

Beersma, D.G.M., S. Daan and R.F. van den Hoofdakker. The timing of sleep in depression, theoretical considerations. Psychiatry Res. 16: 253-262, 1985.

Beersma, D.G.M., D.J. Dijk, C.G.H. Blok and I. Everhardus. REM sleep deprivation during five hours leads to an immediate REM sleep rebound and to suppression of non-REM sleep intensity. Electroencephalogr. Clin. Neurophysiol. 76: 114-122, 1990

Beersma, D.G.M. and R.H. van den Hoofdakker. Can non-REM sleep be depressogenic? J. Affective Disord. 24: 101-108, 1992.

Bemmel, A.L. van. De invloed van antidepressiva op de slaap: klinische en theoretische aspekten. In: W. Verhoeven (red) Slaap en Depressie, Symposium onder auspicien van het Interdisciplinair Genoorschap yoor Biologische Psychiatrie. Searle, Maarssen: 31-38, 1990.

Benca, R.M., W.H. Obermeyer, R.A. Thisted and J.C. Gillin. Sleep and psychiatric disorders: a meta-analysis. Arch. Gen. Psychiat. 49: 651-668, 1992

Berger, M., R. Lund, T. Bronisch and D. von Zerssen. REM latency in neurotic and endogenous depression and the cholinergic REM induction test. Psychiatry Res. 10: 113-123, 1983.

Berger, M., D. Höchli, J. Zulley, C. Lauer and D. von Zerssen. Cholinomimetic drug RS 86, REM sleep and depression. Lancet 1: 1385-1386, 1985.

Berger, M., H.M. Emrich, R. Lund, C. Lauer and D. von Zerssen. Sleep-EEG variables as course criteria and predictors of antidepressant therapy with fluvoxamine/oxaprotiline. Advances in Pharmacotherapy 2: 110-120, 1986.

Berger, M., D. Riemann, D. Höchli and R. Spiegel. The cholinergic REM sleep induction test with RS 86: state or trait-marker of depression? Arch. Gen. Psychiatry. 46: 421-428, 1989.

Berger, M., D. Riemano and C. Krieg. Cholinergic drugs as diagnostic and therapeutic tools in affective disorders. Acta Psychiatr. Scand. Suppl. 366: 52-60, 1991.

Blier, P.C., D. Montigny and Y. Chaput. Modifications of the serotonin system by antidepressant treatments: implications for the therapeutic response in major depression. J. Clin. Psychopharmacology 6 [Suppl.6]: 24-35, 1987.

Bfois, R. and J.M. Gaillard. Effects of moclobemide on sleep in healthy human subjects. Acta Psychiatr. Scand. Suppl. 360: 63-75, 1990.

Borbély, A.A., F. Buumann, D. Brandeis, I. Strauch and D. Lehmann. Sleep deprivation: effect on sleep stages and EEG power density in man. Electroencephalogr. Clin. Neurophysiol, 51 : 483$493,1981$.

Borbély, A.A. A two-process model of sleep regulation. Hum. Neurobiol. 1: 195-204, 1982.

Borbély, A.A. and A. Wirz-Justice. Sleep, sleep deprivation and depression. Hum. Neurobiol. 1: $205-210,1982$. 
Borbély, A.A., I. Tobler, M. Loepfe, D.J. Kupfer, R.E. Ulrich, V. Grochocinski, J.Doman and G. Mathews. All-night spectral analysis of the sleep FEG in untreated depressives and normal controls. Psychiatr. Res. $12: 27-33,1984$.

Borbély, A,A. The secrets of sleep. Penguin Books, 1986.

Borbély, A.A. The S-deficiency hypothesis of depression and the two process model of sleep regulation. Pharmacopsychiatry 20: 23-29, 1987.

Borbély, A.A. and I. Tobler. Endogenous sleep-promoring substances and sleep regulation. Physiol. Rev. 69:605-670, 1989.

Borbély, A.A. and P. Achermann. Concepts and models of sleep regulation: an overview. J. Sleep Res. 1: 63\%79, 1992.

Bramanti, P, L. Bianchi, M. Benedetto, R.M. Ricci, M.A. Scribano and R. Di Perri. Study of the hypnic effect of amineptine evaluation by polygraphy and tests. Prog. Neuropsychopharamacol. Biol, Psychiatry 9: 157 165, 1985.

Brebbia, D.R., M.H. Branchey, E. Pyne, J. Watson, A. Brebbia and G. Simpson. The effects of amoxapine on electroencephalographic stages of sleep in normal human subjects. Psychopharmacologia 45: 1-7, 1975.

Brezinova, V., S. Borrow, I. Oswald and D. Robinson. Effect of butriptyline on subjective feelings and sleep. Br. J. Clin. Pharmacol. 4: 243-245, 1977a.

Brezinova, V., K. Adam, K. Chapman, I. Oswald and J. Thomson. Viloxazine, sleep and subjective feelings. Psychopharmacology 55: 121-128, 1977b.

Brown, S-L., A. Bleich and H.M. van Prang. The monoamine hypothesis of depression: the case for serotonin. In: S-L. Brown and H.M. van Praag (eds) The role of serotonin in psychiatric disorders. Brunner/Mazel Publishers, New York: 91-128, 1991.

Cespuglio, R., F. Houdouin, M. Oulerich, M. El Mansari and M. Jouvet. Axonal and somaticdendritic modalities of serotonin release: their involwement in sleep preparation and maintenance. J. Sleep Res. 1: 150-156, 1992

Chen, C.N. Sleep, depression and antidepressants. Br. J. Psychiatry 135: 385-402, 1979.

Cohen, R.M., D.Pickar, D. Garnett, S. Lipper, J.C. Gillin and D.L. Murphy. REM sleep suppres sion induced by selective monoamine oxidase inhibitors. Psychopharmacology 78: 137-140, 1982.

Daan, S., D.G.M. Beersma and A.A. Borbély. Timing of human sleep: Recovery process gated by a circadian pacemaker. Am. J. Physiol. 246, R161-R178, 1984.

Dement, W.C. The effect of dream deprivation. Science 131: 1705-1707, 1960.

Dement, W.C. Some must watch while some must sleep. Stanford allumni association, Stanford, California, 1972 .

Dijk, D.J., D.G.M. Beersma and S. Daan. EEG power density during nap sleep; reflections of an hourglass measuring the duration of prior wakefulness. J. Biol. Rliythms 2: 207-219, 1987 a.

Dijk, D.J., D.G.M. Beersma, S. Daan, G.M. Bloem and R.H. van den Hoofdakker. Quantitative analysis of the effect of slow wave sleep deprivation during the first $3 \mathrm{~h}$ of sleep on subsequent EEG power density. Eur. Arch. Psychiatr. Neurol. Sci. 236: 323-328, 1987b.

Dijk, D.J. Spectral analysis of the sleep EEG: experiments inspired by the two-process model of sleep regulation. Ph.D. thesis, Rijksuniversiteit Groningen, the Netherlands, 1988.

Dijk, D.J., A. Strijkstra, S. Dian, D.G.M. Beersma and R.H. wan den Hoofdakker. Effect of clomipramine on EEG power spectra in the diurnal rodent Eutamias Sibiricus. Psychopharmacology 103: 375-379, 1991.

Di Perri, R., F. Mailland and P. Bramanti. The effects of amineptine on the mood and nocturnal sleep of depressed pacients. Prog, Neuropsychopharmacol. Biol. Psychiarry 11:65-70, 1986.

Dubé, S. Cholinergic supersensitivity in affective disorders. In: I. J. Mann and D.J. Kupfer (eds) Biology of depressive disorders, Part A: a systems perspective. Plenum Press, New York: 51-78, 1993.

Dunleavy, D.L.F., V. Brezinova, I. Oswald, A.W. MacLean and M. Tinker. Changes during weeks in effects of tricyclic drugs on the human slecping brain. Br. J. Psychiatry 120: 663-672, 1972. 
Dunleavy, D.L.F. and I. Oswald. Phenelzine, mood response and sleep. Arch. Gen. Psychiatry 28: $353-356,1973$.

Elsenga, S. and R.H. van den Hoofdakker. Clinical effects of sleep deprivation and clomipramine in endogenous depression. J. Psychiatr. Res. 17: 361-374, 1983.

Fernstrom, ].D. and R.H. Pastel. The neuropharmacology of serotonin and sleep : an evaluation. In: G.F. Koob, C.L. Ehlers and D.J. Kupfer (eds). Animal models of depression. Birkhäuser, Boston: 261-280, 1989.

Feuillade, P., D. Pringuey, J.L. Belugou, P. Robert and G. Darcourt. Trimipramine: acute and lasting effects on sleep in healthy and major depressive subjects. J. Affect. Disord. 24: 135-146, 1992.

Fisher, C. and W.C. Dement. Studies on the psychopathology of sleep and dreams. Am. J. Psychiatry 119: 1160-1168, 1963.

Gaillard, J-M., R. Blois, L. Couto and J. Richard. Modifications of paradoxical sleep by desipramine in elderly depressed patients. Advances in Biological Psychiatry 13:224-228, 1983.

Gaillard, J-M. Neurotransmitters and sleep pharmacology. In: M.J. Thorpy (ed) Handbook of sleep disorders. Dekker, New York: 55-76, 1990.

Gillin, J.C. and R. Wyatt. Schizophrenia: perchance a dream ? Int. Rev. Neurobiol. 17: 297-342, 1975.

Gillin, J.C., S. Lipper, N. Sitaram, D. Garnett and D.L. Murphy. The effects of clorgyline and paragyline on the sleep of depressed patients. Sleep Res. 7: 109-111, 1976.

Gillin, J.C., R.J. Wyatt. D. Fram and F. Snyder. The relationship between changes in REM sleep and clinical improvement in depressed patients treated with amitriptyline. Psychopharmacology 59: 267-272, 1978 .

Gillin, J.C. Sleep studies in affective illness: diagnostic, therapeutic and pathophysiological implications. Psychiatric Annals 13:367-384, 1983a.

Gillin, J.C. The sleep therapies of depression. Prog. Neuropsychopharmacol. Biol. Psychiatry 7: $351-364,1983 b$.

Gillin, J.C. and N. Sitaram. Rapid eye movement sleep: cholinergic mechanisms. Psychol. Med. 14 501-506, 1984.

Gillin, J.C., N. Sitaram, T. Wehr, W. Duncan, R.M. Post, D.L. Murphy, W.B. Mendelson, R.J. Wyatt and W.E. Bunney. Sleep and affective illness. In: R.M. Post and J.C. Ballenger (eds). Neurobiology of Mood Disorders. Williams \& Wilkins, Baltimore: 157-189, 1984.

Gillin, J.C. and A.A. Borbély. Sleep: a neurobiological window on affective disorders. Trends Neurosci. 8: 537-542, 1985.

Gillin, J.C. and Shiromani. Cholinergic mechanisms in sleep: basic and clinical applications. In: J. Montplaisir and R. Godbout (eds) Sleep and biological thythms. Oxford Univ. Press: 186-208, 1990.

Goodwin, F.K. and K.R. Jamison. Manic-depressive illness. Oxford University Press, 1990.

Hartmann, E. The functions of sleep. Yale Univ. Press, London, 1973.

Hartmann, E. and J. Cravens. The effects of long term administration of psychotropic drugs on human sleep. III. The effects of amitriptyline. Psychopharmacologia 33: 185-202, 1973.

Havermans, A.G. en A.L. wan Bemmel. De invloed van antidepressiva op de slaap en de mogelijke betekenis voor her cherapeutisch werkingsmechanisme. T. voor Psychiatrie 33: 645-663, 1991.

Hobson, J.A., R.W. McCarley and P.W. Wyzinski. Sleep cycle oscillation: reciprocal discharge by two brainstem neuronal groups. Science 189:55-58, 1975.

Hobson, J.A. and R.W. McCarley. The brain as a dream state generator: an activation-synthesis hypothesis of the drean process. Am. J. Psychiatry 134: 1335-1368, 1977.

Hobson, J.A., R. Lydic and H.A. Baghdoyan. Evolving concepts of sleep cycle generation: from brain centers to neuronal populations. Behavioral and Brain Sciences 9: 371-448, 1986.

Hoofdakker, R.H. van den, D.G.M. Beersma, D.J. Dijk, A.L. Bouhuys and L.C.W. Dols. Effects of total sleep deprivation on mood and chronophysiology in depression. In: C. Shagass et al. (eds), Bialogicall Psychiatry 1985. Elsevier: 969-971, 1986. 
Hoofdakker, R.H. van den and D.G.M. Beersma. On the contribution of sleep wake physiology to the explanation and the treatment of depression. Acta Psychiatr. Scand. Suppl. 77 [Suppl. 341]: 53-71, 1988 .

Hoofdakker, R.H. van den and D.G.M. Beersma. The role of NREMS pressure and body temperature in the antidepressant response to total sleep deprivation. J. Sleep Res. 1 [Suppl.1]: 238, 1992.

ICSD, International classification of sleep disorders: Diagnostic and coding manual. Diagnostic Classification Steering Committee, Thorpy M.J., Chairman. Rochester, Minnesota: American Sleep Disorders Association, 1990

Jackson, S.W. Melancholia and depression: from Hippocratic times to modern times. Yale University Press, 1986.

Janowsky, D.S., M.K. El-Yousef and J.M. Davis. A cholinergic-adrenergic hypothesis of mania and depression. Lancet 2; 632-635, 1972.

Jouvet, M. Biogenic amines and the states of sleep. Science $163: 32-41,1969$.

Jouvet, M. Neuropharmacology of the sleep-wake cycle. In: L.L. Iversen, S.D. Iversen and S.H. Snyder (eds). Drugs, neurotransmitters and behavior. Plenum Press: 233-293, 1977.

Kales, A., F.S. Hoedenakers, A. Jacobson and E.L. Lichtenstein. Drean deprivation: an experi mental reappraisal. Nature 204: 1337-1338, 1964.

Kasper, S. G. Voll, A. Vieira and H. Kick. Response to total sleep deprivation before and during treatment with fluvoxamine and maprotiline in patients with major depression. Pharmacopsychiatry 23: 135-142, 1990.

Keller, M.B. Current concepts in affective disorders. J. Clin. Psychiatry 50: 157-162, 1989.

Kerkhofs, M., C. Rielaert, V. de Maertelaer, P. Linkowski, M. Czarka and J. Mendlewicz. Fluoxetine in major depression; efficay, safety and effects on sleep polygraphic wariables. Int. Clin. Psychopharmacol. 5: 253-260, 1990.

Klein, E., A. Hefez and P. Lavic. Effects of clomipramine infusion on sleep in depressed patients. Neuropsychobiology 1: 85-88, 1984.

Kleitman, N. Sleep and wakefulness. Univ. of Chicago Press, Chicago (2nd ed), 1963.

Klerman, G.L. History and development of modern concepts of affective illness. In: R.M. Post, J.C. Ballenger (eds) Neurobiology of mood disorders. Williams and Wilkins, Baltimore: 1-19, 1984.

Kupfer, D.J. and M.B. Bowers. REM sleep and central monoamine oxidase inhibition. Psychopharmacologia 27: 183-190, 1972.

Kupfer, D.J., G. Foster, L. Reich, K.S. Thompson and B. Weiss. EEG sleep changes as predictors in depression. Am. J. Psychiatry 133: 622-626, 1976.

Kupfer, D.J., D.G. Spiker, P. Coble and R.J. Mc.I artland. Amitriptyline and EEG sleep in depressed patients: I. Drug effects. Sleep 1: 149-159, 1978.

Kupfer, D.J., P. Coble, J. Kane, T. Petti and K. Conners. Imipramine and EEG sleep in children with depressive symptoms. Psychopharmacology 60: 117-123, 1979.

Kupfer, D.J., D.G. Spiker, P.A. Coble, J.F. Neill, R. Ulrich and D.H. Shaw. Sleep and treatment prediction in endogenous depression. Am. J. Psychiatry $138: 429-434,1981$.

Kupfer, D.J., D.G. Spiker, A. Rossi, P.A. Coble, D. Shaw and R. Ulrich. Nortriptyline and EEG sleep in depressed patients. Biol. Psychiatry 17: 535-546, 1982.

Kupfer, D.J., R.F. Ulrich, P.A. Coble, D.B. Jarratt, V. Grochocinski, J. Doman, G. Matthews and A.A. Borbély. Application of automated REM and slow we sleep analysis: II Testing the assumption of the two-process model of sleep regulation in normals and depressed subjects. Psychiatry Res. 13: 335-343, 1984.

Kupfer, D.J., C.J. Ehlers, B.G. Pollock, R. Swami Nathan and J.M. Perel. Clomipramine and EEG sleep in depression. Psychiatry Res. 30: 165-180, 1989.

Kupfer, D.J., J.M. Perel, B.G. Pollock, R.S. Nathan, V.J. Grochocinski, M.J. Wilson and A.B. McEachran. Fluvoxamine versus desipramine: comparative polysomnographic effects. Biol. Psychiatry 29:23-40, 1991 . 
Lawer, C., J. Zulley, J-C. Krieg, D. Riemann and M. Berger. EEG sleep and the cholinergic REM induction test in anorexic and bulimic patients. Psychiatry Res. 26: 171-181, 1988.

Leibenluft, E. and T.A. Wehr. Is sleep deprivation useful in the treatment of depression? Am. J. Psychiatry 149: 156-168, 1992.

Maeda, Y., T." Hayashi, H. Furuta, Y. Kim, K. Morikawa, N. Eshiguro, K. Ueno, J. Sano and N. Yamaguchi. Effects of mianserin on human sleep. Neuropsychobiology 24: 198-204, 1.990.

McCarley, R.W. and J.A. Hobson. Neuronal excitability modulation over the sleep cycle: a structural and mathematical model. Science 189:58-60, 1975.

McCarley, R.W. REM sleep and depression: common neurobiological control mechanisms. Am. J. Psychiatry 139: 565-570, 1982.

McPartland, R.J., D.J. Kupfer, P. Coble, D.H. Shaw and D.G. Spiker. An automated analysis of REM sleep in primary depression. Biol. Psycliatry 17; 767-776., 1979.

Meltzer, H.Y. and M.T. Lowy. The serotonin hypothesis of depression. In: H.Y. Meltzer (ed) Psychopharmacology: the third generation of progress. Raven Press, New York: 513-526, 1987.

Mendelson, W.B. Human sleep, research and clinical care. Plenum, New York, 1987.

Mendelson, W.B., D.A. Sack, S.P. James, J.V. Martin, R. Wagner, D. Garnet, J. Milton and T.A. Wehr. Frequency analysis of the sleep EEG in depression. Psychintry Res. 21: 89-94, 1987.

Mendelson, W.B. Pharmacology of slow wave sleep in illness and health. In: A. Wauquier, C. Dugovic and M. Radulovacki (eds) Slow wave sleep: physiological, pathophysiological and functional aspects. Raven Press, New York: 155-165, 1989.

Mendelson, W.B. Neurotransmitters, sleep and affective disorders. In: C. Idzikowski and P.J. Cowen (eds) Serotonin, sleep and mental disorder. Wrightson Biomedical Publishing Ltd, Petersfield: 277-288, 1991.

Mendlewicz, J., G.C. Dunbar and G. Hoffman. Changes in sleep EEG architecture during the treatment of depressed putients with mianserin. Acta Psychiatr. Scand. 72: 26-29, 1985.

Mendlewicz, J., C. Kempenacrs and V. de Maertelaer. Sleep EEG and amitriptyline treatment in depressed inpatients. Biol. P'sychiatry 30:691-702, 1991.

Monti, J.M., P. Alterwain and D. Monti. The effects of moclobenide on nocturnal sleep of depressed patients. J. Affect. Disord. $20: 201-208,1990$.

Morgan, K., I. Oswalld and S. Borrow. Effects of a single dose of mianserin on sleep. Br.J. Clin. Pharmacol. 10:525-527, 1980.

Mouret, J., P. Lemoine, M.P. Minuit, C. Benkeffat and M. Renardet. Effects of trazodone on the sleep of depressed subjects, a. polygraphic study. Psychopharmacology Suppl, 95: S37-S43, 1988.

Nicholson, A.R. and P.A. Pascoe. 5-Hydroxytryptamine and noradrenaline uptake inhibition: studies on sleep in man. Neturopharmacology 25: 1079-1083, 1986a.

Nicholson, A.R., P.A. Pascoe and B.M. Stone. Modulation of catecholamine transmission and sleep in man. Neuropharmacology 25: $271-274,1986 b$.

Nicholson, A.N. and P.A. Pascoe. Srudies on the modulation of the sleep-wakefulness continuum in man by fluoxerine, a 5-HT uptake inhibitor. Neuropharmacology 27:597-602, 1988.

Nicholson, A.N., P.A. Pascoe and C. Turner. Modulation of sleep by trimipramine in man. Eur. J. Pharmacol. 37: 145-150, 1989.

Nicholson, A.N. and P.A. Pascoe. Monoaminergic transmission and sleep in man. In: C. Idzikowski and P.J. Cowen (eds) Serotonin, sleep and mental disorder, Wrightson Biomedical Publishing ITD, Petersfield: 215-226, 1991.

Nolen, W.A. P.M.J. Haffmans, P.E. Bouvy and H.J. Duivenvoorden. Monoamine oxidase inhibitors in resistant major depression. J. Affect. Disord. 28: 189-197, 1993.

Oswald, I. and K. Adam. Effects of paroxecine on human sleep. Br. J. Clin. Pharmacol. 22: 97-99, 1986.

Passouant, P., J. Cadhilac and M. Billiard. Withdrawal of the paradoxal sleep by clomipramine: electrophysiological, histochemical and biochemical study. Int. J. Neurol. 10: 186-197, 1975. 
Paykel, E.S. T'reatment of depression: the relewance of research for clinical practice. Br.J. Psychiatry 155: 754-763, 1989.

Praag, H.M. van. Central monoamine metabolism in depression, $\mathrm{I}$, serotonin and related compounds. Comp. Psychiatr. 21: 30-43, 1980.

Praag, H.M. van. Neurotransmitters and CNS disease. Lancet ii: 1259-1263, 1982.

Praag, H.M. van. Affective disorders: evidence for a common biological factor. Suicide Life Threat. Beh. 16: 103-132, 1986.

Rechtschaffen, A. and A. Kales. A manual for standardized terminology, techniques and scoring system for sleep stages of human subjects. Brain Information Serwice, Brain Research Institute, Los Angeles, 1968.

Reynolds, C.F. and D.J. Kupfer. Sleep research in affective illness: state of the art circa 1987. Sleep 10: 199-215, 1987.

Reynolds, C.F., C.C. Hoch, D.J. Buysse, C.J. George, P.R. Houck, S. Maxumbar, M. Miller, B.G. Pollock, H. Rifai, E. Frank, C. Cornes, R.K. Morycz and D.J. Kupfer. Sleep in late-life recurrent depression: changes during early continuation therapy. Neuropsychopharmacology 5:85-96, 1991.

Riemann, D. and M. Berger. The effects of total sleep deprivation and subsequent treatment with clomipramine on depressive symptoms and sleep electroencephalography in patients with a major depressive disorder. Acta Psychiatr. Scand. 81: 24-31, 1990.

Riemann, D., S. Velthaus, S. Laubenthal, W.E. Muller and M. Berger. REM-suppressing effects of amitriptyline and amitriptyline- $\mathrm{N}$-oxide after acute medication in healthy volunteers: results of two uncontrolled pilot trials. Pharmacopsychiatry 23: 253-258, 1990.

Roth, T., F. Zorick, R. Wittig, A. McLenachan and T. Roehrs. The effects of doxepine HCL on sleep and depression. J. Clin. Psychiatry 43:366-368, 1982.

Rush, A.J., D.E. Giles, D.B. Jarrett, F. Feldmann-Koffler, J.R. Debus, J. Weissenburger, P.J. Orsulah and H.P. Roffwarg. Reduced REM latency predicts response to tricyclic medication in depressed outpatients. Biol. Psychiatry 26:61-72, 1989.

Saletu, B., R. Frey, M. Krupka, P. Anderer, J. Grunberger and W.R. See. Sleep laboratory studies on the single-dose effects of serotonin uptake inhibitors paroxetine and fluoxetine on human sleep and waking qualities. Sleep 14:439-447,1991.

Scherschlicht, R., P. Polc, J. Schneeberger, M. Steiner and W. Haefe]y. Sellectiwe suppression of rapid eye movement sleep in cats by typical and atypical antidepressants. In: E. Costa and $G$. Racagni (eds) Typical and atypical antidepressants: molecular mecthanisms. Raven Press, New York: 359-364, 1982.

Sharpley, A.L., A.E.S. Walsh and P.J. Cowen. Nefazodone-A novel amidepressant- may increase REM sleep. Biol. Psychiatry 31: 1070-1073, 1992.

Shipley, J.E., D.J. Kupfer, R.S. Dealy, S.J. Griftin, P.A. Coble, A.D. MeEachran and V.J. Grachocinski. Differential effects of amitriptyline and of zimelidine on the sleep electroencephalogram of depressed patients. Clin. Pharmacol. Ther. 36: 251-259, 1984.

Shipley, J.E., D.J. Kupfer, S.J. Griffin, R.S. Dealy, P.A. Coble, A.D. McEchran, V.J. Grachocinski, R. Ulrich and M. Perel: Comparison of effects of desipramine and anitriptyline on EEG sleep of depressed parients. Psychopharmacology 85: 14-22, 1985.

Sitaram, N. and J.C. Gillin. Development and use of pharmacological probes of the CNS in man: evidence of cholinergic abnormality in primary affectiwe illness. Biol. Psychiatry 15: 925-955, 1980.

Sitaram, N., J.J. Nurnberger, E.S. Gershon and J.C. Gillin. Cholinergic regulation of mood and REM sleep: potential marker of vulnerability to affective disorder. Am. J. Psychiatry 139: 571 $576,1982$.

Snyder, F. The new biology of dreaming. Arch. Gen. Psychiatry 8: 381-391, 1963.

Snyder, F. The dynamic aspects of sleep disturbances in relation to mental illness. Biol. Psychiatry 1:119-130, 1969 
Steiger, A., F. Holsboer and O. Benkert. Long-term studies on the effect of tricyclic antidepressants and selective $\mathrm{MAO}$-A-inhibitors on sleep, nocturnal penile tumescence and hormonal secretion in normal controls. In: W.P. Koella (ed) Sleep '86. Fischer Verlag: 335-337, 1988.

Steriade, M. and $\mathbb{R}$.W. McCarley. Brainstem control of wakefulness and sleep. Plenum Press, New York, 1990.

Vogel, G.W. REM deprivation III. Dreaming and psychosis. Arch. Gen. Psychiatry 18: 312-329, 1968.

Vogel, G.W. and A.C. Traub. REM deprivation. II. The effects on depressed patients. Arch. Gen. Psychiatry 18: 301-311, 1968a.

Vogel, G.W. and A.C. Traub. The effects of REM deprivacion on psychotically depressed patients. Psychophysiology $4: 2,1968 \mathrm{~b}$.

Vogel, G.W. and A.C. Traub. Further studies on REM deprivation of depressed patients. Psychophysiology 5: 239, 1968 c.

Vogel, G.W. A review of REM sleep deprivation. Arch. Gen. Psychiatry 32: 749-761, 1975.

Vogel, G.W., A. Thurmond, P. Gibbons, K. Sloan, M. Boyd and M. Walker. REM sleep reduction effects on depression syndromes. Arch. Gen. Psychiatry 32: 765-777, 1975.

Vogel, G.W., R. McAbee, K. Barker and A. Thurmond. Endogenous depression improvement and REM pressure. Arch. Gen. Psychiarry 34: 96-97, 1977.

Vogel, G.W., F. Vogel, R.S. McAbee and A.J. Thurmond. Improvenent of depression by REM sleep deprivation, new findings and a theory. Arch. Gen. Psychiatry 37: 247-253, 1980.

Vogel, G.W., A.Buffenstein, K. Minter and A. Hennessey. Drug effects on REM sleep and on endogenous depression. Neurosci. Biobehav. Rev. 14: 49-63, 1990.

Ware, J.C. The effect of trimipramine on sleep in patients with major depressive disorder. Pharmacopsychiatry 19:198-199, 1986.

Ware, J.C., F.W. Brown, P.J. Morad, J.T. Pittard and B. Cohert. Effects on sleep: a double blind study comparing trimipramine to imipramine in depressed insomniac patients. Sleep 12:537-549, 1989.

Ware, J.C. Increased decep sleep after trazodone use: a double-blind placebo-controlled study in healthy young adults. J. Clin. Psychiatry, Suppl. 519: 18-22, 1990.

Wehr, T.A. and D.A. Sack. The relevance of sleep research to affective illness, In : W.P. Koella, F. Obal, H. Schulz and P. Visser (eds) Sleep '86. Gustàv Fischer Verlag, Stuttgart New York: 207$211,1988$.

Wehr, T.A. Effects of wakefulness and sleep on depression and mania. In: J. Montplaisir and R. Godbout (eds) Sleep and biological thythms: basic mechanisms and applications to psychiatry. Oxford Univ. Press: 42-86, 1990.

Wiegand, M., M. Berger, J. Zulley and D. von Zerssen. The effect of trimipramine on sleep in patients with major depressive disorder. Pharmacopsychiatry 19:198-199, 1986.

Wyatt, R.J., D.J. Kupfer, J. Scott, D.S. Robinson and F. Snyder, Longitudinal studies of the effect of monoamine oxidase inhibitors on sleep in man. Psychopharmacologia 15: 236-244, 1969.

Wyatt, R.J., D.H. Fram, D.J. Kupfer and F. Snyder. Total prolonged drug-induced REM sleep suppression in anxious-depressed patients. Arch. Gen. Psychiatry 24 : 145-155, 1971.

Zung, W.W.K. Effect of antidepressant drugs on sleeping and dreaming. III. On the depressed patient. Biol. Psychiatry $1: 283-287,1969$. 


\section{Effects of trazodone on EEG sleep and clinical state in major depression}

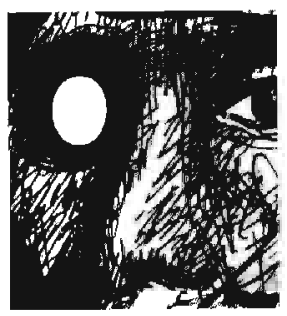

A. L. van Bemmel, A. G. Havermans, and R. van Diest

Department of Psychiatry, University of Limburg

Published in Psychopharmacology 107: 569-574, 1992 


\section{SUMMARY}

The effects of the antidepressant trazodone on clinical state and on EEG sleep in eight outpatients with a major depressive disorder were investigated in a single blind study. A medication period of five weeks was preceded and followed by one week placebo treatment. Five subjects showed a positive treatment response. Trazodone did not influence sleep continuity and slow wave sleep, but did suppress REM sleep significantly. A significant increase of REM sleep latency was also found. These results are in contrast with earlier reports on trazodone's effects on EEG sleep but are in accordance with the general finding that antidepressants influence REM sleep characteristics without necessarily affecting sleep continuity.

\section{INTRODUCTION}

The sleep of subjects with a major depressive disorder shows frequent disturbances: prolonged sleep latency, frequent awakenings, early sleep termination, diminished slow wave sleep (SWS), shortened rapid eye movement (REM) sleep latency, and large variability in non-REM/REM cycle duration are the main characteristics (Gillin and Borbély 1985). Antidepressant drugs (ADs) of all existing neurochemical classes bring about changes in EEG sleep (Nicholson et al. 1989). Because almost all ADs suppress REM sleep, and selective REM sleep deprivation over 3 weeks alleviates depression, the assumption has been proposed that strong, sustained REM sleep suppression is the key mechanism underlying treatment response (Vogel 1983; Vogel et al. 1990). Although they constitute no general finding, the changes in sleep continuity, i.e. the reduction of nocturnal wakefulness, and the increase of the duration of the various stages of non-REM sleep produced by ADs might also be of therapeutic importance (Nicholson et al. 1989). In addition to this, an increase of sws might be relevant, because sws has been postulated to play an important role in the "rest and restoration" which sleep is thought to subserve (Gillin et al. 1989).

Mouret et al. (1988) reported that the AD trazodone did not suppress REM sleep in endogenous depressives, whereas REM sleep latency, sws and sleep efficiency were increased. An increase in sws was further reported by Montgomery et al. (1983) in elderly non-depressed subjects suffering from insomnia. In this study trazodone suppressed REM sleep and a REM sleep rebound was observed during withdrawal. Finally, Ware et al. (1990), studying the effects of trazodone on the sleep of healthy young adults, reported apart from 
an increase in sws a slight REM sleep suppression and a slight lengthening of REM sleep latency. Trazodone's effects seem to question the significance of REM sleep suppression in the pharmacologicall alleviation of depression. In fact, sws increase and amelioration of sleep continuity rather than REM sleep decrease might be of therapeutical significance.

The aim of this study was to contribute to this controversial issue by comparing the sleep physiological and antidepressant effects of trazodone more precisely than was done in previous studies.

\section{MATERIALS AND METHODS}

\section{Study design}

Table 1 shows the main aspects of the study design and the dosage regimen. There were three consecutive treatment periods encompassing a total of seven weeks. In week 1 placebo was administered; in weeks 2-6 the subjects were treated with trazodone; in week 7 trazodone was substituted by placebo. "The administration of placebo and trazodone was single blind. Subjects were informed, however, that placebo treatment could occur. An exception to the dosage regimen was made for subjects whose depression failed to improve after 1 week of treatment with trazodone at the $300 \mathrm{mg} /$ day level. (week 4). Their dosage was increased to $400 \mathrm{mg} /$ day (days 28-41: 1:00 p.m. $200 \mathrm{mg}, 10: 00$ p.m. 200 $\mathrm{mg}$ ).

Table 1. Study design: experimental days, dosage regimen and the schedule of the sleep recordings. PI.A = placebo

\begin{tabular}{lcccc}
\hline Days & \multicolumn{2}{c}{ Dosage regimen } & $\begin{array}{c}\text { Trazodone } \\
\text { daily dose } \\
\text { (mg) }\end{array}$ & $\begin{array}{c}\text { Sleep } \\
\text { recordings } \\
\text { (days) }\end{array}$ \\
\hline $1-6$ & $1: 00 \mathrm{p.m}$. & $10: 00 \mathrm{p} . \mathrm{m}$. & 0 & $6-7$ \\
$7-9$ & PLA & PLA & 100 & \\
$10-13$ & PLA & 100 & 150 & $13-14$ \\
$14-16$ & PLA & 150 & 200 & \\
$17-20$ & 50 & 150 & 250 & $20-21$ \\
$21-41$ & 50 & 200 & 300 & $27-28$ \\
$(28-41)$ & 100 & 200 & $(400)$ & $34-35$ \\
$42-48$ & $(200)$ & $(200)$ & & $41-42$ \\
& PLA & PLA & 0 & $48-49$ \\
\hline
\end{tabular}




\section{Subjects}

The participants had to be outpatients and had to suffer from a major depression, single or recurrent (DSM-III-R (APA 1987) codes 296.2 and 296.3), including insomnia (DSM-III-R code 307.42). In addition to this, a score of 17 or higher on the Hamilton Rating Scale for Depression (HRSD, 17 items; Hamilton. 1967) was required. Subjects were only included when two psychiatrists agreed with respect to diagnosis. Sleep disorders such as sleep apnea or nocturnal myoclonus were not present. The results of physical examination, ECG, blood chemistry and hematology were within normal limits. Subjects were free of psycho-active medication for at least 1 week before participating in the study. The protocol was reviewred and approved by the institutional Ethics Review Committee and the subjects gave informed consent.

\section{Measurements}

The severity of depression of the previous week was assessed preceding each sleep recording by means of the HRSD, by two independent psychiatrists. Both preceding (evening) and after (morning) each sleep recording self-rated mood was assessed using the Adjective Mood Scale (AMS, von Zerssen 1976). The AMS consists of 28 items and yields a score ranging from $O$ (not depressed) to 56 (very depressed). It is particularly well suited for frequent use at short intervals. 'The Dutch version of the AMS has been shown to be psychometrically reliable (Elsenga 1988). Subjective sleep quality (SQ) was assessed after each sleep recording with a self-rating questionnaire (Mulder-Hajonides van der Meulen 1981). The SQ consists of 14 items and yields a score ranging from 0 (very good sleep) to 14 (very bad sleep).

Sleep EEG was recorded berween 11:00 p.m. and 7:00 a.m. in our sleep laboratory at the end of every week. The baseline night, recorded in the first week, was preceded by an adaptation night. The recordings were made at a paper speed of $10 \mathrm{~mm} / \mathrm{s}$ from standard leads: two EOGS, two EEGs (C3-A2 and C4-A1) and a submental chin EMG. The time constants for the EOG and EEG recordings were $0.3 \mathrm{~s}$; the high frequency cut-off was $35 \mathrm{~Hz}$.

\section{Measures}

\section{Clinical state}

For every subject the average of the independent HRSD ratings was used as index of the severity of depression. A HRSD reduction at the end of week 6 of at lcast $50 \%$ of the baseline score (week 1) was taken as criterion for a positive 
treatment response. The averages between the AMS evening and morning scores were used to monitor changes in self-rated mood.

\section{Sleep recordings}

These were visually analyzed in successive 30-s epochs according to the scoring rules of Rechtschaffen and Kales (1968). The following EEG sleep parameters were assessed (Coble et al. 1981): sleep continuity: total recording time (TRT): from "lights out" until arising in minutes; sleep onset (so): the first epoch of stages $2,3,4$ or REM, followed by at least 10 min of sleep interrupted by no more than 2 min of stage 1 or wakefulness; sleep latency (SL): the time between "lights out" and so in minutes; end of sleep (ES): the last epoch of stages 2,3 or 4 , or REM, preceded by at least 10 min of sleep interrupted by no more than 2 min of stage 1 or wakefulness; total time awake: the time awake between so and ES in minutes; sleep period: the time between SO and and ES in minutes; total time spent asleep (TSA): the time spent in stages $\mathbb{1 - 4}$ and REM between SO and ES in minutes; sleep efficiency: the ratio between TSA and TRT x $100 \%$.

\section{REM sleep measures}

REM period, the first REM period has to last at least $3 \mathrm{~min}$, subsequent REM periods have to last at least $5 \mathrm{~min}$. Interruption by non-REM sleep, wakefulness or movement time may not last more than $15 \mathrm{~min}$; REM latency: the time between SO and the first REM period in minutes.

\section{Sleep stages}

The time spent in each sleep stage in minutes; percentage of time spent in sleep stages: the time spent in each sleep stage in minutes/TSA x $100 \%$.

\section{Analyses}

A one-way MANOVA for repeated measures (O'Brien and Kister Kaiser 1985) was applied over the seven experimental weeks. Because of the large interindividual variability in the timing of the effects of trazodone on sleep and behavior, the five treatment weeks were pooled into one estimate. Subsequently, the baseline, pooled trazodone treatment and withdrawal period were analyzed by means of a $1 \times 3$ MANOVA for repeated measures. The Newman-Keuls (NK) posthoc procedure was used to detect where significant results were located. $P$ values of $<0.05$ were accepted as significant. 


\section{RESULTS}

Biographic and clinical characteristics at entrance are shown in Table 2.

Eight outpatients (six females, two males; mean age $=43.5$ years, $\mathrm{SD}=7.3$ ) participated in the study. "Their mean HRSD score at entrance was 27.5 (SD = 3.2). Five subjects met the criterion of a positive treatment response and three did not. The latter three received the higher dosage of trazodone. There was, however, still no improvement at the end of week 6.

'Table 2. Biographic and clinical characteristics of each subject, DSM-III-R codes and HRSD scores at entrance

\begin{tabular}{lllll}
\hline SEX & $\begin{array}{l}\text { AGE } \\
\text { yYS }\end{array}$ & $\begin{array}{l}\text { USM- } \\
\text { III-R }\end{array}$ & HRSD & $\begin{array}{l}\text { R } \\
\text { NR }\end{array}$ \\
\hline F & 49 & 296.3 & 22 & R \\
$\mathrm{F}$ & 56 & 296.2 & 25 & $\mathrm{R}$ \\
$\mathrm{F}$ & 39 & 296.3 & 30 & $\mathrm{R}$ \\
$\mathrm{F}$ & 46 & 296.2 & 27 & $\mathrm{R}$ \\
$\mathrm{F}$ & 42 & 296.3 & 32 & $\mathrm{R}$ \\
$\mathrm{M}$ & 36 & 296.2 & 26 & $\mathrm{NR}$ \\
$\mathrm{F}$ & 34 & 296.2 & 28 & $\mathrm{NR}$ \\
$\mathrm{M}$ & 46 & 296.2 & 30 & $\mathrm{NR}$ \\
\hline
\end{tabular}

$\mathrm{F}=$ female $\mathrm{M}=$ male; $\mathrm{R}=$ responder $\mathrm{NR}=$ nonresponder

\section{Clinical state and subjective sleep}

The mean values and standard deviations of HRSD, AMS (the average between the scores prior to and after the sleep recording) and SQ scores during the seven experimental weeks are shown in Table 3.

A MANOVA Over seven weeks with the scores of HRSD, AMS (evening, morning scores and their average separately) and SQ did not show significant results. A $1 \times 3$ MANOVA revealed a significant result in HRSD scores $\left(\mathrm{F}_{2,6}=11.9 ; \mathrm{P}=0.01\right)$ and no significant results for the different AMS scores and the SQ scores. The NK procedure showed that the HRSD result could be attributed to a significant improvement in depression during the pooled trazodone treatment period compared to baseline. There was no significant difference between treatment and withdrawal period. 
Table 3. Clinical measures: depressive mood (HRSD), self-rated mood (AMS: the average between the scores assessed prior and after each sleep recording) and subjective sleep quality (so). Mean values and standard deviations. (n=8) during the 7 experimental weeks

\begin{tabular}{cccccccc}
\hline & PB & T1 & T2 & T3 & T4 & T5 & PW \\
\hline HRSD & 26.3 & 20.8 & 14.5 & 16.4 & 15.5 & 11.6 & 16.5 \\
& $(3.5)$ & $(6.5)$ & $(8.5)$ & $(9.8)$ & $(8.3)$ & $(9.4)$ & $(8.5)$ \\
\hline \multirow{2}{*}{ AMS } & 35.9 & 31.2 & 32.9 & 31.0 & 33.5 & 27.2 & 26.2 \\
& $(15.1)$ & $(14.8)$ & $(14.2)$ & $(16.8)$ & $(14.3)$ & $(16.8)$ & $(17.8)$ \\
\hline SQ & 8.0 & 6.4 & 8.9 & 6.4 & 6.1 & 6.3 & 7.3 \\
& $(4.0)$ & $(4.1)$ & $(3.0)$ & $(3.3)$ & $(3.6)$ & $(3.1)$ & $(3.7)$ \\
\hline
\end{tabular}

$\mathrm{PB}=$ placebo baseline; $\mathrm{T1}-\mathrm{T} 5=$ the 5 trazodone treatment weeks; $\mathbb{m} \mathrm{W}=$ placebo withdrawal

\section{Sleep continuity and REM sleep latency}

The mean values and standard deviations of sleep continuity parameters and REM sleep latency during the seven experimental weeks are shown in Table 4.

Neither $1 \times 7$ MANOVA nor $1 \times 3$ MANOVA yielded significant results for the different indicators of sleep continuity, i.e., sleep latency, sleep period, total time asleep, total time awake, and sleep efficiency. Although $1 \times 7$ MANOva did not produce a significant result for REM sleep latency, a $1 \times 3$ MANOVA did $\left(\mathrm{F}_{2,6}=6.1\right.$; $\mathrm{P}=0.04)$. The NK procedure showed that this was due to a significant lengthening of REM sleep latency during the pooled trazodone treatment period compared to either baseline or withdrawal.

\section{Sleep stages}

The mean values and standard deviations of the sleep stages (minutes and percentage) during the seven experimenta] weeks are also shown in Table 4. A MANOVA over seven weeks showed only a significant result for stage non-REM 2 (minutes: $F_{3,6}=26.5 ; P=0.04$; and percentage: $F_{3,4}=27.6 ; P=0.04$ ). NK posthoc analysis tevealed that this result could not be attributed to significant differences between specific period pairs. A $1 \times 3$ MANOVA revealed significant results for all sleep stages, expressed either in minutes or in percentage: non-REM 1 (minutes: $F_{2,6}=10.7 ; P=0.01$; percentage: $F_{2,6}=13.7 ; P=0.01$ ), non-REM 2 (minutes: $F_{2, s}$ $=30.6 ; P<0.01$; percentage: $F_{2,6}=94.3 ; P<0.01$ ), non-REM $3 \& 4$ (minutes: $F_{2,6}$ $=8.1 ; \mathrm{P}=0.02$; percentage: $\mathrm{F}_{2,6}=6.4 ; \mathrm{P}=0.03$ ), REM (minutes: $\mathrm{F}_{2,6}=25.9 ; \mathrm{P}<$ 0.01 ; percentage: $F_{2,6}=30.2 ; P<0.01$ ). The NK procedure showed the following: 
Table 4. Sleep measures as derived from the EEG sleep recordings. Mean values and standard deviations $(n=8)$ during the 7 experimental weeks

T3

$T 4$

$\mathrm{T} 5$

PW

Sleep continuity and REM sleep latency

\begin{tabular}{lccccccc} 
Sleep & 59.6 & 50.3 & 37.9 & 38.3 & 45.4 & 35.3 & 42.8 \\
latency & $(31.8)$ & $(14.2)$ & $(16.5)$ & $(14.5)$ & $(29.5)$ & $(20.7)$ & $(40.1)$ \\
Sleep & 398.8 & 396.9 & 409.6 & 423.6 & 406.5 & 417.7 & 409.2 \\
period & $(28.7)$ & $(41.7)$ & $(40.1)$ & $(21.8)$ & $(56.0)$ & $(32.1)$ & $(44.3)$ \\
Total time & 362.3 & 372.9 & 383.7 & 401.8 & 389.4 & 396.4 & 385.0 \\
asleep & $(39.6)$ & $(41.8)$ & $(40.1)$ & $(38.7)$ & $(53.3)$ & $(29.8)$ & $(51.6)$ \\
Total time & 36.5 & 24.0 & 25.9 & 21.8 & 17.1 & 21.3 & 24.2 \\
awake & $(25.9)$ & $(29.3)$ & $(23.1)$ & $(22.6)$ & $(10.9)$ & $(11.1)$ & $(12.8)$ \\
Sleep & 76 & 79 & 82 & 85 & 82 & 85 & 83 \\
efficiency & $(8)$ & $(8)$ & $(8)$ & $(7)$ & $(11)$ & $(6)$ & $(11)$ \\
REM sleep & 97.0 & 192.9 & 221.1 & 137.6 & 157.9 & 156.9 & 84.3 \\
latency & $(34.5)$ & $(47.8)$ & $(98.7)$ & $(37.8)$ & $(108.8)$ & $(61.0)$ & $(47.8)$ \\
\hline Sleep stages (min) & & & & & & & \\
& & & & & & & \\
Stage 1 & 28.4 & 35.4 & 31.4 & 31.5 & 35.9 & 39.6 & 56.7 \\
& $(9.5)$ & $(23.9)$ & $(19.9)$ & $(12.1)$ & $(26.4)$ & $(18.0)$ & $(16.6)$ \\
Stage 2 & 220.3 & 253.6 & 258.6 & 269.1 & 262.1 & 248.1 & 215.7 \\
& $(25.6)$ & $(46.1)$ & $(38.5)$ & $(48.1)$ & $(62.3)$ & $(48.2)$ & $(56.4)$ \\
Stages 384 & 36.7 & 34.8 & 50.4 & 38.8 & 43.1 & 45.8 & 25.0 \\
& $(27.1)$ & $(28.5)$ & $(30.6)$ & $(25.3)$ & $(30.6)$ & $(30.4)$ & $(21.5)$ \\
Stage REM & 76.9 & 49.1 & 43.3 & 62.4 & 48.3 & 62.9 & 87.6 \\
& $(16.6)$ & $(27.8)$ & $(24.2)$ & $(14.4)$ & $(19.1)$ & $(29.9)$ & $(17.8)$ \\
& & & & & & &
\end{tabular}

Slecp stages (\% from total time spent asleep)

\begin{tabular}{lccccccc} 
Stage 1 & 7.8 & 9.5 & 8.2 & 7.8 & 9.2 & 10.1 & 14.7 \\
& $(2.5)$ & $(6.2)$ & $(5.3)$ & $(2.8)$ & $(6.1)$ & $(4.6)$ & $(3.5)$ \\
Stage 2 & 60.8 & 68.0 & 67.4 & 67.0 & 67.3 & 62.6 & 56.0 \\
& $(6.5)$ & $(8.1)$ & $(7.6)$ & $(7.5)$ & $(9.2)$ & $(11.1)$ & $(9.9)$ \\
Stages 38.4 & 10.1 & 9.3 & 13.1 & 9.7 & 11.1 & 11.6 & 6.5 \\
& $(7.2)$ & $(9.0)$ & $(7.9)$ & $(6.5)$ & $(9.3)$ & $(8.4)$ & $(6.0)$ \\
Stage REM & 21.2 & 13.2 & 11.3 & 15.5 & 12.4 & 15.9 & 22.8 \\
& $(3.4)$ & $(7.4)$ & $(5.6)$ & $(3.6)$ & $(5.5)$ & $(7.0)$ & $(5.5)$ \\
\hline
\end{tabular}

$\mathrm{PB}=$ placebo baseline; $\mathrm{T} 1-\mathrm{TS}=$ the 5 trazodone treatment weeks; $\mathrm{PQ}=$ placebo withdrawal

the non-REM 1 result could be attributed to a significant increase in non-REM 1 sleep during the withdrawal period compared to either the baseline or the trazodone treatment period. The non-REM 2 result could be attributed to a significant decrease in non-REM 2 sleep during the withdrawal period compared to either baseline or trazodone treatment period. The NK procedure failed to show 
where a significant overall difference in stage non-REM 3 and 4 was located. The REM sleep result could be attributed to a significant decrease of REM sleep during the trazodone treatment period compared to both baseline and withdrawal.

Comparison of REM sleep, REM sleep latency and sws in responders and nonresponders

The weekly changes in severity of depression (HRSD scores), REM sleep (min), REM sleep latency and sws (min) for each subject are shown in Fig.1.

Fig.1. The course of mood (total HRSD-score) (A), REM sleep (B), REM sleep latency (C) and sws (D) for each subject (weekly measurements). The values are expressed relative to the values of the placebo baseline period. Solid lines = responders; broken lines = nonresponders. $P B=$ placebo baseline week; $\mathrm{T} 1-\mathrm{T} 5$ = the 5 trazodone treatment weeks; $\mathrm{Pw}=$ placebo withd rawal week.

A

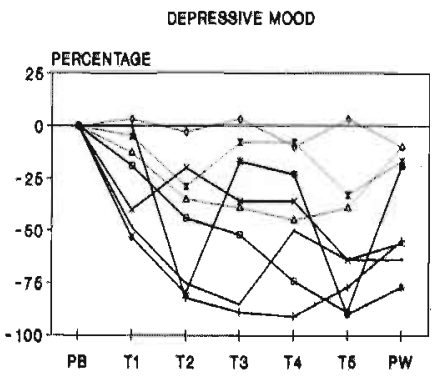

C

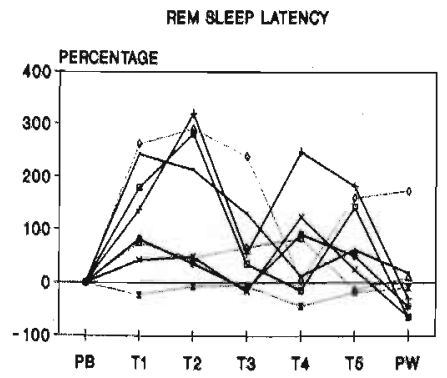

B

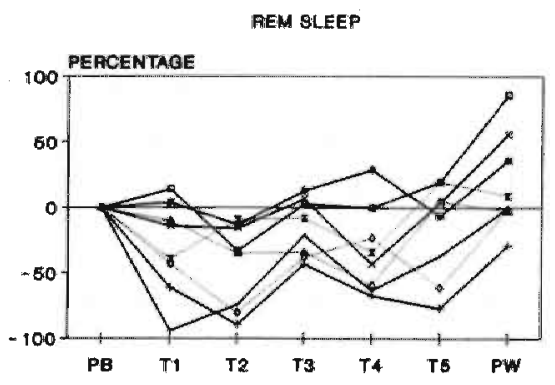

D

BLOW MMVE BLEEEP

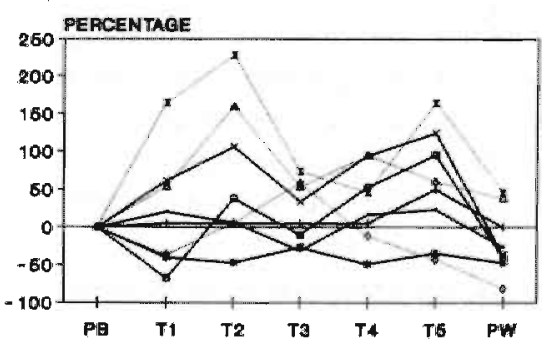


Upon inspection, the major differences between responders ( $n=5)$ and nonresponders $(n=3)$ are the following. Compared to trazodone treatment week 5 , an increase of RIM sleep duration is observed in all responders and in one nonresponder during withdrawal of trazodone (Fig. 1B). Furthermore, compared to trazodone treatment week 5, all responders show a decrease of REM sleep latency during withdrawal (Fig. 1C). With respect to sws responders and nonresponders do not show obvious differences (Fig. 1D).

\section{DISCUSSION}

Trazodone proved to be an effective $A D$, at least as reflected in the HRSD ratings made by two independent psychiatrists. Trazodone, however, did not improve significantly self-rated mood nor did it improve subjective sleep quality. The difference between the results for HRSD and AMS might be caused by the difference in period over which mood was evaluated. HRSD ratings reflect the global clinical state of the patient during the previous week, AMS scores concern the state at the moment of scoring.

The statistical analyses revealed that trazodone did not change sleep continuity, but suppressed REM sleep and increased REM sleep latency significantly. These parameters returned to baseline values after one week placebo-withdrawal. In spite of the absence of change of non-REM stages 1 and 2 during trazodone treatment compared to baseline, these stages appeared to change significantly during one week placebo-withdrawal of trazodone, i.e., stage 1 increased and stage 2 decreased. These findings suggest that withdrawal of trazodone might have caused a lighter sleep. MANOVA further provided a significant difference in the distribution of sws over the conditions. By post-hoc analysis these differences could not be elucidated. There is some indication that trazodone increased sws time and that withdrawal caused a rebound decrease. The data, however, are merely suggestive. Furthermore, the present study did not show a clear-cut relationship either between clinical response and sws or between clinical response and REM sleep parameters.

Our results are only partly in agreement with those of Mouret et al. (1988). These authors also found an increased REM sleep latency in their depressed subjects, but the increase in sleep duration and in sws duration, and the absence of REM sleep suppression in their study are at variance with our findings. The studies, however, are not completely comparable. In the study of Mouret et al. (1988) only the initial effects of trazodone on EEG sleep and those after 4 weeks of trazodone administration were assessed, whereas in our study a weekly monitoring provided the basis for the results. An inspection of our data in the 
first and fourth treatment week with those of Mouret also suggest no agreement between the two studies. The disagreement may be due to two factors: differences in dosage regimen and in baseline sleep. In Mouret et al.'s study higher and variable dosages were employed (mean daily dosage of $422-570 \mathrm{mg}$ ), while the baseline sleep characteristics indicate more severe sleep disturbances; particularly the much lower amount of sw/s, both in minutes and percentage, may be relevant. Comparison of our results with those of Montgomery et al. (1983) and Ware et al. (1990) has also limited value, mainly because these studies concerned nondepressed subjects and lower daily dosages of trazodone were used (respectively 150 and $200 \mathrm{mg}$ ).

We therefore conclude that trazodone is an $\mathrm{AD}$ that induces a distinct decrease in REM sleep, whereas its effects on SWS are less clear. These results suggest that the effects of trazodone on EEG sleep are in accordance with the general finding that ADs influence REM sleep without necessarily affecting sleep continuity (Vogel et al. 1990).

The hypothesis of Vogel (1983) that strong, sustained REM sleep suppression is responsible for improvement of depression is not confirmed by the results of the present study. An alternative explanation, however, is feasible. According to a recent model on the link between sleep and depression non-REM sleep rather than REM sleep parameters are of crucial importance for the depressive state (Borbély 1987). According to this model the pressure for non-REM sleep as expressed in the power density in the sleep EEG is deficient in depression and therapeutic effects must be expected from an increase of this pressure. Borbély et al. (1981) have demonstrated in normal subjects that the power density of the sleep EEG revealed within individual non-REM sleep stages marked, progressive alterations that could not be recognized on the basis of visual scoring of the sleep EEG. Recently, it was shown that REM sleep suppression produces an increased pressure for non-REM sleep in healthy volunteers (Beersma et al. 1990). Furthermore, it should be mentioned that in chipmunks the administration of the $\mathrm{AD}$ clomipramine resulted not only in REM sleep suppression, but also in a dramatic decrease in non-REM sleep intensity and therefore probably an increase in the pressure for non-REM sleep (Dijk et al. 1991). The results of both studies indicate that the antidepressant effect of REM sleep reduction may be due to the reduction of non-REM sleep intensity it entails. In a next analysis of our data this possibility will be examined by analyzing the effects of trazodone on non-REM sleep intensity as expressed by the EEG power density. 


\section{ACKNOWLEDGEMENTS}

We thank Prof. R.H. van den Hoofdakker and Dr. D.G.M. Beersma (University of Groningen), and Dr. J. O'Hanlon (University of Limburg) for their comments, and Angelini International Corporation for financial support. 


\section{REFERENCES}

American Psychiatric Association: diagnostic and statistical manual of mental disorders (DSMIII-R). APA, 3rd revised edn, Washington DC, 1987.

Beersma, D.G.M., D.J. Dijk, C.G.H. Blok and I. Everhardus. REM sleep deprivation during 5 hours leads to an immediate REM sleep rebound and to suppression of non-REM sleep intensity. Electroencephalogr. Clin. Neurophysiol. 76:114-122, 1990.

Borbély, A.A., F. Baumann, D. Brandeis, I. Strauch and D. Lehmann. Sleep deprivation: Effect on sleep stages and EEG power density in man. Electroencephalogr Clin Neurophysiol 51: 483-493, 1981 .

Borbély, A.A. The S-Deficiency hypothesis of depression and the two-process model of sleep regulation. Pharmacopsychiatry 20:23-29, 1987.

Coble, P.A., D.J. Kupfer and D.H. Shaw. Distribution of REM latency in depression. Biof Psychiatry 16: 453-466, 1981.

Dijk, D.J., A. Strijkstra, S. Daan, D.G.M. Beersma and R.H. van den Hoofdakker. Effect of clomipramine on sleep and EEG power spectra in the diurnal rodent Eutamias Sibiricus. Psychopharmacology 103: 375-379, 1991.

Elsenga, S. Een zelfbeoordelingsschaal voor depressie. T. voor Psychiatrie 30: 114-126, 1988.

Gillin, J.C. and A.A. Borbély. Sleep, a neurobiological window on affective disorders. Trends Neurosci 8: 537-542, 1985.

Gillin, J.C., D.F. Kripke, S.C. Risch and M. Schuckit. Slow wave sleep: relationship to primary alcoholism and to sleep deprivation in depression. In: Wauquier, A., C. Dugovic, M. Radulovacki (eds) Slow wave sleep. Raven Press, New York, 141-153, 1989.

Hamilton, M. Development of a rating scale for primary depressive illness. Br. I. Soc. Clin, Psychiatry 16: 278-296, 1967.

Montgomery, J., I. Oswald andK. Morgan. Trazodone enhances sleep in subjective quallity but not objective duration. J. Clin. Pharmacol. 16: 139-144, 1983.

Mouret, J., P. Lemoine, M.P. Minuit, C. Benkelfat and M. Renardet. Effects of trazodone on the sleep of depressed subjects, a polygraplic study. Psychopharmacology 95: S37-S43, 1988.

Mulder-Hajonides van der Meulen, W.R.E.H. Measurement of subjective sleep quality. In: Proceedings of the European Sleep Congress, Amsterdam, The Netherlands, 1981.

Nicholson, A.N., C.M. Bradley and P.E. Pascoe. Medications: effect on sleep and wakefulness. In: Kryger, M., T. Roth, W. Dement (eds) Principles and practice of sleep medicine. WB Saunders, Philadelphia: 228-236, 1989.

O'Brien, R.G. and M. Kister Kaiser. MANOVA method for anallyzing repeated measures designs: an extensive primer. Psychol Bull 97; 316-333, 1985.

Rechtschaffen, A. and A. Kales. A manual of standardized terminology, techniques and scoring system for sleep stages of human subjects. UCLA Brain Information Service Institute, Los Angeles, 1968.

Vogel, G.W. Evidence for REM sleep deprivation as the mechanism of action of antidepressant drugs. Prog. Neuropsychopharmacol. Biol. Psychiatry 7: 343-349, 1983.

Vogel, G.W., A. Buffenstein, K. Minter and A. Hennessey. Drug effects on REM sleep and on endogenous depression. Neurosci. Biobehav. Rev. 14: 49-63, 1990.

Ware, J.C. and J.T. Pittard. Increased deep sleep after trazodone use: a double-blind placebo-controlled study in healthy young adults. J Clin Psychiatry 51 : 9 [suppl]: 18-22, 1990

Zerssen, D. von Die Befindlichkeitsskala. Manual. Beltz Test, Weinheim, 1976. 

CHAPTER 3

\section{Changes in EEG power density of non-REM sleep in depressed patients during treatment with trazodone}

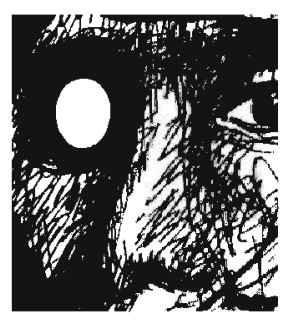

Alex L. van Bemmel (1), Domien G.M. Beersma (2),

Rutger H. van den Hoofdakker (2), and Gert Jan Mevius (1)

(1) Department of Psychiatry, University of Limburg

(2) Department of Biological Psychiatry, University of Groningen

Submitted to Psychiatry Research, 1993 


\section{SUMMARY}

Recently it was hypothesized that suppression of EEG slow wave activity (SWA) would be essential for the antidepressant action of various antidepressant treatments. According to this hypothesis one would expect a relationship between SWA suppression and improvement. This expectation is examined in this paper. Eight outpatients with a major depression were treated with trazodone in a single-blind design. Five weeks of trazodone treatment were preceded and followed by one week of placebo treatment. Sleep was recorded at the end of every week. The effects on SWA were evaluated on the basis of power spectrum analysis. During trazodone treatment the 13 and $14 \mathrm{~Hz}$ bins showed a significant reduction in EEG power. Although four out of five clinically improved subjects ( $>50 \%$ reduction of their Hamilton Depression Rating Score) demonstrated a lowering of EEG power during and after treatment, there was no overall significant relationship between power suppression and clinical improvement.

\section{INTRODUCTION}

The most consistently reported effects of most antidepressant drugs (ADs) on sleep in both healthy and depressed subjects are reduction of the amount of Rapid Eye Movement Sleep (REMS), and lengthening of REMS latency, while a REMS rebound is observed during withdrawal (Vogel et al., 1990). The effects of ADS on REMS and the therapeutic effects of repeated REMS deprivations over 3 weeks have led to the hypothesis that sustained REMS suppression is a significant factor in the mechanism under)ying recovery from depression (Vogel et al. 1975). Studies in depressives with various ADs, however, could not demonstrate a direct relationship between the amelioration of depression and REMS suppression (Riemann and Berger, 1990; Van Bemmel et al., 1992).

The reports on the effects of ADs on non-REMS are inconsistent. Tricyclic ADs have been reported to increase, decrease or not affect non-REMs (Mendelson, 1989; Nicholson et al., 1989). It is not clear whether the effects on non-REMS are related to the effects on mood. This may be due to the fact that it is not sufficient to quantify non-REMS in terms of its duration only. Borbély et al. (1981) have demonstrated in healthy subjects that the power density of the sleep EEG (which is proportional to the square of the EEG amplitude) within individual non-REMS stages revealed marked alterations that could not be recognized on the basis of visual scoring of the sleep lEG. This type of analysis might perhaps 
reveal relationships between non-REMS and mood which cannot be detected on the basis of classical non-REMS analysis.

According to a model on the link between sleep and depression the pressure for non-REMS as expressed in the power density of the sleep EEG is deficient in depression and therapeutic effects could be expected from an increase of this pressure, e.g. by sleep deprivation (Borbély and Wirz-Justice, 1982; Borbély, 1987). Recently, it was shown in healthy subjects that REMS deprivation by arousals resulted in a simultaneous reduction of slow-wave activity (SWA) in non-REMs (Beersma et al., 1990). In chipmunks it was demonstrated that the administration of the A.D clomipramine resulted not only in REMS suppression, but also in a decrease in non-REMs power of frequencies between 1.5 and 13.5 $\mathrm{Hz}$ (Dijk et al., 1991). It has been hypothesized that the antidepressant effect of REMS reduction may be due to the reduction of non-REMS SWA it entails (Beersma and Van den Hoofdakker, 1992). Summarizing, according to both hypotheses ADs might be effective because of the non-REMS power suppression during treatment.

In an earlier report on the patients in the present study (Van Bemmel et al., 1992) it was shown that during trazodone treatment REMS decreased and REMS latency increased, whereas visually scored slow wave sleep (sws) did not change significantly. The REMS variables returned to baseline values after one week placebo-withdrawal. Furthermore, no clear-cut relationships between clinical change and REMS variables, and between clinical change and visually scored sws could be found. The present report concerns an analysis of the relationship between changes in EEG power density and clinical improvement.

\section{MATERIALS AND METHODS}

\section{Study design}

Table 1 shows the main aspects of the study design and the dosage regimen. There were three consecutive treatment periods encompassing a total of seven weeks. In week 1 a placebo was administered; in weeks 2-6 the subjects were treated with trazodone; at the end of week 6 trazodone was abruptly discontinued and substituted by a placebo. The administration of the placebo and trazodone was single-blind. Subjects were informed that placebo treatment could occur. An exception to the dosage regimen was made for subjects whose depression failed to improve after 1 week of treatment with trazodone at the $300 \mathrm{mg} /$ day level (week 4). Their dosage was increased to $400 \mathrm{mg} /$ day (days 2841:1:00 p.m. 200 mg, 10:00 p.m. $200 \mathrm{mg}$ ). 
Table 1. Study design: experimental days, dosage regimen and the schedule of the sleep recordings. $P L A=$ placebo

\begin{tabular}{|c|c|c|c|c|}
\hline \multirow[t]{2}{*}{ Days } & \multicolumn{2}{|c|}{ Dosage regimen } & \multirow{2}{*}{$\begin{array}{c}\text { Trazodone } \\
\text { daily dose } \\
\text { (mg) }\end{array}$} & \multirow{2}{*}{$\begin{array}{l}\text { Sleep } \\
\text { recording } \\
\text { (days) }\end{array}$} \\
\hline & 1:00 p.m. & 10:00 p.m. & & \\
\hline $1-6$ & PLA & PLA & 0 & $6-7$ \\
\hline 7.9 & $\mathbb{P L A}$ & 100 & 100 & \\
\hline $10-13$ & PLA & 150 & 150 & $13-14$ \\
\hline $14-16$ & 50 & 150 & 200 & \\
\hline $17-20$ & 50 & 200 & 250 & $20-21$ \\
\hline $21-41$ & 100 & 200 & 300 & $27-28$ \\
\hline \multirow[t]{2}{*}{$(28-41)$} & $(200)$ & $(200)$ & $(400)$ & $34-35$ \\
\hline & & & & $41-42$ \\
\hline $42-48$ & PLA & PLA & 0 & $48-49$ \\
\hline
\end{tabular}

\section{Subjects}

The participants were outpatients suffering from a major depression, single or recurrent [DSM-III-R (APA, 1987) codes 296.2 and 296.3], including insomnia (DSM-III-R code 307.42). In addition to this, a score of 17 or higher on the Hamilton Rating Scale for Depression (HRSD, 17 items; Hamilton, 1967) was required. Subjects were only inchuded if two psychiatrists agreed with respect to diagnosis. Patients with a current history of sleep disorders such as sleep apnea or nocturnal myoclonus were excluded on the basis of a medical intervicw. 'The results of physical examination, ECG, blood chemistry and hematology were within normal limits. Subjects were free from psychoactive medication. for at least 1 week before Week 1 with placebo. During the study alcohol consumption, consumption of beverages containing caffeine (from lunch time), comedication, and napping were not allowed. The compliance to the instruction not to nap was not controlled for by objective measurements. The protocol was reviewed and approved by the institutional Ethics Review Committee and the subjects gave informed consent.

\section{Measurements}

Prior to each sleep recording the severity of depression of the previous week was assessed by means of the HRSD, rated by two psychiatrists.

Sleep EEG of each subject was recorded between 11:00 p.m. and 7:00 a.m. at the end of each experimental week in our sleep laboratory. The baseline night, recorded in the first week, was preceded by an adaptation night. The recor- 
dings were obtained at a paper speed of $10 \mathrm{~mm} / \mathrm{s}$ from standard. leads: two EOGS, two EEGS (C3-A2 and C4-A1) and a submental chin EMG. The time constants for the EOG and EEG recordings were $0.3 \mathrm{~s}$; the high-frequency cut-off was $35 \mathrm{~Hz}$. All signals were stored on magnetic tape for off-line analyses.

\section{Measures}

\section{Depression}

For every subject the average of the two FIRSD ratings was used as an index of the severity of depression. For each assessment the rank correlations between the two HRSD ratings obtained in all patients were calculated. The resulting seven correlation values showed a range between 0.91 and 0.97 . 'This indicates a close overall correspondence ( $>80 \%$ ) between the two HRSD raters with respect to the assessment of the severity of depression. An HRSD reduction at the end of the trazodone treatment (Week 6) of $50 \%$ of the baseline score (Week 1) was taken as the criterion for a clinically significant improvement.

\section{Sleep recordings}

These were visually analyzed in successive 30-s epochs according to the scoring rules of Rechtschaffen and Kales (1968). Sleep onset (so) was defined as follows: the first epoch, after "lights out", of stages $2,3,4$ or REM, followed by at least $10 \mathrm{~min}$ of sleep, interrupted by no more than 2 min of stage 1 or wakefulness.

One EEG signal [i.e. in each subject obtained from the same lead in all conditions ( $\mathrm{C} 3-\mathrm{A} 2$ or $\mathrm{C} 4-\mathrm{A} 1)$ ] was low-pass filtered for spectral analysis at $25 \mathrm{kz}$ (24 $\mathrm{dB} / \mathrm{oct}$ ) and subsequently digitized at 64 samples/s. Digitized data were processed by a fast Fourier transform routine. Power spectra were calcullated over $4-\mathrm{s}$ intervals from $0.75-15 \mathrm{~Hz}$ in $0.25 \mathrm{~Hz}$ bins, by applying a rectangular window. The 0.25 bins were condensed into $1 \mathrm{~Hz}$ wide frequency bins. Bins will be referred to by mentioning their upper limit, so power density in the $1 \mathrm{~Hz}$ bin is the sum of the power density of 0.75 and $1 \mathrm{~Hz}$; power density in the $2 \mathrm{~Hz}$ bin is the sum of the power density of $1.25,1.50,1.75$ and $2 \mathrm{~Hz}$ etc. To obtain a resolution of 30-s, power values of 7.5 adjacent 4 -s epochs were summed for each frequency bin thus calculated. Visual scores of the same 30-s epochs were synchronized with the series of power spectral epochs. Figure 1 shows an example of the time course of EEG power density and visually assessed sleep stages derived from one sleep recording. 
Figure 1. Time course of EEG power densicy $\left(\mu \mathrm{V}^{2} / \mathrm{Hz}\right)$, integrated from 0.75 to $15 \mathrm{~Hz}$, and sleep staging from one sleep recording during placebo-withdrawal (from subject B: male, $46 \mathrm{yrs}$ ). (N)REM = (non) rapid eye movement sleep; $M T=$ movement time

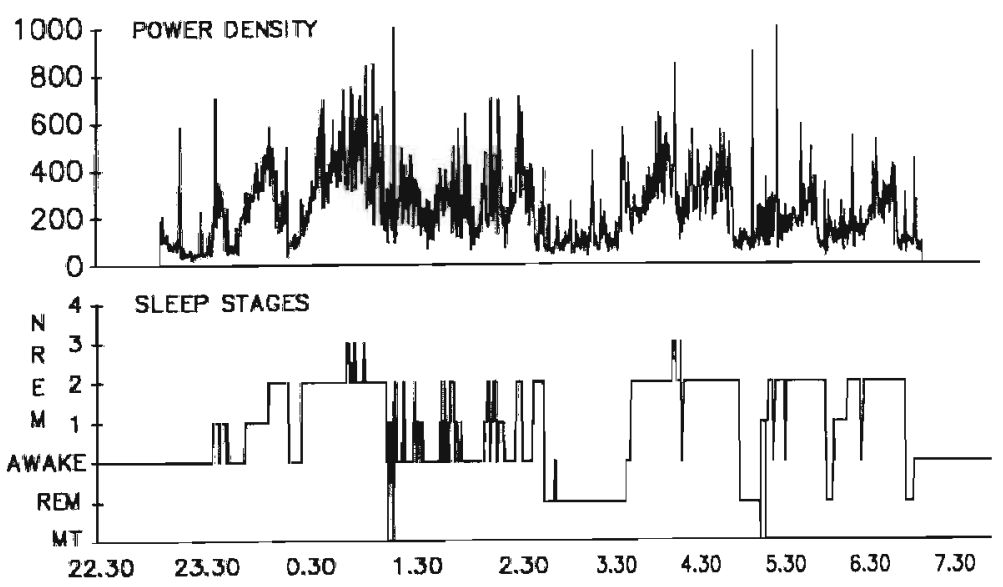

The influence of trazodone on non-REMs power was analysed on the basis of the longest common amount of non-REMS stages $2,3 \& 4$, accumulated from sleep onset onwards (see Discussion). 30-s epochs of non-REMS stages 2, $3 \& 4$ containing EEG-artefacts [mean: $5.9 \%(\mathrm{SD}=2.8)$ of all non-REMS $2,3 \& 4$ epochs] were omitted from further spectral analysis, on the basis of visual inspection of the original tracings.

Since the absolute values of the power densities of the higher frequencies are several orders of magnitude lower than those of the lower frequencies and since the interindividual variation is considerable, absolute values are not very suitable for a visualization of changes in power spectra (Dijk et al.,1989). Therefore, in the figures power values of each subject were expressed relative to power values in baseline, which latter values are taken as $100 \%$.

\section{Analyses}

Because of the large interindividual variability in the timing of the effects of trazodone on sleep and clinical state, for each subject the absolute EEG power values of the different frequency bins over the five trazodone treatment weeks were averaged into an estimate for one night. A one-way MANOVA for repeated measures (O'Brien and Kister Kaiser, 1985) was applied over the baseline period, the averaged trazodone treatment period and the withdrawal period. 
The Newman-Keuls (NK) post-hoc procedure was used to detect where significant results were located. P values $<0.05$ were accepted as significant.

\section{RESULTS}

\section{Depression}

Table 2 shows the clinical characteristics of the eight patients who participated in the study.

Table 2. Age, sex ( $\mathrm{F}=$ female; $M=$ male), baseline HRSD scores, and changes in TIRSD scores at the end of the trazocone treatment period expressed relative to placebo-baseline values of each subject. The rank order of the subjects is based on the clinical response. Subjects $A, B$ and $C$ teceived the higher dosage of trazodone; there was, however, still no clinically significant improvement at the end of the trazodone treatment period

\begin{tabular}{ccccc}
\hline Subject & $\begin{array}{c}\text { Age } \\
\text { yrs }\end{array}$ & Sex & $\begin{array}{c}\text { HRRS } \\
\text { Score }\end{array}$ & $\begin{array}{c}\text { FRSD } \\
\text { change (\%) }\end{array}$ \\
\hline A & 36 & M & 29 & 0 \\
B & 46 & M & 24 & 34 \\
C & 34 & F & 31 & 39 \\
D & 49 & F & 22 & 63 \\
E & 42 & F & 25 & 64 \\
F & 56 & F & 22 & 77 \\
G & 46 & F & 27 & 89 \\
H & 39 & F & 30 & 90 \\
\hline
\end{tabular}

\section{Power spectra in non-REMS}

The longest common amount of non-REMS stages 2,3 \& 4 was 168.5 minutes. Figure 2 shows the means of the power spectra of the patient group during the 5 trazodone treatment weeks and the withdrawal period, relative to the power spectra of baseline $(=100 \%)$. 
Figure 2. Power spectra of 168.5 min non-REMs during the 5 trazodone treatment weeks (T1-T5) and the withdrawal period ( $\mathrm{PW}$ ), relative to power spectra of baseline ( $\mathrm{PB}=100 \%$ ). Means of the patient group $(n=8)$. Power densities are plotted at the upper bounderies of the frequency bins. The frequency ranges in which the power values varied significantly $(\mathrm{P}<0.05 ;$ MANOVA) over the three experimental periods ( $\mathrm{PB}, \mathrm{T} 1-\mathrm{TS}$, and $\mathrm{Pw}$ ) are indicated by black bars above the abscissa

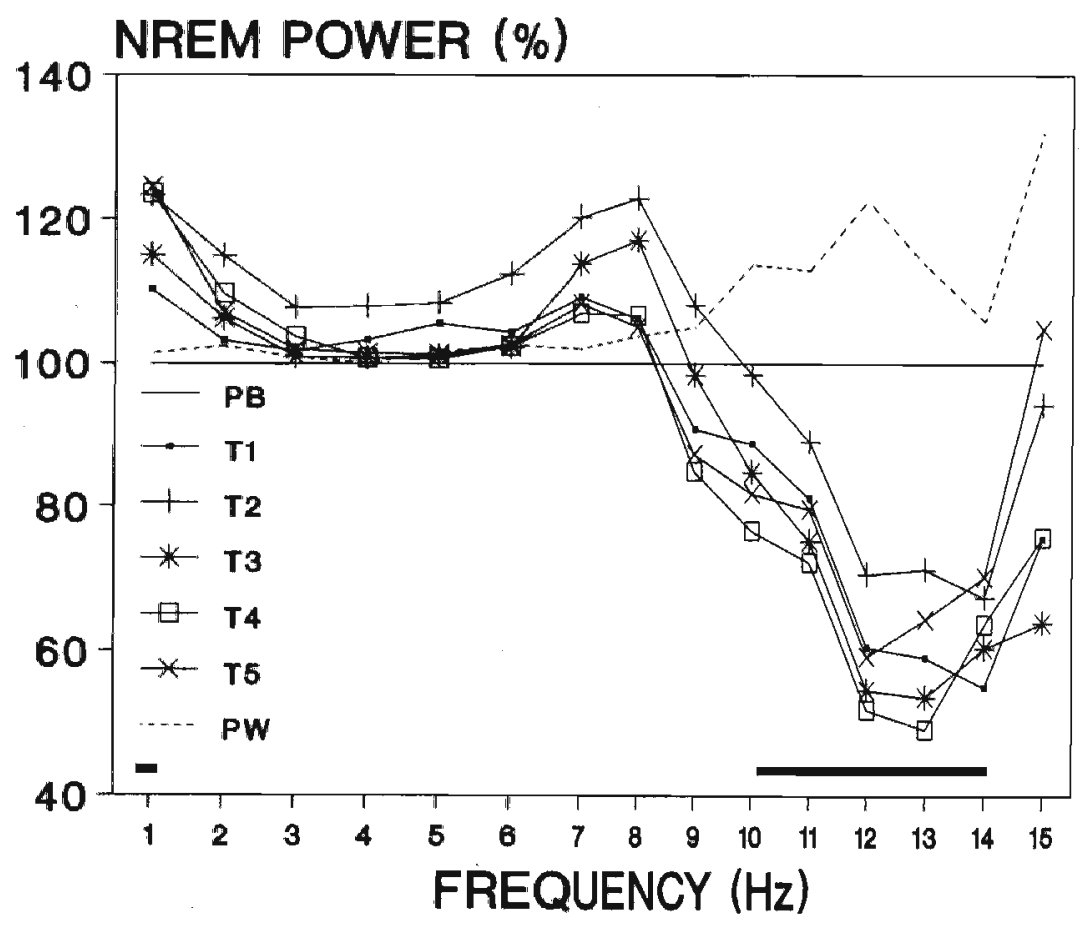

The repeated measures MANOVA yielded significant results for the $1 \mathrm{~Hz}$ band and the 11 through $14 \mathrm{~Hz}$ bands. According to the post-hoc analysis, the 5week trazodone treatment reduced the power density of the non-REMS EEG in the 13 and $14 \mathrm{~Hz}$ bins. These values returned to baseline values one week after placebo-withdrawal. No significant change of EEG power was found in the lower frequency range during trazodone treatment, but a significant decrease of the values of the $1 \mathrm{~Hz}$ bin one week after withdrawal compared to the 5 -week trazodone treatment was noted. The post-hoc procedure further showed that the $11 \mathrm{~Hz}$ result could not be attributed to significant differences between period pairs; the $12 \mathrm{~Hz}$ result coulld be attributed to a significant increase in EEG power during withdrawal compared to the 5 -week trazodone treatment. 


\section{Depression and EEG power spectra in non-REMS}

Figure 3 shows the power spectra of each subject separately during the trazodone treatment weeks and the withdrawal period, relative to the power spectra of baseline $(=100 \%)$.

Visual inspection of the power spectra of each subject suggests that there are major differences between clinically improved $>50 \%$ HRSD reduction at the end of the trazodone treatment) and non-improved subjects. Compared to baseline, the mean EEG energy in the delta-theta frequency range decreased during trazodone treatment and after withdrawal in four improved subjects ( $D$, $\mathrm{E}, \mathrm{F}$ and $\mathrm{G}$ ). The deviant spectral response pattern of subject $\mathrm{H}$ (improved) could not be related to peculiarities in clinical characteristics or visually assessed sleep variables. 
Figure 3. Power spectra of 1.68 .5 min non-REMS of each subject separately (A to H; codes corresponding with those of Table 2) during the five trazodone treatment weeks and the wichdrawal period, relative to power spectra of baseline $(=100 \%)$. Power densities are plotted at the upper bounderies of the frequency bins. For symbols see Fig. 2 .
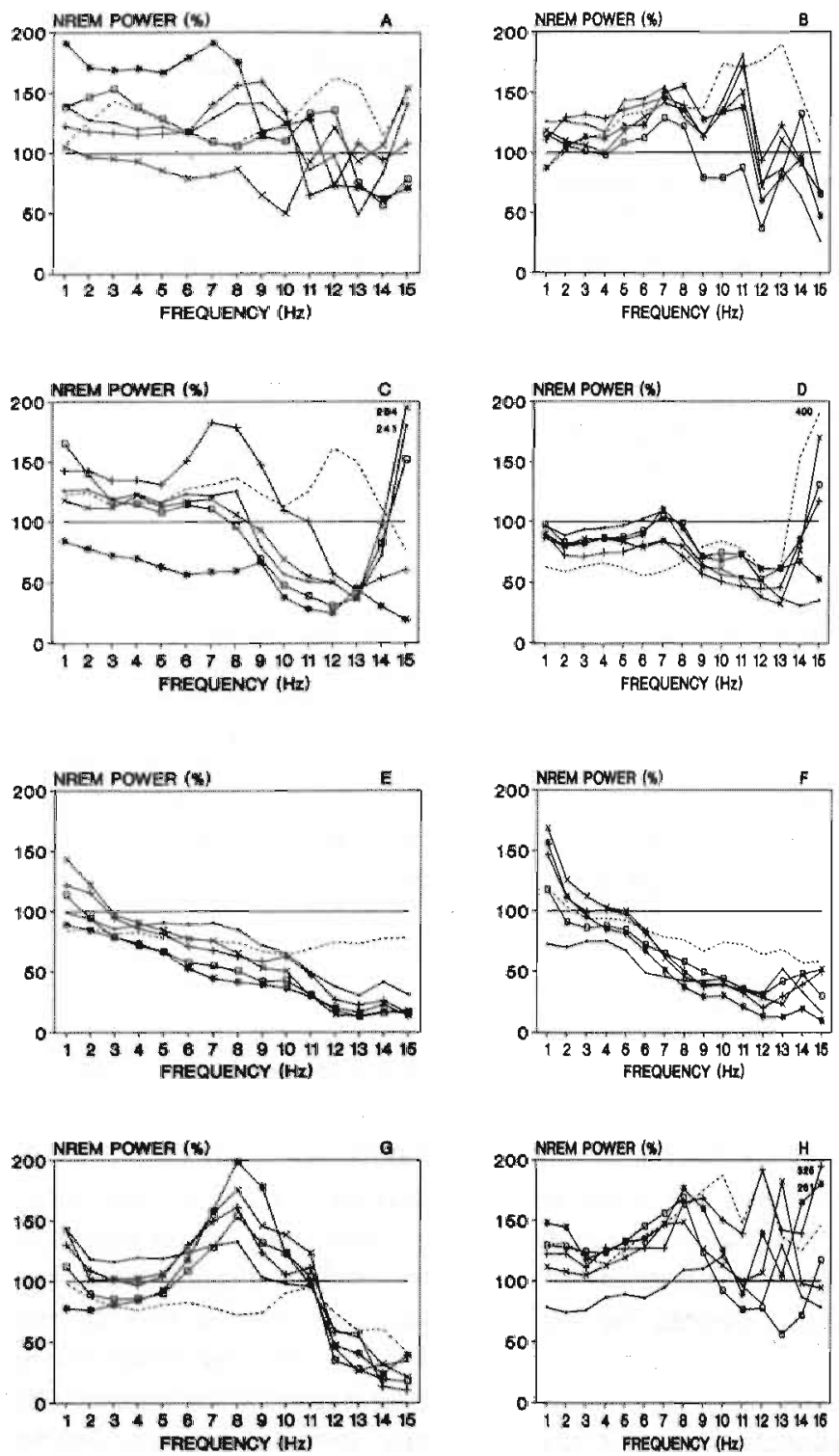


\section{DISCUSSION}

Before dealing with the main findings of this study we will discuss our choice for the longest common amount of non-REMS stages 2, $3 \& 4$ as the basis for the spectral analysis. In assessing the effects on non-REMS power of particular treatments, there are several major pitfalls. Usually, EEG power is high during the first non-REMS episode and low during the last one (Borbely et al., 1981). Furthermore, EEG power waxes and wanes with the non-REMS-REMS alternation. The best simple and direct way to assess the influence of a treatment on non-REMS power is by analyzing the effects over the longest common amount of non-REMS, and not over a fixed EEG-interval (Kupfer et al., 1989) or over the entire recording. The reasons for this are most easily explained in the following examples. Let us assume that a particular treatment does not have any effects on non-REMS power nor on total sleep time, but there are effects on intermittent waking or REMS. Increased time in waking and REMS leads to reduced time in non-REMS. As a result the contribution of the low non-REMS power values at the end of the night will be reduced leading to the false interpretation that the treatment interfered with non-REMS power. Alternatively, suppose that the treatment induced a change in sleep duration. Since EEG power is uswally low at the end of a sleep episode, longer sleep will $₫$ ead to a lower average EEG power, even if this variable is not directly affected by the treatment. Again, one obtains a false interpretation. Some authors have chosen to restrict the analysis to the first non-REMS-REMS cycle in order to avoid the aforementioned problem (Reynolds et al., 1991). However, then another problem arises. In the course of a non-REMS episode EEG power increases towards a plateau value, followed by a rather steep decline shortly before REMS (Achermann and Borbély, 1990). If a treatment merely lengthens REMS latency, the EEG power plateau will last longer, and the average level of EEG power will increase, again leading to the false impression that the treatment directly interferes with non-REMS power. In summary, the most straightforward way to study whether an $\mathrm{AD}$ influences nonREMS power is by comparing the longest common non-REMS amount in baseline and during treatment.

Our analysis resulted in the finding that during trazodone treatment the EEG power of the 13 and $14 \mathrm{~Hz}$ bins during non-REMS was significantly suppressed. No significant change was found, however, for the EEG power values of the delta frequency range $(1-4 \mathrm{~Hz})$, i.e. of SWA. However, improved and nonimproved patients showed some differences in SWA changes. A decrease of SWA was observed in four out of five clinically improved subjects and not in the unimproved subjects. Although these findings may suggest some support of the hypothesis that suppression of non-REMS power is involved in the reduction of depressive symptomatology (Beersma and Van den Hoofdakker, 1992), the evi- 
dence is very weak. Moreover, the number of subjects does not allow statistical evaluation, and the results are based on comparisons with just one baseline sleep recording.

Our results are not in agreement with those of other studies. In the study of Kupfer et al. (1989) on spectral analysis of EEG sleep in depressive patients treated with the AD clomipramine, the first $100 \mathrm{~min}$ of baseline sleep were compared with the same interval of sleep after a 'loading dose' of clomipramine. It was concluded that non-REMS power over the 100 min interval was significantly increased in response to clomipramine. In our view this conclusion is questionable, because the result is based on a fixed recording interval (100 min). The duration of REMS and wakkefulness within the 100-min intervals would be expected to be very different under the two conditions. However, no data regarding these critical issues are provided by the authors. As argued before changes in power may have been due to other mechanisms than power suppression. The same holds for the study of Reynolds et al. (1991) on the effects of nortriptyline. They found an enhancement of SWA in the first non-REMS episode, which was correlated with clinical improvement. Again, changes in SWA cannot be interpreted in terms of direct interference with sWA with any certainty.

In summary, neither our previous analysis (Van Bemmel et al., 1992) showed relationships between changes in duration of visually assessed non-REMS and clinical change, nor the present analysis provided clear evidence of involvement of non-REMS in the mechanisms underlying clinical change during trazodone treatment. 


\section{REFERENCES}

Achermann, P. and A.A. Borbély. Simulation of human sleep: ultradian dynamics of electroencephalographic slow-wave activity. Journal of Biological Rhythms, 5: 141-157, 1990.

American Psychiatric Association: Diagnostic and statistical manual of mental disorders (DSMIII-R). APA, Washington DC (3rd ed-revised): 1987.

Beersma, D.G.M., D.J. Dijk, C.G.H. Blok and I. Evertaardus. REM sleep deprivation during 5 hours leads to an immidiate REM slecp rebound and to suppression of non-REM sleep intensity. Electroencephalography and Clinical Neurophysiology, 76: 114 122, 1990.

Beersma, D.G.M. and R.H. Van den Hoofdakker. Can non-REM sleep be depressogenic? Journal of Affective Disorders, 24 : 101-108, 1992.

Borbély, A.A., F. Baumann, D. Brandeis, I. Strauch and D. Lehmann. Sleep deprivation: effect on. sleep stages and EEG power density in man. Electroencephalography and Clinical. Neurophysiology, $51: 483-493,1981$

Borbély, A.A. and A. Wirz-justice. Sleep, sleep deprivation and depression. Human Neurobiology, 1: 205-210, 1982.

Borbély, A.A. The S-defiency hypothesis of depression and the two process model of sleep regulation. Pharnacopsychiatry, 20:23-29, 1987.

O'Brien, R.G. and M. Kister Kaiser. MANOVA method for analyzing repeated measures designs: an extensive primer. Psychological Bulletin, 97: 316-333, 1985.

Dijk, D.J., D.G.M. Beersma, S. Dan and R.H. Van den Hoofdakker. Effects of seganserin, 5 H'T2 antagonist, and temazepan on human sleep stages and EEG power spectra. European Journal of Pharmacology, 171: 207.218, 1989.

Dijk, D.J., A. Strijkstra, S. Daan, D.G.M. Beersma and R.H. Van den Hoofdakker. Effect of clomipramine on sleep and EEG power specra in the diurnal rodent Eutamias Sibiricus. Psychophamacology, 103: 375-379, 1991.

Hamilton, M. Development of a rating scale for primary depressive illness. British Journal of Social and Clinical Psychiatry, 16: 278-296, 1967.

Kupfer, D.J., C.L. Ehlers, B.G. Pollock, R.S. Nathan and J.M. Perel. Clomipramine and EEG sleep in depression. Psychiatry Research, 30: 165-180, 1989.

Mendelson, W.B. Pharmacology of slow wave sleep in illness and health. In: Wauquier, A., C. Dugovic and M. Radulovacki, eds. Slow wave Sleep: physiological, pathophysiological and functional aspects. Raven Press, New York, pp.155-165. 1989.

Nicholson A.N., C.M. Bradley and P.E. Pascoe. Medications: effect on sleep and wakefulness. In: Kryger, M. and T. Roth, W. Dement, eds. Principles and practice of sleep medicine. WB Saunders, Philadelphia, pp. 228-236. 1989.

Rechtschaffen, A. and A. Kales. A manual of standardized terminology, techniques and scoring system for sleep stages of human subjects. UCLA Brain Information Service Institute, Los Angeles, 1968.

Reynolds, C.F., C.C. Hoch, D.J. Buysse, C.]. George, P.R. Houck, S. Mazumdar, M. Miller, B.G. Pollock, H. Rifia, E. Frank, C. Cornes, R.K. Morycz and D.J. Kupfer. Sleep in late-life recurrent depression, changes during early continuation therapy with nortripryline. Neuropharmacology, $5: 85-96,1991$.

Riemann, D. and M. Berger. The effects of total sleep deprivation and subsequent treatment with clomipramine on depressive symptoms and slecp electroencephalography in patients with a major depressive disorder. Acta Psychiatrica Scandirnavica, 81: 24-31, 1990.

Van Bemmel, A.L., A.G. Havermans and R. van Diest. Fffects of trazodone on I:EG sleep and clinical state in major depression. Psychopharmacology, $107: 569-574,1992$.

Vogel, G.W., A.J. Thurmond, P. Gibbons, K. Sloan, M. Boyd and M. Walker. REM sleep reduc.. tion effects on depression syndromes. Archives of General Psychiatry, 32: 765-777, 1975. 
Vogel, G.W., A. Buffenstein, K. Minter and A. Hennessey. Drug effects on REM sleep and on endogenous depression. Neurosciences \& Biobehavioral Reviews, 14: 49-63, 1990. 


\section{Changes in sleep polygraphic variables and clinical state in depressed patients during treatment with citalopram}

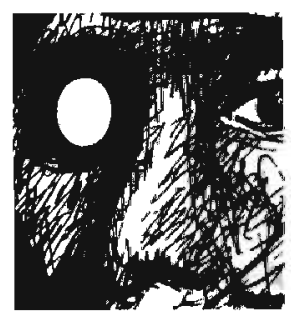

Alex L. van Bemmel (1), Rutger H. van den Hoofdakker (2), Domien G.M. Beersma (2), and Antoinette L. Bouhuys (2)

(1) Department of Psychiatry, University of Limburg

(2) Department of Biological Psychiatry, University of Groningen

Accepted for publication in Psychopharmacology, 1993 
Drug-induced improvement of depression may be mediated by changes in sleep physiology. The aim of this study was to relate changes in sleep polygraphic variables to clinical state during treatment with citalopram, a highly specific serotonin uptake inhibitor. Sixteen patients took part. The study was singleblind and uncontrolled. A 1-week wash-out period was followed by 1 week of placebo administration, a medication period of five weeks, and a 1-week placebo period. For the entire group a significant decrease of rapid eye movement sleep (REMS) and a significant lengthening of REMS latency were observed initially as well as at the end of treatment. No changes in sleep continuity were found, but non-REMS stage 2 (percentage) was significantly increased. On the basis of clinical change, as expressed by the scores of the Hamilton Rating Scale for Depression, at the end of the citalopram treatment the patient group was split in two halves: eight less and eight more improved patients. The groups did not differ with respect to any sleep polygraphic variable.

\section{INTRODUCTION}

Drugs with antidepressant properties, of all existing chemical classes, not only interfere with depressive symptomatology, but also cause changes in sleep polygraphic variables (Nicholson et al. 1989). Furthermore, a number of nonpharmacological interventions in sleep, such as total, partial or rapid eye movement sleep (REMS) deprivation, ameliorate symptoms of depression (Leibenluft and Wehr 1992). These observations suggest that changes in sleep might be involved in the mechanisms underlying the recovery of depression.

Because nearly all antidepressants (ADS) reduce the amount of REMS (Vogel et al. 1990), and because selective REMS deprivation over 3 weeks alleviates depression, it has been suggested that particularly strong initial and sustained REMS suppression might be of central importance for the therapeutic process in depression (Vogel et al. 1975, 1980). Kupfer et al. (1981) showed that clinical response to amitriptyline measured after 5 weeks of treatment in 82 depressed patients could be predicted on the basis of the amount of REMS suppression during the first 2 nights of treatment. Gillin et al. (1978) obtained similar results in six patients. However, clinical response after 19 days of treatment in 14 patients with the AD clomipramine [which is known for its strong REMs inhibiting effect (Oswald 1973)] did not correlate with the amount of initial REMS reduction (Riemann and Berger 1990). Furthermore, the degree of REMS sup- 
pression measured weekly during a 5-week treatment with the $\mathrm{AD}$ trazodone in eight patients did not show a clear-cut relationship with the course of clinical change (Van Bemmel et al. 1992).

The reports on the effects of ADs on non-REMS do not reveal a consistent pattern (Mendelson 1989). 'The question whether the effects on non-REMS are related to the effects on mood is hardly studied. In the only longitudinal study on this subject no clear-cut relation was found (Van Bemmel et al. 1992). In view of the acute antidepressant effects of total and partial sleep deprivation (in the later part of the night) the AD induced changes of non-REMS deserve more attention. It has been hypothesized that an increase in non-REMS pressure might be an important component in the mechanism underlying recovery of depression (Borbély and Wirz-Justice 1982; Beersma and Van den Hoofdakker 1992).

Summarizing, changes in both REMS and non-REMS have been proposed to play a crucial role in the recovery of depression. However, studies on the relationships between clinical state and the magnitude of changes in sleep polygraphic variables during treatment with ADs are scarce. In the present study we address this issue by analyzing the quantitative relationships between mood changes and sleep measures during treatment with the AD citalopram. The drug was chosen because of its high selectivity with respect to serotonin (5-HT) uptake inhibition. Citalopram appears to have little effect on noradrenergic or dopaminergic systems, and it is practically devoid of anticholinergic and antihistaminergic properties (Hyttel 1982). Compared to reference ADs, in particular tricyclics, the efficacy of citalopram after 6 weeks of treatment is similar (Bech and Cialdella 1992). Citalopram has been shown to suppress REMS in cats and to promote slow wave sleep (Hilakivi et al. 1987). No sleep data have been published for humans.

\section{MATERIALS AND METHODS}

\section{Study design}

After a 1-week wash-out period there were three consecutive treatment periods encompassing a total of 7 weeks. In week 1 a placebo was administered; in weeks 2-6 the subjects were treated with citalopram (week 2: $20 \mathrm{mg} /$ day; weeks 3-6: $40 \mathrm{mg} /$ daily at 6:00 p.m.); in week 7 citalopram was substituted by a placebo. The administration of the placebo and citalopram was single-blind. Subjects were informed, however, that placebo treatment could occur. 


\section{Subjects}

The participants were outpatients suffering from major depression, single or recurrent [DSM-III-R (APA 1987) codes 296.2 and 296.3], including insomnia (DSM-III-R code 307.42 ). Subjects were only included if two psychiatrists agreed on the diagnosis. A score of 20 or higher on the Hamilton Rating Scale for Depression (HRSD, 17 items; Hamilton 1967) was required for inclusion. Patients with sleep disorders such as sleep apnea or nocturnal myoclonus were excluded on the basis of a medical interview. The results of physical examination, blood chemistry and hematology were within the normal range. Subjects were free of psychoactive medication for at least 1 week before placebo-week 1 and their eligibility was decided after this wash-out period. At the end of week 1 (placebo-baseline) only subjects whose HRSD score was 20 or higher and those with a decrease of no more than $30 \%$ compared to the initial HRSD score after wash-out were included. During the study alcohol consumption, consumption of beverages containing caffeine (from lunch time), and napping were not allowed. The compliance to the instruction not to nap was not controlled for by objective measurements. No comedication was allowed. An exception was made in cases in which subjects complained of nausea due to citalopram; these patients received Motilium as anti-emetic medication $(3 \times 10 \mathrm{mg} /$ day). The protocol was reviewed and approved by the institutional Ethics Review Committee and the subjects gave informed consent.

\section{Measurements}

\section{Depression}

The severity of depression of the previous week was assessed at the end of each week by means of the HRSD, rated by two psychiatrists.

Subjective sleep quality and self-rated depressed mood

Subjective sleep quality was assessed after each sleep recording with a selfrating questionnaire (Mulder-Hajonides van der Meulen 1981). The questionnaire consists of 14 items and yields a score ranging from $O$ (very good sleep) to 14 (very bad sleep). During 4 separate days self-assessments were made: during the last day of week 1 (baseline), the second day of citalopram treatment (acute treatment), and during the last days of both week 6 (end of citalopram treatment) and week 7 (after 1 week withdrawal). During these four experimental periods self-rated depressed mood was assessed three times each day $(9.00$ a.m., 5.00 p.m. and $10.00 \mathrm{p} . \mathrm{m}$.) using the Adjective Mood Scale (AMS, von Zerssen 1976). The AMS consists of 28 items and yields a score ranging from 0 (not 
depressed) to 56 (very depressed). The Dutch version of the AMS has been shown to be psychometrically reliable (Elsenga 1988).

\section{Plasma levels}

Plasma levels of citalopram (C) and desmethylcitalopram (DC) were measured at 8:00 a.m., on the last day of week 1 (baseline control), week 6 (end of treatment) and week 7 (withdrawal). $C$ and DC were analyzed according to the method reported by Oyehaug and Ostensen (1984) with some minor modifications [mobile phase: $45 \%(\mathrm{v} / \mathrm{v})$ acetonitrile in $0.5 \mathrm{mMol}$ phosphate buffer $\mathrm{pH}$ $3.0,5.7 \mathrm{~g} / \mathrm{l}$; ammoniumperchlorate, $25 \%$ phosphoric acid to $\mathrm{pH} 2.9]$. The limits of identification and quantification were 3 and $12 \mathrm{nM} / 1$ respectively for $\mathrm{C}$ and DC. The intra-assay coefficient of variation (CV) was $1.3 \%$ for $\mathrm{C}$ and $3.3 \%$ for $D C$ (at $56 \mathrm{nM} / 1$ for $C$ and $58 \mathrm{nM} / 1$ for $\mathrm{DC}$ ).

\section{Sleep recordings}

These were made of each subject during 7 nights between 11:00 p.m. and 7:00 a.m. in our sleep laboratory. The sleep recordings were scheduled in such a way as to enable evaluation of the baseline characteristics of sleep ( 2 consecutive nights at the end of week 1), the acute effects of citalopram on sleep (the night after the first citalopram treatment day), the effects at the end of the citalopram treatment period ( 2 consecutive nights at the end of week 6), and the effects of 1 week placebo-withdrawal ( 2 consecutive nights at the end of week 7). The first baseline night was preceded by an adaptation night. The recordings were made at a paper speed of $10 \mathrm{~mm} / \mathrm{s}$ from standard leads: two EOGs, two EEGs (C3-A2 and $\mathrm{C} 4-\mathrm{A} 1$ ) and a submental EMG. The time constants for the EOG and EEG recordings were $0.3 \mathrm{~s}$; the high frequency cut-off was $35 \mathrm{~Hz}$.

\section{Measures}

\section{Depression}

For each subject the average of the two HRSD ratings during each experimental week was used as an index of the severity of depression. For each assessment the rank correlations between the two HRSD ratings obtained in all patients were calculated. The resulting seven correlation values showed a range between 0.90 and 0.96 . This indicates a close overall correspondence $(>80 \%)$ between the two HRSD raters with respect to the assessment of the severity of depression. The average HRSD score at the end of week 6 , relative to that of placebobaseline (week 1), was taken as a measure for the clinical change at the end of the 5 -week citalopram treatment. 
Subjective sleep quality and self-rated depressed mood

To monitor changes in subjective sleep quality over the four experimental periods the following data were used: the average of the two sleep quality scores during baseline, the score of the second citalopram treatment day, the average of the two scores obtained at the end of citalopram treatment, and the average of those obtained 1 week after withdrawal. The averages of the three daily AMS scores obtained during the four experimental periods were used to monitor changes in self-rated depressed mood.

\section{Sleep recordings}

These were visually analyzed in successive 30-s epochs according to the scoring rules of Rechtschaffen and Kales (1968). The following additional variables were assessed: sleep onset: the first epoch, after "lights out", of stages 2,3,4 or REMS, followed by at least $10 \mathrm{~min}$ of sleep interrupted by no more than $2 \mathrm{~min}$ of stage 1 or wakefulness; end of sleep: the last epoch of stages 2, 3, 4 or REMS, preceded by at least $10 \mathrm{~min}$ of sleep interrupted by no more than $2 \mathrm{~min}$ of stage 1 or wakefulness; REMS latency: the time between sleep onset and the first REMS period in minutes. The first REMS period had to last at least 3 min; interruption by non-REMS, wakefulness or movement time had to last less than $15 \mathrm{~min}$.

To monitor changes in sleep variables over the four experimental periods the following variables were used: the averages of the sleep data at the end of week 1 , the data of the night after the first citalopram treatment day, the averages of the data at the end of week 6 and those of the data at the end of week 7.

\section{Analyses}

MANOVA for repeated measures (O'Brien and Kister Kaiser 1985) was applied over the four experimental periods. The Newman-Keuls (NK) post-hoc procedure was used to detect where significant results were located. With respect to mood change a rank order of the patients was made on the basis of the difference between the HRSD scores at the end of the citalopram treatment period and those in baseline. Subsequently, the entire patient group was divided into two: a group with relatively small changes in HRSD scores, the less improved group, and a second group with relatively large changes in HRSD scores, the more improved group. Comparisons between the two groups were made by means of MANOVA for repeated measures. Because of the skewed distribution of the results of the self-assessments (i.e. sleep quality and AMs) log-transformed values were used for statistical tests. P values $<0.05$ were accepted as significant. 


\section{RESULTS}

Sixteen outpatients (seven females, nine males; mean age $=41.9$ years, $\mathrm{SD}=10.6$ ) participated in the study. Their mean HRSD score at entrance was $26.4(\mathrm{~S} D=2.9)$. The mean clinical change of all patients was $48.5 \%$. The group was split in two halves on the basis of clinical improvement. The resulting groups will be called the "less improved" (three females, five males; mean age $=47.0$ years, $S D=8.7$ ) with an average HRSD reduction of $28.3 \%$ (range: 0 to $54 \%$ ), and the "more improved" group (four females, four males; mean age $=36.8, \mathrm{sD}=10.3$ ) with an average HRSD reduction of $68.8 \%$ (range: 56 to $87 \%$ ). The two groups did not differ significantly with respect to age and sex. Two patients (one in each group) used Motilium during the second citalopram week.

\section{Depression}

The mean values and standard deviations of HRSD scores of all patients, and those of the less and more improved patients are shown in Table 1.

Table 1. Severity of depression (HRSD). Mean values and standard deviations during the 7 experimental weeks of the entire patient group (All), the less improved (LI), and the more improved (MI) patients

\begin{tabular}{lllllll}
\hline WEEKS & All & $(\mathrm{n}=16)$ & LJ & $(\mathrm{n}=8)$ & MI & $(\mathrm{n}=8)$ \\
\hline PB & 26.3 & $(3.7)$ & 27.9 & $(3.1)$ & 24.7 & $(3.8)$ \\
CIT-1 & 21.8 & $(6.5)$ & 25.9 & $(4.2)$ & 16.7 & $(5.1)$ \\
CIT-2 & 19.5 & $(6.4)$ & 24.3 & $(4.1)$ & 14.6 & $(4.6)$ \\
CIT-3 & 18.4 & $(7.3)$ & 22.1 & $(5.1)$ & 14.7 & $(7.5)$ \\
CIT-4 & 16.9 & $(7.8)$ & 21.4 & $(5.0)$ & 12.4 & $(5.2)$ \\
CIT-5 & 13.8 & $(6.9)$ & 18.9 & $(6.1)$ & 8.6 & $(2.3)$ \\
PWW & 14.1 & $(6.8)$ & 19.2 & $(5.2)$ & 8.9 & $(3.4)$ \\
\hline
\end{tabular}

$\mathrm{PB}=$ placebo baseline; CIT-1 to CIT-5 = the 5 citalopram treatment weeks; $\mathrm{PW}=$ placebo withdrawal

During placebo-baseline the less and more improved patients did not differ significantly with respect to HRSD scores $\left(\mathrm{F}_{1,14}=3.5 ; \mathrm{P}=0.09\right)$. Over the 7 experimental weeks of the protocol the HRSD of the entire patient group showed a significant variation over time $\left(\mathrm{F}_{6,84}=21.5 ; \mathrm{P}<0.01\right)$. This result could be attributed to a significant change in depressive mood during the period between weeks 2 and 6 (citalopram treatment and withdrawal) compared to baseline as well as to the first citalopram treatment week. 
Subjective sleep quality and self-rated depressed mood

The mean values and standard deviations of sleep quality and Ams scores of the entire patient group, and those of the less and more improved groups are shown in Table 2.

Table 2. Self-assessments: subjective sleep quality ( $(\mathrm{Q})$ and, self-rated depressed mood (AMS). Mean values and standard deviations during the 4 experimental periods of all patients (All) $(n=16)$, the less improved (LI) $(n=8)$, and the more improved (MI) $(n=8)$ patients

\begin{tabular}{cccccc}
\hline & & PB & CIT-A & CIT-E & PW \\
\hline SQ & All & 8.4 & 9.0 & 7.9 & 8.3 \\
& & $(3.0)$ & $(2.5)$ & $(3.4)$ & $(2.4)$ \\
& LI & 8.3 & 8.5 & 10.2 & 9.3 \\
& & $(3.4)$ & $(3.0)$ & $(1.3)$ & $(2.1)$ \\
& \multirow{4}{*}{ MI } & 8.5 & 8.9 & 5.6 & 7.3 \\
& & $(2.8)$ & $(2.1)$ & $(3.3)$ & $(2.3)$ \\
& & & & & \\
\hline \multirow{2}{*}{ AMS } & \multirow{4}{*}{ All } & 36.0 & 44.7 & 30.4 & 27.6 \\
& & $(14.7)$ & $(18.0)$ & $(14.9)$ & $(15.2)$ \\
& \multirow{4}{*}{ LI } & 42.4 & 45.3 & 40.0 & 37.0 \\
& & $(9.0)$ & $(9.3)$ & $(9.8)$ & $(10.2)$ \\
& \multirow{2}{*}{ MII } & 29.5 & 44.0 & 20.9 & 18.1 \\
& & $(17.0)$ & $(24.7)$ & $(13.1)$ & $(13.7)$ \\
\hline
\end{tabular}

$\mathrm{PB}=$ placebo baselinc; $\mathrm{CIT}-\mathrm{A}=$ acute citalopram treatment; $\mathrm{CIT}-\mathrm{E}=$ the end of citalopram treatnent; PW $=$ placebo withdrawal

No significant variation over time was found for the sleep quality scores. A significant variation over the four assessments was found for the AMS values of the entire group ( $\left.\mathrm{F}_{3,42}=7.7 ; \mathrm{P}<0.01\right)$. The post-hoc procedure failed to show, however, where significant overall differences in self-rated depressed mood were located. As to the less and more improved group no significant differences in mean baseline levels of sleep quality and AMS were found. However, they differed significantly on self-rated depressed mood measures in the course of the experiment $\left(\mathrm{F}_{1,14}=8.2 ; \mathrm{P}=0.01\right)$. A significant interaction effect between group and time was found for slleep quality $\left(\mathrm{F}_{3,2}=5.5 ; \mathrm{P}<0.01\right)$ and for AMS $\left(F_{3,42}=2.9 ; \mathbb{P}=0.04\right)$. The sleep quality result could be attributed to a significant improvement of subjective sleep quality in the more improved patients at the end of citalopram treatment $\left(\mathrm{F}_{\mathrm{b}, 4}=8.5 ; \mathrm{P}=0.01\right)$. The AMS result could be attributed to a significant improvement of self-rated depressed mood in the more 
improved patients both at the end of citalopram treatment $\left(\mathrm{F}_{1,14}=10.8 ; \mathrm{P}=0.01\right)$ and 1 week after withdrawal $\left(F_{3,1}=9.8 ; \mathbb{P}=0.01\right)$.

\section{Plasma levels}

The mean values and standard deviations of the plasma levels of citalopram and desmethylcitalopram measured both at the end of citalopram treatment and after 1-week placebo-withdrawal, for the entire patient group and for the less and more improved groups, are shown in Table 3.

Table 3. The plasma levels (nM/l) of citalopram and desmethylcialopram at the end of citalopram treatment and after one week withdrawal. Means and standard deviations of the entire patient group (All) ( $\mathrm{n}=16)$, the less improved (LI) ( $\mathrm{n}=8)$, and the more improved (MI) $(\mathrm{n}=8)$ patients

\begin{tabular}{ccc|cc}
\multicolumn{3}{c}{ Citalopram } & \multicolumn{3}{c}{$\begin{array}{c}\text { Desnethyl- } \\
\text { citalopram }\end{array}$} \\
\cline { 2 - 5 } & CIT-E & PW & CIT-E & PW \\
\hline All & 251.3 & 48.1 & 96.3 & 35.7 \\
& $(103.2)$ & $(38.2)$ & $(43.5)$ & $(18.7)$ \\
LI & 235.9 & 34.5 & 101.8 & 29.0 \\
& $(91.2)$ & $(23.4)$ & $(27.4)$ & $(11.9)$ \\
WI & 266.7 & 61.6 & 90.5 & 42.5 \\
& $(118.0)$ & $(46.2)$ & $(56.7)$ & $(22.5)$ \\
\hline
\end{tabular}

$\mathrm{Cr}-\mathrm{E}=$ the end of citalopram treatment; $\mathrm{PW}=$ placebo withdrawal

After 1-week withdrawal of citalopram the mean plasma level of citalopram was decreased to $19 \%$ and that of desmethylcitalopram to $37 \%$ as compared to the end of treatment. The mean of the citalopram plasma level values at the end of the citalopram treatment was in accordance with that reported for steady-state after $40 \mathrm{mg}$ citalopram daily administration [mean $=245.0 \mathrm{nM} / \mathrm{L}(\mathrm{SD}=$ 105.0); Overo 1982]. The less and more improved patients did not differ significantly. 


\section{Sleep continuity and REMS latency}

The mean values and standard deviations of sleep continuity variables and REMS latency of the entire patient group and of the less and more improved groups at the four assessments are shown in Table 4.

'Iable 4. Sleep continuity and REMs latency measures as derived from the sleep recordings of all patients (All) ( $n=16)$, the less improved (LI) ( $n=8)$, and the more improved (MI) $(n=8)$ patients. Mean valucsind standard deviations during the 4 experimental periods. Except sleep efficiency (= the ratio between total time aslleep and total recording time $x 100 \%$ ) the values are in minutes

\begin{tabular}{llrrrrrrrr}
\hline & & \multicolumn{2}{c}{ PB } & \multicolumn{3}{c}{ CIT-A } & \multicolumn{2}{c}{ CrT-E } & \multicolumn{3}{c}{ PW } \\
Sleep & All & 47.6 & $(23.0)$ & 56.8 & $(40.0)$ & 55.0 & $(23.0)$ & 61.2 & $(34.3)$ \\
latency & LII & 38.6 & $(22.4)$ & 43.8 & $(32.5)$ & 48.2 & $(21.8)$ & 53.2 & $(31.4)$ \\
& MI & 56.5 & $(21.1)$ & 69.4 & $(50.0)$ & 61.7 & $(23.5)$ & 69.2 & $(37.3)$ \\
Sleep & All & 420.8 & $(25.7)$ & 40.8 .3 & $(37.8)$ & 413.8 & $(22.0)$ & 403.4 & $(33.7)$ \\
period & LI & 426.6 & $(28.3)$ & 421.0 & $(28.9)$ & 416.4 & $(22.4)$ & 406.3 & $(31.6)$ \\
& MI & 415.11 & $(23.1)$ & 395.5 & $(43.0)$ & 411.3 & $(22.9)$ & 400.3 & $(37.7)$ \\
Total time & All & 386.7 & $(31.1)$ & 360.9 & $(54.1)$ & 378.7 & $(20.1)$ & 364.5 & $(42.4)$ \\
asleep & LI & 399.9 & $(25.6)$ & 363.7 & $(51.2)$ & 375.8 & $(19.6)$ & 361.5 & $(44.8)$ \\
& MI & 373.5 & $(32.0)$ & 358.4 & $(60.1)$ & 381.6 & $(21.4)$ & 367.5 & $(42.7)$ \\
Total time & All & 34.1 & $(22.4)$ & 47.3 & $(37.5)$ & 35.1 & $(16.7)$ & 38.9 & $(29.6)$ \\
awake & LI & 26.7 & $(9.8)$ & 57.6 & $(38.0)$ & 40.6 & $(14.9)$ & 45.0 & $(39.7)$ \\
& MI & 41.5 & $(29.2)$ & 37.1 & $(36.4)$ & 29.7 & $(17.6)$ & 32.8 & $(14.8)$ \\
Sleep & All & 80.9 & $(6.7)$ & 75.6 & $(11.5)$ & 79.4 & $(4.2)$ & 76.5 & $(8.7)$ \\
efficiency & LI & 83.7 & $(5.5)$ & 76.1 & $(10.6)$ & 78.9 & $(3.7)$ & 75.9 & $(9.4)$ \\
& MI & 78.1 & $(6.9)$ & 75.2 & $(13.1)$ & 80.0 & $(4.9)$ & 77.1 & $(8.6)$ \\
REMS & All & 64.3 & $(48.5)$ & 195.6 & $(98.9)$ & 186.6 & $(56.3)$ & 66.4 & $(35.8)$ \\
latency & LI & 55.3 & $(17.9)$ & 196.2 & $(98.7)$ & 186.9 & $(36.9)$ & 61.8 & $(14.7)$ \\
& MII & 73.2 & $(67.4)$ & 195.0 & $(99.1)$ & 186.4 & $(73.7)$ & 71.0 & $(49.9)$ \\
\hline
\end{tabular}

$P B=$ placebo baseline; $C I T-A=$ acute citalopram treatment; $C I T-E=$ the end of citalopram treatment; $p w=$ placebo withdrawal

No significant variations over time were found for the various indicators of sleep continuity, i.e. sleep latency, sleep period, total time asleep, total time awake, and sleep efficiency in the entire patient group. A significant result for REMs latency was found $\left(\mathrm{F}_{3,42}=26.0 ; \mathrm{P}<0.01\right)$. The post-hoc procedure showed that this was due to a significant lengthening of REMS latency both during acute citalopram treatment and at the end of citalopram treatment compared to baseline as well as withdrawal. Neither the main effect on group (i.e. less versus more improved) nor the interaction effect between group and time were significant. 


\section{Sleep stages}

The mean values and standard deviations of the sleep stages in minutes and percentages of total time asleep of the entire patient group and of the less and more improved groups during the four experimental periods are shown in Table 5.

Table 5. Sleep stages. Time spent in each sleep stage in minutes, and in percentages of total time spent asleep as derived from the sleep recordings of all parients (All) ( $\mathrm{n}=16$ ), the less improved (LI) $(n=8)$, and the more improved (MI) $(n=8)$ patients. Mean values and standard devintions duriag the 4 experimental periods

\begin{tabular}{|c|c|c|c|c|c|c|c|c|c|}
\hline Minutes & & \multicolumn{2}{|c|}{ PB } & \multicolumn{2}{|c|}{$C D-A$} & \multicolumn{2}{|c|}{ CUT-E } & \multicolumn{2}{|c|}{ PW } \\
\hline \multirow[t]{3}{*}{ Stage 1} & All & 36.4 & $(28.1)$ & 40.3 & $(23.0)$ & 49.5 & $(20.2)$ & 37.8 & $(23.5)$ \\
\hline & $\mathrm{LI}$ & 36.4 & (23.4) & 42.1 & $(1.4 .9)$ & 49.3 & $(21.2)$ & 42.0 & $(26.5)$ \\
\hline & MI & 36.4 & $(33.7)$ & 38.5 & $(30.1)$ & 49.7 & $(20.7)$ & 33.6 & $(21.1)$ \\
\hline \multirow[t]{3}{*}{ Stage 2} & All & 234.6 & $(41.5)$ & 252.8 & $(52.5)$ & 253.3 & $(23.5)$ & 201.0 & $(33.8)$ \\
\hline & $\mathrm{LI}$ & 248.2 & $(25.3)$ & 263.1 & $(27.1)$ & 260.2 & $(18.5)$ & 206.2 & $(35.2)$ \\
\hline & MI & 221.0 & $(51.3)$ & 242,6 & $(70.2)$ & 246.5 & $(27.0)$ & 195.6 & $(33.8)$ \\
\hline \multirow[t]{3}{*}{ Stages 3844} & All & 18.5 & (25.1) & 20.1 & $(26.1)$ & 14.0 & $(22,0)$ & 150 & $(22.3)$ \\
\hline & $\mathrm{LI}$ & 6.8 & $(21.6)$ & 10.1 & $(18.2)$ & 7.2 & $(17.2)$ & 8.3 & $(21.0)$ \\
\hline & MI & 30.1 & $(30.1)$ & 30.1 & $(30.0)$ & 20.7 & $(25,2)$ & 21.6 & $(22.9)$ \\
\hline \multirow[t]{3}{*}{ REMS } & All & 97.2 & $(22.0)$ & 47.7 & $(26.9)$ & 62.0 & $(22.7)$ & 11.0 .0 & $(24.9)$ \\
\hline & L. & 108.5 & $(22.2)$ & 48.1 & $(25.3)$ & 59.1 & $(18.5)$ & 104.9 & $(24.7)$ \\
\hline & MI & 85.9 & $(16.0)$ & 47.3 & $(30.2)$ & 64.8 & $(27.0)$ & 1.16 .7 & $(25,2)$ \\
\hline \multicolumn{10}{|l|}{ Percentage } \\
\hline \multirow[t]{3}{*}{ Stage 1} & All & 9.6 & $(8.3)$ & 12.0 & $(9.2)$ & 13.0 & (5.3) & 10.5 & $(6.6)$ \\
\hline & Lr & 8.9 & $(5.3)$ & 11.9 & $(4.8)$ & $13 . \pi$ & (5.8) & 11.5 & (7.1.) \\
\hline & MI & 10.3 & $(10.8)$ & 12.0 & $(12.6)$ & 12.9 & (5.2) & 9.4 & $(6.5)$ \\
\hline \multirow[t]{3}{*}{ Stage 2} & All & 60.4 & $(8.0)$ & 69.9 & $(10.8)$ & 66.3 & (5.8) & 55.1 & $(6.3)$ \\
\hline & LI & 62.1 & $(5.1)$ & 72.9 & $(6.9)$ & 69.3 & (4.9) & 57.1 & (6.8) \\
\hline & MI & 58.7 & $(10.2)$ & 66.8 & $(13.4)$ & 64.6 & $(6.0)$ & 53.1 & $(5.3)$ \\
\hline \multirow[t]{3}{*}{ Stages 384} & All & 5.0 & $(6.9)$ & 5.4 & $(7.1)$ & 3.7 & $(5.8)$ & 4.0 & $(6.0)$ \\
\hline & LI & 1.8 & $(3.1)$ & 2.4 & $(4.3)$ & 1.8 & $(4.3)$ & 2.2 & $(5.6)$ \\
\hline & $\mathrm{MI}$ & 8.1 & $(8.3)$ & 8.4 & (8.3) & 5.5 & $(6.7)$ & 5.8 & $(6.1)$ \\
\hline \multirow[t]{3}{*}{ REMS } & All & 25.1 & $(5.1)$ & 12.8 & $(6.5)$ & 16.4 & $(6.3)$ & 30.4 & $(5.9)$ \\
\hline & LI & 27.2 & $(6.0)$ & 12.8 & (5.8) & 15.8 & (5.3) & 29.2 & (6.3) \\
\hline & MI & 22.9 & $(3.0)$ & 12.9 & $(7.6)$ & 17.0 & $(7.5)$ & 31.6 & $(5.7)$ \\
\hline
\end{tabular}

$\mathrm{PB}=$ placebo baseline; $\mathrm{CrT}-\mathrm{A}=$ acute citalopram treatment: $\mathrm{CT}-\mathrm{E}=$ the end of citalopram treatment; $P W=$ placebo withdrawal 
Significant variations over time were only found for non-REMS stage 2 (min: $F_{3,42}$ $=8.8 ; \mathrm{P}<0.01$; percent: $\mathrm{F}_{3,+2}=20.3$; $\mathrm{P}<0.01$ ) and REMS (min: $\mathrm{F}_{3,2}=32.1 ; \mathrm{P}<$ 0.01 ; percent: $F_{3,42}=41.3 . ; P<0.01$ ) in the entire patient group. Post-hoc analysis showed the following: the non-REMS stage 2 ( $\mathrm{min}$ ) result could be attributed to a significant decrease in non-REMS 2 sleep during the withdrawal period compared to baseline, acute treatment and the end of the citalopram treatment. The non-REMS stage 2 (percent) result could be attributed to a significant increase of its percentage of total time asleep during acute citalopram treatment as well as at the end of citalopram treatment compared to either baseline or withdrawal. Both the REMS (min) and the REMS (percent) results could be attributed to a significant decrease during acute citalopram treatment and at the end of citalopram treatment compared to baseline as well as withdrawal. The REMS (percent) result could further be attributed to a significant increase during withdrawal compared to baseline. Neither the main effect on group (i.e. less versus more improved) nor the interaction effect between group and time were significant.

\section{DISCUSSION}

In this study a so-called A-B-A design was applied. Although the design does not allow any conclusions on drug efficacy, the changes in sleep polygraphic variables in relation to clinical changes can be studied adequately.

The main changes of sleep polygraphic variables in the entire patient group were as follows. REMS (min and percent) was suppressed and REMS latency was significantly increased, both initially and at the end of citalopram treatment. These variables returned to baseline values 1 week after placebo withdrawal. REMS (percent) further showed a significant rebound increase during withdrawal compared to baseline. No significant changes over the entire experimental period were found for any sleep continuity variable. Because no significant change was found in total time asleep, the decrease in REMS is independent from changes in total time asleep. With respect to non-REMS an increase of stage 2 (percent) was observed both during acute treatment and at the end of citalopram treatment. The amount of stage 2 in minutes decreased significantly during withdrawal of citalopram. Summarizing, just like many other ADs citalopram reduced REMS without affecting sleep continuity (Nicholson et al. 1989).

The less and more improved patients differed significantly with respect to changes in subjective sleep quality and self-rated depressed mood. Nevertheless, no significant differences between the two groups could be demonstrated with respect to any of the sleep polygraphic variables. In particu- 
lar, the amount of both initial and sustained REMS suppression was not related to clinical change. This does not support the hypothesis of Vogel et al. (1975; 1980) that REMS suppression is of central importance for the therapeutic process. On the other hand, the hypothesis is also not disproved by the results, because strong initial and sustained REMS suppression might be a necessary although not sufficient component of the mechanism underlying treatment response. Because no reduction of non-REMS duration was observed during treatment, even less support was found for the proposal that non-REMS suppression would be essential for the beneficial effect of antidepressive treatment (Borbély and Wirz-Justice 1982; Beersma and van den Hoofdakker 1992). However, this conclusion is preliminary, since duration is not the only variable by which non-REMS changes can be expressed. The power density of the sleep EEG is another. Spectral analysis may reveal alterations in non-REMS which are not recognized on the basis of visual scoring of the sleep EEG (Borbély et al. 1981). In a later spectral analysis of our sleep data the influence of citalopram on non-REMS power density will be examined.

\section{ACKNOWLEDGEMENTS}

The research assistance of Gert Jan Mevius is gratefully acknowledged.

We thank Gert H. Beuman for assessment of citalopram plasma levels and Dr. Joëlle Adrien (INSERM, Paris) for comments on an earlier version of the manuscript. This study was made possible through the financial support of H. Lundbeck A/S, Denmark and The Netherlands. 


\section{REFERENCES}

American Psychiatric Association: Diagnostic and statistical manual of mental disorders (DSMIII-R), 3rd revised edn. A.PA, Washington DC, 1987.

Bech, P. and P. Cialdella. Citalopram, meta-analysis of intended and unintended effects. Int. Clin. Psychopharmacol, 6 [Suppl 5]: 45-54, 1992.

Beersma, D.G.M. and R.H. van den Hoofdalker. Can non-REM sleep be depressogenic? J. Affect. Dis. 24: 101-108, 1992.

Borbély, A.A. and A. Wirz-Justice. Sleep, sleep deprivation and depression: a hypothesis derived from a modell of sleep regulation. Hum Neurobiol 1:205-210, 1982

Borbély, A.A., F. Baumann, D. Brandeis, I. Strauch, D. Lelimann. Sleep deprivation: Effect on sleep stages and EEG power density in man. Electroencephalogr. Clin. Neurophysiol. 51: 483$493,1981$.

Elsenga, S. Een zelfbeoordelingsschaal voor depressie. T. v Psychiacrie 30: 114-126, 1988.

Gillin, J.C., R.J. Wyate, D. Fram and F. Snyder. The relationship between changes in REM sleep and clinical improvement in depressed patients treated with amitripcyline. Psychopharmacology 59: $267-272,1978$

Hamilton, M. Development of a rating scale for primary depressive illness. Br. J. Soc. Clin. Psychiatry 16:278-296, 1967.

Hilakivi, $\mathbb{I}$., T. Kovala, A. Leppävuori and A. Shvaloff. Effects of serotonin and noradrenaline uptake blockers on wakefulness and sleep in cats. Pharmacol \& Toxicol 60; 161-166, 1987.

Hyttel, J. Citalopram-pharmacological profile of a specific serotonin uptake inhibitor with antidepressant activity. Prog Neuropsychopharmacol Biol Psychiatry 6: 277-295, 1982.

Kupfer, D.J., D.G. Spiker, P.A. Coble, J.F. Neil, R. Ulrich and D.H. Shaw. Sleep and treatment prediction in endogenous depression. Am J Psychiatry 138: 429-434, 1981.

Leibenluft, E. and T.A. Wehr. Is sleep deprivation useful in the treatment of depression? Am J Psychiatry 149: 159-168, 1992.

Mendelson, W.B. Pharmacology of slow wave sleep in illness and health. In: Wauquier, A., L. Dogovic and M. Radulovacki (eds) Slow wave sleep: physiological, pathophysiolocal and functional aspects. Raven, New York, pp 155-165, 1989.

Mulder-Hajonides van der Meulen, W.R.E.H. Measurement of subjective sleep quality. In: Proceedings of the European Sleep Congress, Amsterdam, The Nerherlands, 1981.

Nicholson, A.N., C.M. Bradley and P.E. Pascoe. Medications: effect on sleep and wakefulness. In: Rryger, M., T. Roth and W. Dement (eds) Principles and practice of sleep medicine. WB Saunders, Philadelphia, pp 228-236, 1989.

O'Brien, R.G.and M. Kister Kaiser. MANOVA method for analyzing repeated measures designs: an extensive primer. Psychol Bill 97: 316-333, 1985.

Oswald, I. Sleep studies with clomipramine (Anafranil) and related drugs. J Int Med Res 1: 296 $298,1973$.

Oyehaug, E. and E.T. Ostensen. High-performance liquid chromatographic determination of citalopram and four of its metabolites in plasma and urine samples from psychiatric patients. J. Chromatogr. 308: 199-208, 1984.

Overo, K.F. Kinetics of citalopram in man: plasma levels in patients. Prog. Neuropsychopharmacol. Biol. Psychiatry 6: 3\1-318, 1982.

Rechtschaffen, A. and A. Kales. A manual of standardized terminology, techniques and scoring system for sleep stages of human subjects. UCLA Brain Information Service Institute, Los Angeles, 1968.

Riemann, D. and M. Berger. The effects of total sleep deprivation and subsequent treatment with clomipramine on depressive symptoms and sleep electroencephalography in patients with a major depressive disorder. Acta Psychiatr. Scand. 81: 24-31, 1990. 
Van Bemmel, A.L., A.G. Havermans and R. van Diest. Effects of trazodone on EEG sleep and clinical state in major depression. Psychopharnacology 107 : 569-574, 1992.

Vogel, G.W., A. Thurmond, P. Gibbons, K. Sloan, M. Bouyd and M. Walker. REM sleep reduction effects on depression syndromes. Arch. Gen. Psychiatry 32: 765-777, 1975.

Vogel, G.W., F. Vogel, R.S. McAbee and A. Hennessey. Improvement of depression by REM sleep deprivation: new findings and a theory. Arch. Gen. Psychiatry 37: 247-253, 1980.

Vogel, G.W., A. Buffenstein, K. Minter and A. Henressey. Drug effects on REM sleep and on endogenous depression. Neurosci \& Biobehav Rev 14:49-63, 1990.

Zerssen, D. von. Die Befindlichkeitsskala. Manual. Beltz, Weinheim, 1976 



\section{Changes in EEG power density of non-REM sleep in depressed patients during treatment with citalopram}

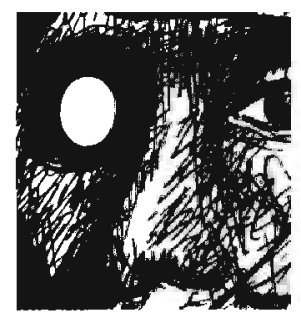

Alex L. van Bemmel (1), Domien G.M. Beersma (2), Rutger $\mathrm{H}$. van den Hoofdakker (2)

(1) Department of Psychiatry, University of Limburg

(2) Department of Biological Psychiatry, University of Groningen

Accepted for publication in the J. of Sleep Research, 1993 


\section{SUMMARY}

According to a recent hypothesis the therapeutic effects of antidepressants might be related to acute or cumulative suppression of non-rapid eye movement sleep (non-REMS) intensity. This intensity has been proposed to be expressed in the EEG power density in non-REMS. In the present study the relationship was examined between the changes of EEG power density in non-REMS and the changes in clinical state in 16 depressed patients during treatment with citalopram, a highly specific serotonin uptake inhibitor. A one-week wash-out period was followed by 1 week of placebo administration, a medication period of 5 weeks, and a one-week placebo period. In order to minimize systematic influences of sleep duration and non-REMS-REMS alterations, EEG power was measured over the longest common amount of non-REMS stages 2, 3 \& 4 (91.5 $\min )$. During the last treatment week and the week after withdrawal, a significant decrease of EEG power as compared to baseline was found in the 8-9 $\mathrm{Hz}$ frequency range. No clear-cut change, however, was observed in the EEG power of the delta frequency range $(1-4 \mathrm{~Hz})$, which is considered to be the principle manifestation of non-REMS intensity. Furthermore, no relationship between changes in EEG power density and changes in clinical state could be demonstrated.

\section{INTRODUCTION}

The majority of antidepressant drugs (ADs) of all existing chemical classes suppress rapid eye movement sleep (REMS) (Vogel et al., 1990) and repeated selective REMS deprivation over 3 weeks alleviates depression. Thus it has been hypothesized that strong initial and sustained REMS suppression is an important factor in the mechanism underlying treatment response (Vogel et al., 1975; 1980). However, no consistent relationships between decreases in REMS and the amelioration of depression have been demonstrated during treatment with ADS (Riemann and Berger, 1990; Van Bemmel et al., 1992a). Hence, REMS suppression may be an important factor in the mechanism underlying treatment response, it is not a sufficient factor.

The reports on the effects of ADs on non-REMS are inconsistent (Mendelson, 1989; Nicholson et al., 1989). It is not clear whether changes in non-REMS are related to the improvement of depression. This may be due to the fact that the quantification of non-REMS changes in terms of changes in duration is insufficient to detect such relationships. Borbély et al. (1981) have demonstrated that 
during the night the power density of the sleep EEG undergoes a marked, progressive decrease across stages. This probably reflects a non-REMS intensity dimension which remains unrecognized by visual scoring of the sleep $\mathrm{EEG}$.

One of the proposals specifying the link between non-REMS and depression, the S-deficiency hypothesis, concerns this non-REMS intensity variable (Borbély and Wirz-Justice, 1982; Borbély, 1987). According to this hypothesis the buildup of process $S$ (i.e. the build-up of the pressure for non-REMS) during waking is impaired. Low levels of $S$ cause depression, increased levels of $S$, e.g. by sleep deprivation, cause normalization of mood. The level of $S$ is considered to be reflected in the EEG power density in non-REMS. Recently, it was shown in healthy subjects that REMS deprivation by arousals resulted in a simultaneous reduction of EEG power in non-REMS (Beersma et al., 1990). Moreover, Dijk et al. (1991a) have demonstrated in chipmunks that the administration of the AD clomipramine resulted not only in REMS suppression, but also in a decrease of non-REMS power in the frequencies between 1.5 and $13.5 \mathrm{~Hz}$. These findings have led to the hypothesis that acute or cumulative suppression of non-REMS intensity rather than suppression of REMS is a key factor in mechanisms underlying improvement (Beersma and Van den Hoofdakker, 1992). Summarizing, ADs therefore might be effective because they suppress non-REMS intensity.

In the present study we examine this possibility by investigating the relationships between changes in non-REMS power and changes in clinical state in patients during treatment with the $\mathrm{AD}$ citalopram. This drug has a number of advantages. It is one of the most selective serotonin (5-HT) uptake inhibitors currently available. An intensification of 5-HT neurotransmission has been associated with recovery of depression (Blier et al., 1987), while the 5-HT properties of ADs seem to play an important role in mediating the RrMs inhibiting effects (Nicholson et al., 1989). The metabolites of citalopram are also 5-HT specific (Hyttel, 1982). Citalopram appears to have little effect on noradrenergic or dopaminergic systems, and it is practically devoid of anticholinergic and antihistaminergic properties. The efficacy of citalopram after 6 weeks of treatment is similar to that of reference ADs, in particular tricyclics (Bech and Cialdella, 1992). For humans no sleep data have been published but the drug has been shown to suppress REMS and to promote slow wave sleep in cats (Hilakivi et al., 1987).

In summary, citalopram was considered to be a rather adequate pharmacological probe in the study on the role of non-REMS intensity changes in the mechanisms underlying drug induced antidepressant effects. 


\section{MATERIALS AND METHODS}

\section{Study design}

After a one week wash-out period there were three consecutive treatment periods encompassing a total of seven weeks. In week 1 a placebo was administered; in weeks 2-6 the subjects were treated with citalopram (week 2: 20 $\mathrm{mg} /$ day; weeks 3-6: $40 \mathrm{mg} /$ daily at 6:00 p.m.); in week 7 citalopram was abruptly discontinued and substituted by a placebo. The administration of the placebo and citalopram was single blind. Subjects were informed, however, that placebo treatment could occur.

\section{Subjects}

The participants were outpatients suffering from major depression, single or recurrent [DSM-III-R (APA, 1987) codes 296.2 and 296.3], including insomnia (DSM-III-R code 307.42). Subjects were only included if two psychiatrists agreed on the diagnosis. A score of 20 or higher on the Hamilton Rating Scale for Depression (HRSD, 17 items; Hamilton 1967) was required. Patients with a current history of sleep disorders such as sleep apnea or nocturnal myoclonus were excluded on the basis of a medical interview. 'The results of physical examination, blood chemistry and haematology were within the normal range. Subjects were free of psychoactive medication for at least one week before placebo week 1 and their eligibility was decided after this wash-out period. At the end of week 1 (placebo-baseline) only subjects whose HRSD score was 20 or higher and those with a decrease of no more than $30 \%$ compared to the initial HRSD score after wash-out were included. During the study alcohol consumption, consumption of beverages containing caffeine (from lunch time), comedication, and napping were not allowed. The compliance to the instruction not to nap was not controlled for by objective measurements. The protocol was reviewed and approved by the institutional Ethics Review Committee and the subjects gave informed consent.

\section{Measurements}

\section{Depression}

The severity of depression of the previous week was assessed at the end of each experimental week by means of the HRSD, rated by two psychiatrists. 
Sleep recordings

Sleep EEGS of each subject were recorded between 11:00 p.m. and 7:00 a.m. for seven nights in our sleep laboratory. The sleep recordings were scheduled in such a way as to enable evaluation of the baseline characteristics of sleep (2 consecutive nights at the end of Week 1), the acute effects of citalopran on sleep (the night after the first citalopram treatment day), the effects at the end of the citalopram treatment period ( 2 consecutive nights at the end of Week 6), and the effects of one-week placebo-withdrawal ( 2 consecutive nights at the end of Week 7). The first baseline night was preceded by an adaptation night.

The recordings were obtained at a paper speed of $10 \mathrm{~mm} / \mathrm{s}$ from standard leads: two EOGS, two EEGs ( $\mathrm{C} 3-\mathrm{A} 2$ and $\mathrm{C} 4-\mathrm{A} 1)$ and a submental EMG. The time constants for the EOG and EEG recordings were $0.3 \mathrm{~s}$; the high frequency cut-off was $35 \mathrm{~Hz}$. All signals were stored on magnetic tape for off-line analyses.

\section{Measures}

\section{Depression}

For each subject the average of the two HRSD ratings during each experimental week was used as an index of the severity of depression. For each assessment the rank correlations between the two HRSD ratings obtained in all patients were calculated. 'The resulting 7 correlation values showed a range between 0.90 and 0.96 . This indicates a close overall correspondence $(>80 \%)$ between the two HRSD raters with respect to the assessment of the severity of depression.

The average HRSD score at the end of week 6, relative to that of placebo-baseline (week 1), was taken as a measure for the clinical change at the end of the 5week citalopram treatment.

\section{Sleep recordings}

These were analysed visually in successive 30-s epochs according to the scoring rules of Rechtschaffen and Kales (1968). The following additional variables were assessed: sleep onset: the first epoch, after "lights out" ${ }^{2}$ of stages 2, 3, 4 or REMS, followed by at least 10 min of sleep interrupted by no more than 2 min of stage 1 or wakefulness; end of sleep: the last epoch of stages 2,3,4 or REMS, preceded by at least 10 min of sleep interrupted by no more than 2 min of stage 1 or wakefulness.

One EEG signal [i.e. in each subject obtained from the same lead in all conditions (C3-A2 or C4-A1)] was low-pass filtered for spectral analysis at $25 \mathrm{~Hz}(24$ $\mathrm{dB} / \mathrm{oct}$ ) and subsequently digitized at $64 \mathrm{samples} / \mathrm{s}$. Digitized data were processed by a fast Fourier transform routine. Power spectra were calculated over 4-s intervals from $0.75-15 \mathrm{~Hz}$ in $0.25 \mathrm{~Hz}$ bins, by applying a rectangular window. The 0.25 bins were condensed into $1 \mathrm{~Hz}$ wide frequency bins. Bins will be 
referred to by mentioning their upper limit, so power density in the $1 \mathrm{~Hz}$ bin is the sum of the power density of $0.75 \mathrm{and} 1 \mathrm{~Hz}$; power density in the $2 \mathrm{~Hz}$ bin is the sum of the power density of $1.25,1.50,1.75$ and $2 \mathrm{~Hz}$ etc. To obtain a resolution of 30-s, power values of 7.5 adjacent 4 -s epochs were summed for each frequency bin thus calculated. Visual scores of the same 30 -s epochs were synchronized with the series of power spectral epochs.

'The influence of citalopram on non-REMS power was analyzed on the basis of the longest common amount of non-REMS stages 2,3 \& 4, accumulated from sleep onset onwards (see Discussion). 30-s epochs of non-REMS stages 2, $3 \& 4$ containing EEG-artefacts [mean: $6.8 \%(\mathrm{SD}=3.1)$ of all non-REMS $2,3 \& 4$ epochs] were omitted from further spectral analysis, on the basis of visual inspection of the original tracings.

Since the absolute values of the power densities of the higher frequencies are several orders of magnitude lower than those of the lower frequencies and since the interindividual variation is considerable, absolute values are not very suitable for a visualization of changes in power spectra (Dijk et al.,1989). Therefore, in the figures power values of each subject were expressed relative to power values in baseline, which were taken as $100 \%$.

To monitor changes in sleep over the four experimental periods the following variables were used: the averages of the sleep data of the two consecutive sleep recordings at the end of week 1 (= placebo baseline), of those at the end of week 6 (= end of citalopram treatment), and of those at the end of week 7 (= placebo withdrawal); the evaluation of the acute treatment effects on sleep is based on the data of the night after the first citalopram treatment day.

\section{Analyses}

MANOVA for repeated measures (O'Brien and Kister Kaiser, 1985) was applied over the four experimental periods. The Newman-Keuls (NK) post-hoc procedure was used to detect where significant results were located. With respect to mood change a rank order of the patients was made on the basis of the difference between the HRSD scores at the end of the citalopram treatment period and those in baseline. Subsequently, the entire patient group was divided into two: a group with relatively small changes in HRSD scores, the less improved group, and a second group with relatively large changes in HRSD scores, the more improved group. Comparisons between the two groups were made by means of MANOVA for repeated measures. Because of the skewed distribution of the results of the sleep EEG power variables log-transformed values were used for statistical tests. P values $<0.05$ were accepted as significant. 


\section{RESULTS}

Table 1 shows the biographic and clinicall characteristics of the 16 patients who participated in the study. The less and more improved groups did not differ significantly with respect to sex and age.

Table 1. Sex $(F=$ female; $M=$ male $)$ age, HRSD baseline scores, and change in HRSD scores at the end of citalopram treatrnent expressed as deviation from the baseline value

\begin{tabular}{|c|c|c|c|c|c|c|c|}
\hline \multicolumn{4}{|c|}{ Less improved patients } & \multicolumn{4}{|c|}{ More improved patients } \\
\hline Sex & Age & $\begin{array}{l}\text { HRSD } \\
\text { baseline } \\
\text { score }\end{array}$ & $\begin{array}{l}\text { HRSD } \\
\text { change } \\
(\%)\end{array}$ & Sex & Age & $\begin{array}{l}\text { HRSD } \\
\text { baseline } \\
\text { score }\end{array}$ & $\begin{array}{l}\text { HRrsD } \\
\text { change } \\
(\%)\end{array}$ \\
\hline M & 51 & 26.0 & 0 & $M$ & 45 & 22.0 & 56 \\
\hline F & 39 & 32.0 & 0 & F & 26 & 24.0 & 57 \\
\hline M & 58 & 28.0 & 12 & $\mathrm{~F}$ & 46 & 30.0 & 60 \\
\hline M & 54 & 28.5 & 20 & F & 24 & 23.5 & 62 \\
\hline M & 52 & 24.0 & 39 & $M$ & 47 & 31.0 & 71 \\
\hline M & 50 & 29.0 & 48 & $\mathrm{M}$ & 30 & 24.0 & 75 \\
\hline $\mathrm{F}$ & 35 & 32.0 & 53 & M & 47 & 22.0 & 82 \\
\hline F & 37 & 24.0 & 54 & $\mathrm{~F}$ & 29 & 21.0 & 87 \\
\hline
\end{tabular}

\section{Depression}

Over the seven experimental weeks of the protocol the HRSD of the entire group showed a significant variation over time $\left(\mathrm{F}_{6,84}=21.5 ; \mathrm{P}<0.01\right)$. This result could be attributed to a significant improvement of depressive mood during the period between the 2 nd and the 6th week compared to baseline as well as to the 1st citalopram treatment week. The less and more improved groups did not differ significantly with respect to HRSD baseline scores ( $\mathbb{F}_{1,14}$ $=3.5 ; \mathrm{P}=0.09$ ) (Table 2). 
Table 2. Severity of depression (HRSD). Mean values and standard deviations during the 7 experimental weteks of the encire group (All), the less improved (LI), and the more improved (MI) patients

\begin{tabular}{llllllll}
\hline WEIKS & All & $(\mathrm{n}=16)$ & LI & $(\mathrm{n}=8)$ & ML & $(\mathrm{n}=8)$ \\
\hline & & & & & & & \\
$\mathrm{PB}$ & 26.3 & $(3.7)$ & 27.9 & $(3.1)$ & 24.7 & $(3.8)$ \\
$\mathrm{CIT}-1$ & 21.8 & $(6.5)$ & 25.9 & $(4.2)$ & 16.7 & $(5.1)$ \\
$\mathrm{CIT}-2$ & 19.5 & $(6.4)$ & 24.3 & $(4.1)$ & 14.6 & $(4.6)$ \\
$\mathrm{CIT}-3$ & 18.4 & $(7.3)$ & 22.1 & $(5.1)$ & 14.7 & $(7.5)$ \\
CIT-4 & 16.9 & $(7.8)$ & 21.4 & $(5.0)$ & 12.4 & $(5.2)$ \\
CIT-5 & 13.8 & $(6.9)$ & 18.9 & $(6.1)$ & 8.6 & $(2.3)$ \\
PW & 14.1 & $(6.8)$ & 19.2 & $(5.2)$ & 8.9 & $(3.4)$ \\
\hline
\end{tabular}

P'B = placebo baseline; CIT-1 to CIT -5 = the 5 citalopram treatment weeks; $P$ PW = placebo withdrawal

\section{Sleep stages}

Table 3 shows the mean values, the standard deviations, and the corresponding statistics of the sleep stages.

Compared to baseline non-REMS was not significantly affected during citalopram treatment. One week after withdrawal the amount of non-REMS was significantly decreased compared to baseline and to both the acute treatment period and the end of the treatment. Citalopram suppressed REMS significantly both during the acute treatment period and at the end of the treatment, compared to both baseline and withdrawal. No significant variation over the four experimental periods was found for total time awake and stage 1 . The less and more improved patients did not differ significantly for any of the sleep variables.

\section{Power spectra in non-REMS}

The longest common amount of non-REMS stages $2,3 \& 4$ turned out to be 91.5 minutes. Figure 1 shows the geometric means, and the corresponding statistics, for the power spectra during 91.5 min of non-REMS (the power spectra of each subject separately are shown in Appendix).

Within these 91.5 min of non-REMS MANOVA over the 4 experimental periods provided significant results for the EEG power of the 4 to $9 \mathrm{~Hz}$ bins and for the $13 \mathrm{~Hz}$ bin. The post-hoc procedure failed to show where overall differences wrere located with respect to the 5,6 and $13 \mathrm{~Hz}$ bins. At the end of the treatment and during withdrawal the EEG power of the 8 and $9 \mathrm{~Hz}$ bins was significantly decreased compared to baseline. The EEG power of the 4 and $7 \mathrm{~Hz}$ bins 
Table 3. The amounts in minutes between sleep onser and end of sleep of non-REMS stages $2,3 \& 4$ (NREMS); REMS; total time awake (AWAKE); and non-REMS stage 1 (NRFMS-1). Mean values and standard deviations of the entire patient group (All) $(\mathrm{n}=16)$, the less improved (LI) (n=8) and the more improved (MI) (n=8) patients

\begin{tabular}{|c|c|c|c|c|c|c|}
\hline $\begin{array}{l}\text { Sleep } \\
\text { stage }\end{array}$ & Group & & $\mathrm{PB}$ & CrT-A & $\mathrm{CIT}-\mathrm{E}$ & $\mathrm{pw}$ \\
\hline \multirow[t]{3}{*}{$\begin{array}{r}\text { NREMS } \\
\text { (min) }\end{array}$} & All & $(*)$ & $\begin{array}{l}253.1 \\
(35.6)\end{array}$ & $\begin{array}{c}272.9 \\
(58.6)\end{array}$ & $\begin{array}{l}267.3 \\
(23.4)\end{array}$ & $\begin{array}{l}216.0 \\
(35.4)\end{array}$ \\
\hline & $\mathrm{LI}$ & & $\begin{array}{l}255.1 \\
(22.6)\end{array}$ & $\begin{array}{l}273.1 \\
(42.2)\end{array}$ & $\begin{array}{l}267.4 \\
(23.2)\end{array}$ & $\begin{array}{l}214.6 \\
(30.8)\end{array}$ \\
\hline & MI & & $\begin{array}{l}251.2 \\
(46.9)\end{array}$ & $\begin{array}{l}272.7 \\
(74.6)\end{array}$ & $\begin{array}{l}267.2 \\
(25.3)\end{array}$ & $\begin{array}{l}217.2 \\
(41.7)\end{array}$ \\
\hline \multirow[t]{3}{*}{$\begin{array}{l}\text { REMS } \\
(\mathrm{min})\end{array}$} & All & $(* * ;)$ & $\begin{array}{c}97.2 \\
(22.0)\end{array}$ & $\begin{array}{c}47.7 \\
(26.9)\end{array}$ & $\begin{array}{c}62.0 \\
(22.7)\end{array}$ & $\begin{array}{l}110.8 \\
(24.9)\end{array}$ \\
\hline & $\mathrm{LI}$ & & $\begin{array}{l}108.5 \\
(22.2)\end{array}$ & $\begin{array}{c}48.1 \\
(25.3)\end{array}$ & $\begin{array}{c}59.1 \\
(18.9)\end{array}$ & $\begin{array}{l}104.9 \\
(24.7)\end{array}$ \\
\hline & $M I$ & & $\begin{array}{c}85.9 \\
(16.0)\end{array}$ & $\begin{array}{c}47.3 \\
(30.2)\end{array}$ & $\begin{array}{c}64.8 \\
(27.0)\end{array}$ & $\begin{array}{l}116.7 \\
(25.2)\end{array}$ \\
\hline \multirow[t]{3}{*}{$\begin{array}{l}\text { AW/AKE } \\
\text { (min) }\end{array}$} & All & & $\begin{array}{c}34.1 \\
(22.4)\end{array}$ & $\begin{array}{c}47.3 \\
(37.5)\end{array}$ & $\begin{array}{c}35.1 \\
(16.7)\end{array}$ & $\begin{array}{c}38.9 \\
(29.6)\end{array}$ \\
\hline & $\mathrm{LI}$ & & $\begin{array}{l}26.7 \\
(9.8)\end{array}$ & $\begin{array}{c}57.6 \\
(38.0)\end{array}$ & $\begin{array}{c}40.6 \\
(14.9)\end{array}$ & $\begin{array}{c}45.0 \\
(39.7)\end{array}$ \\
\hline & MI & & $\begin{array}{c}41.5 \\
(29.2)\end{array}$ & $\begin{array}{c}37.1 \\
(36.4)\end{array}$ & $\begin{array}{c}29.7 \\
(17.6)\end{array}$ & $\begin{array}{c}32.8 \\
(114.8)\end{array}$ \\
\hline \multirow[t]{3}{*}{$\begin{array}{c}\text { NREMS-1 } \\
(\mathrm{min})\end{array}$} & All & & $\begin{array}{c}36.4 \\
(28.1)\end{array}$ & $\begin{array}{c}40.3 \\
(23.0)\end{array}$ & $\begin{array}{c}49.5 \\
(20.2)\end{array}$ & $\begin{array}{c}37.8 \\
(23.5)\end{array}$ \\
\hline & LI & & $\begin{array}{c}36.4 \\
(23.4)\end{array}$ & $\begin{array}{c}42.1 \\
(14.9)\end{array}$ & $\begin{array}{c}49.3 \\
(21.2)\end{array}$ & $\begin{array}{c}42.0 \\
(26.5)\end{array}$ \\
\hline & MI & & $\begin{array}{c}36.4 \\
(33.7)\end{array}$ & $\begin{array}{c}38.5 \\
(30.1)\end{array}$ & $\begin{array}{c}49.7 \\
(20.7)\end{array}$ & $\begin{array}{c}33.6 \\
(21.1)\end{array}$ \\
\hline
\end{tabular}

$\mathrm{PB}=$ placebo baseline; $\mathrm{CrT}-\mathrm{A}=$ acute citalopram treatment; $\mathrm{CIT}-\mathrm{E}=$ = end of citalopram treatment; $\mathrm{PW}$ $=$ placebo withdrawal. Significant MANOVAs over the 4 experimental periods: $(\$) F_{x, a 2}=10.2(\mathrm{P}<$ $0.01) ;\left(^{* *}\right) F_{3,2}=32.1(P<0.01)$. Neither the main effect on group (i.e. less versus more improved) nor the interaction effect between group and time were significant for any of the sleep variables

was significantly decreased during withdrawal compared to baseline.

On inspection, the effect of citalopram on EEG power seemed to be more pronounced in the less improved patient group (B) than in the more improved group (C). However, these groups did not differ significantly for the EI:G power values in any bin. As the less improved patients were on average about 10 years older than the more improved patients and because on inspection the effects of citalopram on EEG power seemed to differ between the two groups, 
Figure 1. Power spectra of $91.5 \mathrm{~min}$ non-REMS, relative to power spectra of baseline $(=100 \%)$. Geometric means of the entire patient group $(n=16)(A)$, the less improved $(n=8)(B)$, and the more improved $(n=8)(C)$ groups separately. Power densities are plotted at the upper bounderies of the frequency bins. CIT-A = acute citalopram treatment; $C I T-E=$ end of citalopram treatment; $P v=$ placebo withdrawal. The frequency ranges in which the values varied significantly $(p<0.05$; MNOVA) over the 4 experimental periods are indicated by black bars above the abscissa of $A$. Neither the main effect on group (i.e. less versus more improved; $B$ and $C$ ) nor the interaction effect between group and time were significant for the EEG power values in any $1 \mathrm{~Hz}$ bin

A

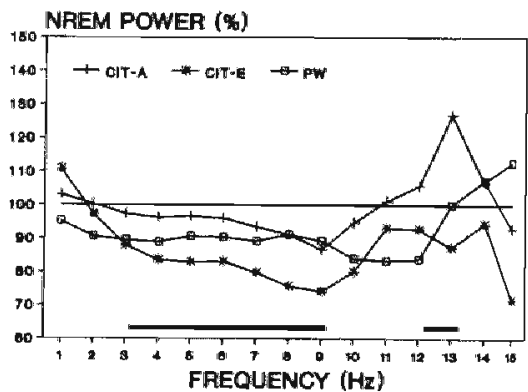

C

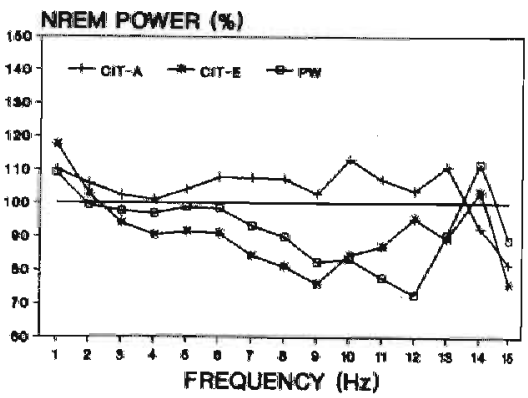

B

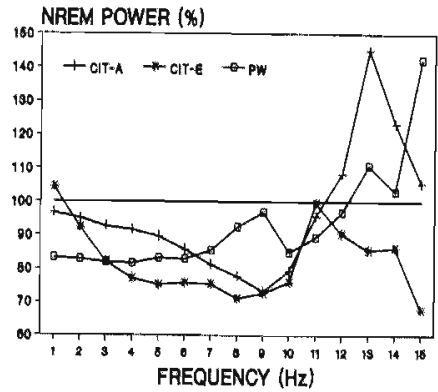

the possible relationship between age and the relative power values in the 4-9 $\mathrm{Hz}$ frequency range was investigated. Only low and non-significant rank correlations could be found [at the end of the citalopram treatment: rho $=-0.44(P=$ $0.10)$; after one week of withdrawal: rho $=-0.37(\mathrm{P}=0.16)$ ]. 


\section{DISCUSSION}

Before we discuss the results of this study, the details of our spectral analysis will be argued. The analysis of the effects of particular treatments on EEG power production offers some serious pitfalls. Usually, EEG power is high during the first non-REMS episode and decreases during the next episodes (Borbély et al., 1981; Achermann and Borbély, 1987; Dijk et al., 1991b). Furthermore, EEG power production waxes and wanes with the non-REMS-REMS alternation, becoming very low in REMS. The best simple and direct way to compare power production within and between subjects is to compare the powers produced in the longest common amount of non-REMS. The following examples may explain why this is a better variable than, e.g., average EEG power over total non-REMS time. Suppose that a particular treatment does not have any effects on nonREMS power or sleep duration, but it does affect intermittent waking or REMS. The average EEG power over total non-REMS time will change then according to the changes in time spent in REMS or in intermittent waking. Using this variable would thus lead to the false interpretation that the treatment interfered with non-REMS power production. Another exanple; suppose that the treatment produces a change in sleep duration. Since EEG power is usually low at the end of sleep, longer sleep will lead to a lower average EEG power, even if power production is not affected by the treatment. Again, reliance on this variable would result in a false interpretation of the real effects of the intervention.

In an attempt to avoid the aforementioned problem, some authors (Reynolds et al., 1991) have chosen to use the power production in the first non-REMSREMS cycle as a critical variable. However, this leads to another problem. In the course of a non-REMS episode EEG power increases until it reaches a plateau value, followed by a rather steep decline shortly before REMs (Achermann and Borbély, 1990). If a treatment merely lengthens REMS latency, the FEG power plateau will last longer, and the average level of EEG power will increase. Average EEG power production would then erroneously suggest that the treatment interferes directly with non-REMS power production per se. Similar remarks can be made with respect to the study of Kupfer et al. (1989). In this study non-REMS power during the first 100 min of baseline sleep was compared with power during the same interval of sleep after a 'loading dose' of clomipramine. However, the duration of REMS and wakefulness within the 100-min intervals would be expected to be very different under the two conditions. No data regarding these critical issues are provided by the authors.

Although the aforementioned pitfalls were awoided in our spectral analysis, some interpretation problems remain. The frequency of sleep interruptions is also of influence upon non-REMS power. An interruption leads to reduced power values, followed by a relaxation period in which power gradually increa- 
ses again. It cannot be excluded that changes in sleep continuity have influenced the power spectra. Knowledge of the dynamics of these processes is not yet sufficient to estimate the consequences of these effects (Achermann and Borbély, 1987). Nevertheless, the absence of significant variations over the experimental periods in total intermittent wakefulness and stage 1 sleep suggests that it is reasonable to assume that changes in sleep continuity were of little influence for the results of our analysis.

The present study shows that citalopram suppresses EEG power of non-REMS mainly in the $8-9 \mathrm{~Hz}$ range and that this effect persists during withdrawal. In addition, MANOVA over the four experimental periods provided significant differences in the EEG power values of the 4 to $7 \mathrm{~Hz}$ bins and of the $13 \mathrm{~Hz}$ bin. By post-hoc analysis these differences could not be attributed to an obvious decrease of EEG power during citalopram treatment. Therefore, no clear-cut decrease was observed in the EEG power of the delta frequency range (1-4 Hz), which is considered to be the principle manifestation of non-REMS intensity (Borbély et al., 1981).

The persistence of the suppression of the $8-9 \mathrm{~Hz}$ activity during withdrawal contrasts with the immediate rebound of REMS. Interestingly, there was no worsening of clinical state during the one week withdrawal period. Hence, the only relationship between sleep physiology and improvement is found in the similarity of the overall time courses of mood and of the 8-9 $\mathrm{Hz}$ range of nonREMS. Unfortunately, in spite of this overall similarity, no significant difference was found between the less and more improved patient groups for EEG power values in any $1 \mathrm{~Hz}$ bin.

In an earlier study (Van Bemmel et al., 1992b) in a sample of eight depressed parients treated with the AD trazodone a similar pattern emerged. Here the clinical response pattern showed considerable similarity to that of the spectral power changes in the 13-14 $\mathrm{Hz}$ band. But at the level of individual changes no clear-cut relationships were observed between magnitude of mood changes and the amount of change in this EEG frequency band.

In summary, no relationships were found between clinical change and changes in power densities, either in the present citalopram study or in the earlier trazodone study. Moreover, the drugs turned out to affect EEG power production very differently: in the $8-9 \mathrm{~Hz}$ and the $13-14 \mathrm{~Hz}$ range respectively. The data do not support the hypothesis that suppression of non-REMS intensity as expressed in the $1-4 \mathrm{~Hz}$ range reflects a common pathway in the antidepressant effects of pharmacological manipulations.

\section{ACKNOWLEDGEMENTS}

The research assistance of Gert Jan Mevius is gratefully acknowledged. This study was made possible through the financial support of $\mathrm{H}$. Lundbeck \& $\mathrm{Co}$. A/S, Denmark and The Netherlands. 


\section{REFERENCES}

Achermann, P. and A.A. Borbély. Dynamics of EEG slow wave activity during physiological sleep and after administration of benzodiazepine hypnotics. Hum. Neurobiol., 6:203-210. 1987.

Achermann, P. and A.A. Borbély. Simulation of human slecp: ultradian dynamics of electroencephalographic slow-wave activity. J. Biol. Rhythms, $5: 141-157.1990$.

APA-American Psychiatric Association: Diagnostic and statistical manual of mental disorders (DSM-III-R). APA, Washington DC, (3rd ed-revised). 1987.

Beersma, D.G.M., D.J. Dijk, C.G.H. Blok and I. Evcrhardus. REM sleep deprivation during 5 hours leads to an immediate REM sleep rebound and to suppression of non-REM sleep intensity. Electroenceph. Clin. Neurophysiol, 76: 114-122. 1990.

Beersma, D.G.M. and R.H. Van den Hoofdakker. Can non-REM sleep be depressogenic? J. Affect. Dis, 24 : 101-108. 1992.

Bech, P. and P. Cialdella. Citalopram, meta-analysis of intended and unintended elfects. Int. Clin. Psychopharmacol., 6 [Suppl 5]: 45-54. 1992.

Blier, P., C. Montigny and Y. Chaput. Modifications of the serotonin system by antidepressant treatments: implications for the therapeutic response in major depression. J. Clin. Psychopharmacol., 7: 24S-35S. 1987.

Borbély, A.A., F. Baumann, D. Brandeis, I. Strauch and D. Lehmann. Sleep deprivation: cffect on sleep stages and EEG power density in man. Electroenceph. Clin. Neurophysiol., 51: 483-493. 1981.

Borbély, A.A. and A. Wirz-Justice. Sleep, sleep deprivation and depression. Hurn. Neurobiol., 1: 205-210. 1982.

Borbély, A.A. The S-defiency hypothesis of depression and the two process model of sleep regulation. Pharmacopsychiatry, 20:23-29. 1987.

O'Brien, R.G. and M. Kister Kaiser. MANOVA method for analyzing repeated measures designs: an extensive primer. Psychol. Bull., 97: 316-333. 1985.

Dijk, D.J., D.G.M. Beersma, S. Daan and R.H. Van den Hoofdakker. Effects of seganserin, a 5 HT2 antagonist, and temazepam on human sleep stages and EEG power spectra. Eur. J. of Pharmacol., 171: 207-218. 1989.

Dijk, D.J., A. Strijkstra, S. Daan, D.G.M. Beersma and R.H. Van den Hoofdakker. Effect of clomipramine on sleep and EEG power spectra in the diurnal rodent Eutamias Sibiricus. Psychophamacology, 103: 375-379. 1991a.

Dijk, D.J., C. Cajochen, I. Tobler and A.A. Borbély. Sleep extension in humans: sleep stages, EEG power spectra and body temperature. Sleep, 14: 294-306. $1991 \mathrm{~b}$.

Hamilton, M. Development of a rating scale for primary depressive illness. Brit. J. of Soc. Clin. Psychiat., 16:278-296. 1967.

Hilakivi, I., T. Kovala, A. Leppävuori and A. Shvaloff. Effects of scrotonin and noradrenaline uptake blockers on wakefulness and sleep in cats. Pharmacol. \& Toxicol., 60: 161-166. 1987.

Hyttel, J. Citalopram-pharmacological profile of a specific serotonin uptake inhibitor with antidepressant activity. Prog. Neuro-Psychoph. \& Biol. Psychol., 6: 277-295. 1982.

Kupfer, D.J., C.L. Ehlers, B.G. Pollock, R.S. Nathan and J.M. Perel. Clomipramine and EEG sleep in depression. Psychiatry Res., 30: 165-180. 1989.

Mendelson, W.B. Pharmacology of slow wave sleep in illness and health. In: A. Wauquier, L. Dogovic and M. Radulovacki, (Eds) Slow wave sleep: physiological, parhophysiolocal and functional aspects. Raven Press, New York, 155-165. 1989.

Nicholson, A.N., C.M. Bradley and P.E. Pascoe. Medications: effect on sleep and wakefulness. In: M. Kryger, T. Roth and W. Dement (Eds) Principles and practice of sleep medicine. WB Saunders, Philadelphia, 228-236. 1989. 
Rechtschaffen, A. and A. Kales. A manual of standardized terminology, techniques and scoring system for sleep stages of human subjecrs. UCLA Brain Information Service Institure, Los Angeles, 1968.

Reynolds, C.F., C.C. Hoch, D.J. Buysse, C.J. George, P.R. Houck, S. Mazumdar, M. Miller, B.G. Pollock, H. Rifia, E. Frank, C. Cornes, R.K. Morycz and D.J. Kupfer. Sleep in late-life recurrent depression, changes during early continuation therapy with nortriptyline. Neuropharmacol., 5 : 85-96. 1991.

Riemann, D. and M. Berger. The effects of total sleep deprivation and subsequent treatment with clomipramine on depressive symptoms and sleep electroencephalography in patients with a major depressive disorder. Acta Psychiatr. Scand., 81: 24-31. 1990.

Van Bemmel, A.L., A.G. Havermans and R. van Diest. Effects of trazodone on EEG sleep and clinical state in major depression. Psychopharmacology, 107:569-574. 1992a.

Van Bemmel, A.L., G.J. Mevius and R. van Diest. EEG power densicy of NREM sleep in depression during treatment with trazodone. J. Sleep Res., 1 [Suppl.1]: 238. $1992 \mathrm{~b}$.

Voggel, G.W., A. Thurmond, P. Gibbons, K. Sloan, M. Bouyd and M. Walker. REM sleep reduction effects on depression syndromes. Arch. Gen. Psychiatry, 32: 765-777. 1975.

Vogel, G.W., F. Vogel, R.S. McAbee and A. Hennessey. Improvement of depression by REM sleep deprivation: new findings and a theory. Arch. Gen. Psychiatry, 37: 247-253. 1980.

Vogel, G.W., A. Buffenstein, K. Minter and A. Hennessey. Drug effects on REM sleep and on endogenous depression. Neurosici. \& Biobehav. Rev., 14: 49-63. 1990. 
CHAPTER 6

\section{Epilogue}

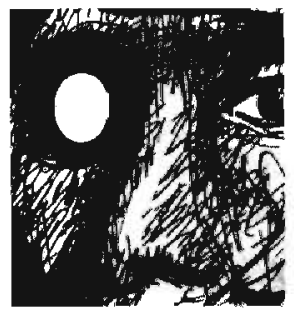

The world, as usual, is not so simple - and thank goodness, for the horizon would probably be a disappointing place anyway.

(WONDERFul LIFE, Stephen Jay Gould) 
In the preceding chapters the importance of the ADs-induced sleep changes for the alleviation of depression was studied. The literature shows that the best documented effect of most efficacious ADs on sleep polygraphic variables in man is REMS suppression, irrespective of their chemical classes. The few reports on the therapeutic significance of the amount of REMS change induced by ADS are inconsistent.

The results of the clinical sleep studies of this thesis could not confirm the hypothesis of Vogel (1983) which offers an explanation for the therapeutic role of REMS suppression. The main results of the studies on sleep polygraphic variables (chapters 2 and 4) indicate that the ADs trazodone and citalopram both produce REMS suppression and lenghtening of REMS latency, whereas no significant changes were found in sleep continuity variables. The observed significant suppression of REMS during the treatment periods in both studies and its return to baseline values after one-week withdrawal of the drugs, indicate that the ADs produce a sustained REMS pressure during treatment. However, in both studies, REMS suppression was clearly not related to the amelioration of the clinical state. This does not support, therefore, the hypothesis of Vogel (1983) that strong initial and sustained Rems suppression is of central importance for the therapeutic process. On the other hand, the hypothesis is also not disproved by the results, because strong initial and sustained REMS suppression (i.e. REMS pressure) might be a prerequisite for the initiation of other, yet unknown, processes which are important for the antidepressant action.

The hypothesis of McCarley (1982) of a common pathophysiological mechanism of REMS disturbance and depression was not tested directly in the present studies. According to this hypothesis a depressive state is supposed to be the expression of a relatively decreased monoaminergic (i.e. serotonergic \& noradrenergic) activity in combination with a relatively increased acetylcholinergic activity. Drugs which modify transmission in these systems upset the balance of activities which are supposed to be essential to the appearance of REMS, and the probability of entering REMS is reduced (Nicholson and Pascoe, 1991). Consequently, such drugs would also have antidepressant properties. Because the drugs under study (i.e. trazodone and citalopram) activate the serotonergic system more or less specifically (Johnson, 1991) and during the treatments REMS suppression was found, it can be stated that the results at least do not refute this prediction derived from McCarley's hypothesis.

In spite of this, our results are in accordance with the observation that drugs which alleviate depression appear to be associated in general with a marked reduction of REMS, with or without sleep reduction (Vogel et al., 1990; Nicholson and Pascoe, 1991). The question whether such a polysomnographic profile of $A D s$ is of clinical significance remains difficult to answer.

Recent fundamental sleep research has provided the first quantitative hypo- 
theses (Borbély and Wirz-Justice, 1982; Borbély, 1987; Beersma and van den Hoofdakker, 1992) on the therapeutic significance of non-REMS intensity changes produced by ADs. According to these hypotheses the antidepressant action of $A D s$ is due to non-REMS intensity suppression. In two of our studies (chapters 3 and 5) this prediction was tested by means of spectral analysis of the sleep EEG. No clear-cut relationship between suppression of EEG power density in non-REMS, especially in the delta frequency range (i.e. SWA), and clinical change could be demonstrated.

Although they are not in agreement with the prediction of the hypotheses, a definite interpretation of our findings, in terms of the hypotheses, must await the elucidation of several fundamental aspects of sleep regulation and their modification by ADs. It can not be excluded that sleep disruptions and changes in the amount and distribution of REMS have played a role in the changes of non-REMS power in our data (Achermann et al., 1990). More knowledge, therefore, about the interference with EEG power production by sleep disruptions or REMS changes is needed to assess the contribution of ADS to non-REMS power production. Quantitative data on the influence of REMS changes on non-REMS power will also enable an evaluation of the effects of ADs on the process of reciprocal interaction between REMS and non-REMS, in terms of the hypothesis of McCarley (1982; see also Massaquoi and McCarley, 1992). To this end studies on the effects of ADs on the sleep EFG in healthy subjects, with non-disturbed baseline sleep are necessary.

At the same time, an interpretation of the observed $A D$-induced EEG power changes in terms of non-REMS regulatory processes is not quite possible. Clearly, our results obtained after the 5-week treatment periods are very different from the characteristic short-term changes of EEG power after non-pharmacological manipulations of non-REMS in healthy subjects. The effects of trazodone were mainly located in the 13-14 $\mathrm{Hz}$ range, those of citalopram in the 8$9 \mathrm{~Hz}$ range. Sleep manipulations, such as sleep deprivation and REMS deprivation, typically result in changes in the $1-7 \mathrm{~Hz}$ range during non-REMS, which changes are considered to reflect non-REMS homeostasis, i.e. process $S$ (see review by Borbély and Achermann, 1992). Because in our studies no significant change was found in the lower EEG frequencies, this would suggest that ADs act merely on EEG generating mechanisms without interfering with non-REMS regulatory mechanisms (Dijk et al., 1991). Alternatively, ADs may affect the sleep EEG directly as well as these sleep regulatory processes. A distinction between these possibilities could be made by means of sleep deprivation, which activates predictively non-REMS regulatory processes. In further studies on the effects of ADs on sleep, therefore, the EEG should be recorded before and after sleep deprivation under placebo as well as during the administration of an AD.

Finally, the interpretation of $\mathrm{AD}$-induced EEG spectral patterns in terms of 
sleep pharmacology needs more research. Our results suggest that ADs do not all produce similar. EEG spectral response patterns. This might be due to differences in pharmacological actions among the various ADs. In support of this notion, further clinical research to identify and to interprete $E E G$ response patterns induced by the various AOs is needed. In this context a better understanding of the neurobiological events underlying the EEG generating mechanisms is also warranted (see review by Steriade et al., 1990). At the moment the neurophysiological and neurochemical origins of specific EEG frequency bands, and their functional significance are largely unknown (Borbély, 1986; Borbély and Achermann, 1992). Recently, two animal studies have provided the first indications of the origin of swA. Steriade et al. (1991) have reported that in the cat hyperpolarized thalamic neurons exhibit fluctuations of membrane potentials in the slow wave frequency range. These fluctuations might be manifestations of the mechanisms underlying sleep homeostasis at the cellular level (Borbély and Achermann, 1992). Lancel et al. (1992) observed enhanced sw/A within non-REMS in the cortical and subcortical EEG of the cat after sleep deprivation. These data may indicate that SWA reflects a recovery process in cortical and subcortical structures. Similar animal studies in which the influence of ADs will be examined, may provide relevant knowledge for pharmacological sleep research in depressives.

Summarizing, knowledge from fundamental sleep research has inspired the clinical studies of this thesis. An attempt has been made to quantitatively relate $\mathrm{AD}$-induced changes in sleep to accompanying clinical changes. Neither our studies on the changes in sleep polygraphic variables, nor those on the changes in non-REMS power produced clear evidence of involvement of REMS or nonREMS intensity in the mechanisms underlying clinical change. The observed EEG spectral response patterns during treatment with the studied ADs were clearly different from the changes in EEG power induced by non-pharmacological manipulations of sleep. These results raise different questions. In order to interprete the effects of ADs on non-REMS regulation in terms of sleep physiological processes more fundamental sleep research is necessary. Also more comparative studies of ADs with similar therapeutic effects but different pharmacological profiles are needed in both healthy and depressed subjects to further quantify the impact of non-REMS modification in the recovery of depression and to differentiate between pharmacological and sleep related aspects. An answer to the important question whether ADs with the same pharmacological specificity will produce similar changes of sleep EEG power spectra can also be expected from further studies. As in the research on hypnotic drugs (Borbély et al., 1991) also in clinical sleep research with ADs spectral analysis of the sleep EEG will become increasingly important for interpreting the effects of ADs on sleep in depressives. 
The near future will show whether the so far inspiring cross-fertilization between clinical and fundamental sleep research will produce more insight into the link between sleep and depression. In this respect a further contribution to fundamental knowledge can be expected from sleep research with ADs.

\section{References}

Achermann, P., D.G.M. Beersma and A.A. Borbély. The two-process model: ultradian dynamics of sleep. In: Horne (ed) Sleep '90. Pontenagel Press, Boclumin: 296-300, 1990.

Beersma, D.G.M. and R.H. van den Hoofdakker. Can non-REM sleep be depressogenic? J. Affect. Dis. 24: 101-108, 1992

Borbély, A.A. and A. Wirz-Justice. Sleep, sleep deprivation and depression. Hum. Neurobiol. 1: 205-210, 1982,

Borbély, A.A. Sleep homeostasis. Open peer commentary on J.A. Hobson, R. Lydic and H.A. Baghdoyan. Evolving concepts of sleep cycle generation, from brain centers to neuronal populations. The Beh. and Brain Sciences 9: 371-448, 1986.

Borbély, A.A. The S-deficiency hypothesis of depression and the two process model of s.cep regulation. Pharmacopsychiarry 20:23-29, 1987.

Borbély, A.A., T. Akerstedt, O. Benoit, F. Holsboer and I. Oswald. Hypnotics and sleep playsiology: a consensus report. Eur. Arch. Psychiatry Clin. Neurosci. 241: 13-21, 1991.

Borbély, A.A. and D. Achermann. Concepts and models of sheep regulation: an overview. J. Sleep Res. $1: 63-79,1992$.

Dijk, D.J., A. Strijkstra, D.G.M. Beersma and R.H. wan den Hoofdalkker. Effects of clomipramine on sleep and EEG power spectra in the diurnal rodent Eutamias Sibiricus. Psychopharmacology 103: 375-379, 1991.

Johnson, A.M. The comparative pharmacological properties of selective serotonin remptake inhibitors in animals. In: J.P. Feighner and W.F. Boyer (eds) Selective serotonin re-uptake inhibitors. John Wiley \& Sons: 37-70, 1991.

Lancel, M., H. van Riezen and A. Glatt. Enhanced slow-wave activity within NREM sleep in the cortical and subcortical EEG of the cat after sleep deprivation. Sleep 15 (2): 102-118, 1992.

Massaquoi, S.G. and R.W. McCarley. Extension of the limit cycle reciprocal interaction model of REM cycle control, an integrated sleep control model. J. Sleep Res. 1: 138-143, 1992.

McCarley, R.W. REM sleep and depression: common neurobiological control mechanisms. Am. J. Psychiatry 139: 565-570, 1982 .

Nicholson, A.N. and P.A. Pascoe. Monoaminergic transmission and sleep in man. In: C. Idzikowski and P. J. Cowen (eds) Serotonin, sleep and mental disorder, Wrightson Biomedical Publishing LTD, Petersfield: 215-226, 1991.

Steriade, M., P. Gloor, R.R. Llinás, F.H. Lopes da Sliva and M.-M. Mesulam. Report of EFCN Committee on Basic Mechanisms: Basic mechanisms of cerebral activities. Electroencephalogr. Clin. Neurophysiol. 76: 481-508, 1990.

Steriade, M., R. Curro Dossi and A. Nunez. Network modulation of a slow intrinsic oscillation of cat thalamocortical neurons implicated in sleep delta wawes: cortically induced synchronization and brainstem cholinergic suppression. J. Neurosci. 11: 3200-3217, 1991.

Vogel, G.W. Evidence for REM sleep deprivation as the mechanism of action of antidepressant drugs. Prog. Neuropsychopharmacol. Biol. Psychiatry 7: 343-349, 1983.

Vogel, G.W., A. Buffenstein, K. Minter and A. Hennesey. Drug effects on REM sleep and on endogenous depression. Neurosci. Biobehav. Rev. 14:49-63, 1990. 


\section{SUMMARY}

The assumption that sleep dysregulation is more than a mere epiphenomenon of depression is based on several observations. Firstly, sleep complaints have been considered as cardinal symptoms of depression for as long as this disorder has been recognized. Approximately $90 \%$ of the patients suffering from a major depressive episode report complaints of severe insomnia. Such sleep disturbances are objectivelly substantiated by means of polysomnography. Secondly, it is now widely recognized that a number of sleep manipulations, particularly sleep deprivation, can alleviate symptoms of depression. Thirdly, antidepressant drugs (ADs) bring about remarkable changes in sleep polygraphic variables. Changes in sleep physiological processes might therefore be intimately involved in the pathogenesis and recovery of depression. The major theme of this thesis was to examine the influence of ADs on sleep in relation to the changes in clinical state during treatment.

In chapter 1 the literature on the effects of ADs on sleep polygraphic variables was reviewed against the background of four existing hypotheses concerning the relationship between sleep and depression. The best documented effect of most ADs, irrespective of their chemical classes, on sleep polygraphic variables in man are reduction of the amount of rapid eye movement sleep (REMS) and lengthening of REMS latency, while a REMS rebound is observed during withdrawal. Both the REMS pressure hypothesis and the hypothesis of a common mechanism controlling both REMS and depression are consistent with this general finding. They both focus on the role of REMS: suppression of REMS during treatment with ADs would be of importance for the improvement of depression. Two hypotheses (i.e. the S-deficiency and non-REMS hypotheses) provide an explanation in terms of non-REMS regulation and predict that an acute or cumulative suppression of non-REMS intensity is responsible for the therapeutic effects of ADS. They are indirectly related to REMS suppression because REMS suppression has been shown to reduce non-REMs intensity.

In chapters $2,3,4$ and 5 the data collected during two research projects in subjects with a major depression and insomnia were presented and discussed: the first project with the $\mathrm{AD}$ trazodone and the second with the $\mathrm{AD}$ citalopram. In both projects the same single blind design was used: a one-week wash-out period was followed by 1 week of placebo administration, a medication period

\footnotetext{
"Non-REMS intensity is considered to be expressed by the EEG power density of mainly the lower frequencies (1-4 HZ) during non-REMS, and can be measured continuously and quantitatively by spectral analysis of the sleep EEG. This variable plays an important role in a recent model, which offers an explanation of sleep regulation in terms of an interaction between a homeostatic and a circadian process. This model, i.e. the two-process model of sleep regulation, has proven to be successful in demonstrating the homeostatic character of non-REMs intensity.
} 
of 5 weeks, and a one-week placebo period. The sleep results were either obtained by polysomnography (chapters 2 and 4) or by spectral analysis of the EEG during non-REMS (chapters 3 and 5).

In chapter 2 the study on the effects of the AD trazodone on clinical state and on sleep polygraphic variables in eight outpatients with a major depressive disorder was presented. Earlier reports on trazodone seem to question the significance of REMS suppression in the pharmacological alleviation of depression. In fact it was suggested that slow wave sleep ( $S W S$ ) increase and amelioration of sleep continuity rather than REMS decrease would be of therapeutical significance. However, in our study trazodone did not influence sleep continuity (i.e., sleep latency, sleep period, total time asleep, total time awake, and sleep efficiency) and SWS, but did suppress REMS significantly. A significant increase of REMS latency was also found. The REMS variables returned to baseline values after one week placebo-withdrawal. No clear-cut relationship, however, was found between clinical response and changes in REMS parameters.

In chapter 3 the effects of trazodone on non-REMS intensity were examined. The EEG power spectra of the entire patient group showed a significant decrease of the power in the 13 and $14 \mathrm{~Hz}$ bins during trazodone treatment and a significant decrease in the $1 \mathrm{~Hz}$ bin one week after withdrawal of this drug. Upon inspection, four out of five clinical responders demonstrated a suppression of EEG power of the lower frequencies during and after trazodone treatment. This shows some consistency with the recent hypothesis on the role of non-REMS intensity suppression in the improvement of depression.

In chapter 4 the effects of the AD citalopram, a highly specific serotonin uptake inhibitor, on sleep polygraphic variables and clinical state in 16 outpatients with a major depression were presented. Compared to the eight "less improved" patients the eight "more improved" patients reported an improvement of both subjective sleep quality and self-rated mood. Citalopram did not influence sleep continuity, but did increase non-REMS stage 2 (percentage) significantly. Both during acute treatment and at the end of citalopram treatment a significant suppression of REMS was found. A significant lengthening of REMS latency was also found. The REMS variables returned to baseline values after one week placebo-withdrawal. However, the "less" and "more improved" patients did not differ significantly with respect to any sleep polygraphic variable.

In chapter 5 the effects of citalopram on non-REMS intensity were presented. At the end of the citalopram treatment and one week after withdrawal, a significant decrease of $E E G$ power mainly in the $8-9 \mathrm{~Hz}$ frequency range compared both to baseline and acute treatment in the entire patient group was found. No obvious change, however, was observed in the EEG power of the delta frequency range (1-4 Hz), which is considered to be the principle manifestation of nonREMS intensity. Furthermore, no relationship between changes in EEG power density and changes in clinical state could be demonstrated. 
In chapter 6 it was concluded that the hypotheses which consider REMS suppression of therapeutic importance are not confirmed in this thesis. Nevertheless REMS suppression might still be a prerequisite for the initiation of other, yet unknown, processes which are of importance for the improvement of depression.

Results from fundamental sleep research based on the two- process model of sleep regulation had inspired the EEG spectral studies of this thesis. The studies did not provide results supporting the hypotheses that suppression of nonREMS intensity is a key factor in the action of ADs. The results make clear that further fundamental and clinical sleep research is necessary. More knowledge is needed about the interference of sleep EEG power production by sleep disruptions or REMS changes and the influence of ADs on sleep homeostatic regulatory processes. Furthermore, there is a need for a better understanding of the neurobiological origins of the EEG spectral response patterns produced by ADs. 


\section{SAMENVATTING}

De veronderstelling dat de relatie tussen stoomissen van de slaap en depressie van betekenis is voor het ontstaan en het herstel van depressie, is gebaseerd op verschillende waarnemingen. Ten eerste: van oudsher worden slaapklachten beschouwd als kenmerkende symptomen van depressie. Ongeveer $90 \%$ van de mensen die een episode met een depressie in engere zin (volgens DSM-III-R criteria) doormaakt, vermeldt ernstige slapeloosheidsklachten. Dergelijke klachten zijn objectief amtoonbaar middels polygrafisch onderzoek van de slaap (d.w.z. tijdens de slaap continue geregistreerde EEG, EOG en EMG). Ten tweede: inmiddels staat vast dat bij ongeveer de helft van deze mensen manipulaties van de slaap, zoals totale slaapdeprivatie, tijdelijk een gunstige verandering van de depressie teweeg kunnen brengen. Ten derde: antidepressieve medicatie blijkt op een opmerkelijke manier de slaap te kunnen beïnvloeden. Dus veranderingen in de slaapfysiologie zouden van betekenis kunnen zijn voor het ontstaan en het herstel van de depressie. In dit proefschrift werd nagegaan wat de samenhang zou kunnen zijn tussen veranderingen van de slaap en van depressieve symptomatologie tijdens een behandeling met een antidepressivum.

In Hoofdstuk 1 werd de literatuur betreffende de effecten van antidepressiva op de slaap besproken, tegen de achtergrond van vier hypothesen m.b.t. de relatie tussen slaap en depressie. De meeste antidepressiva bleken, onafhankelijk van hun farmacologisch profiel, de snelle oogbewegingen slaap (rapid eye movement slaap of REMS) op een opmerkelijke manier te beïnvloeden: de hoeveelheid REMS wordt onderdrukt en de REMS-latentietijd (d.w.z. de tijd tussen het begin van de slaap en het eerste optreden van REMS) wordt verlengd. Het stoppen van een behandeling met een antidepressivum veroorzaakt meestall een terugkeer van deze REMS-waarden naar het nivo van vóór de behandeling. Zowel de REMS-druk (REMS pressure) hypothese, als de hypothese van een gemeenschappelijk controlemechanisme van REMS en depressie (a common control mechanism of both REMS and depression) zijn consistent met deze bevindingen. Ze leggen vooral de nadruk op de rol van de REMS: een onderdrukking van de REMS gaat gepaard met een herstel van de depressie. Twee hypothesen (de S-deficiëntie en de niet-REMs hypothesen) bieden een verklaring in termen van de regulatie van de niet-REMS en voorspellen dat acute of cumulatieve onderdrukking van de niet-REMs-intensiteit ${ }^{5}$ verantwoordelijk is voor de thera-

\footnotetext{
${ }^{5}$ De intensiteit van de niet-REMS (non-REMS intensity) zou tot uiting komen in de encrgie van vooral de lagere frequenties $(1-4 \mathrm{~Hz})$ van het EEG tijdens de niet-REMS. Deze kan continue en kwantitatief gemeten worden middels spectraal analyse van het slaap EEG. Deze variabele speelt cen belangrijke rol in een recent model dat een verklaring beoogt van de slaap regulatie in termen van een interactie tussen een homeostatisch en een circadiaan proces. Dit model (the two-process model of sleep regulation) is tot dusverre vooral succesvol gebleken in het aantonen van het homeostatisch karakter van de intensiteit van de niet-REMS.
} 
peutische effecten van antidepressiva. Een onderdrukking van deze EEG-intensiteit zou verantwoordelijk zijn voor het herstel van de depressieve toestand. Indirekt wordt een relatie gelegd met REMS-onderdrukking, omdat REMSonderdrukking een afname van de niet-REMS-intensiteit te zien geeft.

In de Hoofdstukken 2, 3, 4 en 5 werden de resultaten gepresenteerd en besproken van twee onderzoeksprojecten. In deze projecten werden de effecten. van twee antidepressiva (resp. trazodone en citalopram) op de slaap bij depressieven onderzocht. De onderzoeksopzet was steeds dezelfde: een zogenaamd 'single blind design' met een week 'wash-out', een week placebo-behandeling, een behandelperiode van vijf weken met het antidepressivum en tenslotte een week met een placebo-behandeling. De resultaten van de slaapobservaties waren gebaseerd enerzijds op polygrafische variabelen (Hoofdstukken 2 en 4) en anderzijds op spectraalanalyse van het EEG tijdens de niet-REMS (Hoofdstukken 3 en 5 ).

In Hoofdstuk 2 werd het onderzoek naar de effecten van het antidepressivum trazodone beschreven bij acht depressieve patienten. Eerder onderzoek door anderen met dit antidepressivum liet geen onderdrukking van de REMS zien, maar wel een toename van de langzame golven slaap [slow wave sleep (Sws); een onderdeel van de niet-REMS]. In ons onderzoek vonden we echter wel een significante onderdrukking van de REMS en geen significante verandering van de sws. Tevens werd een significante toename van de REMS-latentietijd vastgesteld. Echter, er kon geen duidelijke samenhang gevonden worden tussen de verbetering van de depressie en de veranderingen van de REMS.

In Hoofdstuk 3 werden de effecten van trazodone op de intensiteit in het slaap-EEG tijdens de niet-REMS nagegaan. Tijdens de trazodone behandeling werden er aanwijzingen gevonden voor een significante verlaging van de EEGenergie in de 13 en $14 \mathrm{~Hz}$ frequenties en tijdens de onttrekking van het medicament bleek de EEG-energie van de $1 \mathrm{~Hz}$ frequentie significant verlaagd te zijn. De EEG-energie in de lagere frequenties was verminderd tijdens de trazodone behandeling bij vier van de vijf patiënten die verbeterden. Dit resultaat kan een aanwijzing zijn dat de voorspelling dat een onderdrukking van de niet-REMSintensiteit een rol speelt bij het verbeteren van de depressie geldig zou kunnen zijn.

In Hoofdstuk 4 werd het onderzoek beschreven naar de effecten van citalopram op de slaap van zestien depressieven. Citalopram werkt zeer specifiek als remmer van de heropname van het neurotransmitter serotonine in de hersenen. In vergelijking met de mensen die relatief weinig verbeterden, bleken de mensen die relatief meer verbeterden aan te geven dat hun slaap en stemming verbeterden. Citalopram beïnvloedde niet de slaap-continuiteit, maar veroorzaakte een significante toename van het niet-REMS-2 stadium. Zowel direct na het begin van de behandeling (na één dag medicatie) als aan het eind van de behandeling werd een significante verlaging van de hoeveelheid REMS vastgesteld. 
Hetzelfde gold voor een significante verlenging van de REMS-latentietijd. Maar een samenhang tussen slaap-polygrafische variabelen en klinische verbetering kon niet worden aangetoond.

In Hoofdstuk 5 werden de effecten van citalopram op de EEG-energie tijdens de niet-REMS onderzocht. Aan het eind van de behandeling en na een week onttrekking van het antidepressivum werd een significante verlaging vastgesteld van de EEG-energie van hoofdzakelijk de 8-9 $\mathrm{Hz}$ frequenties. Er kon geen duidelijke verandering gevonden worden van de EEG-energie in de deltafrequentieband $(1-4 \mathrm{~Hz})$, welke wordt beschouwd als de belangrijkste maat voor de nietREMS intensiteit. Een samenhang tussen de EEG-energie variabelen en de klinische verbetering kon niet worden aangetoond.

In Hoofdstuk 6 werd een nabeschouwing van het onderzoek gepresenteerd. Er werd in geconcludeerd dat de veronderstelling dat REMS-onderdrukking rechtstreeks van belang is voor de verbetering van de depressie niet kon worden bevestigd. Desalniettemin zou de onderdrukking van de REMS een voorwaarde kunnen zijn voor het in werking treden van andere, nog onbekende, processen die van belang zijn voor het therstel van de depressie.

Resultaten van fundamenteel slaaponderzoek op basis van het twee-processenmodel van de slaapregulatie hadden aanleiding gegeven voor het spectraalanalytisch onderzoek van dit proefschrift. Dit onderzoek heeft niet de bevindingen opgeleverd die de hypothesen ondersteunen dat een onderdrukking van de intensiteit van de niet-REMS van belang is voor de therapeutische werking van antidepressiva. De resultaten maken evenwel duidelijk dat de huidige fundamentele kennis nog ontoereikend is om de rol van de slaapfysiologie bij het herstel van de depressie tijdens een behandeling met antidepressiva vast te stellen. 


\section{APPENDIX}

Power spectra during non-REM sleep of each subject separately treated with citalopram

Figures $\mathrm{A}$ to $\mathrm{P}$ show the power spectra during 91.5 min of non-REMS of each subject separately during the acute phase (CrT-A), at the end of citalopram treatment (CIT-E), and the withdrawal period (PW), relative to power spectra of baseline $(=100 \%)$. Power densities are plotted at the upper bounderies of the frequency bins. The codes $\mathrm{A}$ to $\mathrm{P}$ of the figures correspond with those of the table mentioned below. For symbols see Fig. A.

Table. Subject code, sex ( $F=$ female; $M=$ male), age, HRSD baseline scores and change in HRSD scores at the end of citalopram treatment, expressed as deviation from baseline. The rank order is based on clinical response

\begin{tabular}{llllc}
\hline $\begin{array}{l}\text { Subject } \\
\text { code }\end{array}$ & Sex & $\begin{array}{l}\text { Age } \\
\text { yrs }\end{array}$ & $\begin{array}{l}\text { HRSn } \\
\text { baseline } \\
\text { score }\end{array}$ & $\begin{array}{l}\text { HRSD } \\
\text { change } \\
(\%)\end{array}$ \\
\hline A & M & 51 & 26.0 & 0 \\
B & F & 39 & 32.0 & 0 \\
C & M & 58 & 28.0 & 12 \\
D & M & 54 & 28.5 & 20 \\
E & M & 52 & 24.0 & 39 \\
F & M & 50 & 29.0 & 48 \\
G & F & 35 & 32.0 & 53 \\
H & F & 37 & 24.0 & 54 \\
I & M & 45 & 22.0 & 56 \\
J & F & 26 & 24.0 & 57 \\
K & F & 46 & 30.0 & 60 \\
L & F & 24 & 23.5 & 62 \\
M & M & 47 & 31.0 & 71 \\
N & M & 30 & 24.0 & 75 \\
O & M & 47 & 22.0 & 82 \\
F & F & 29 & 21.0 & 87 \\
\hline
\end{tabular}



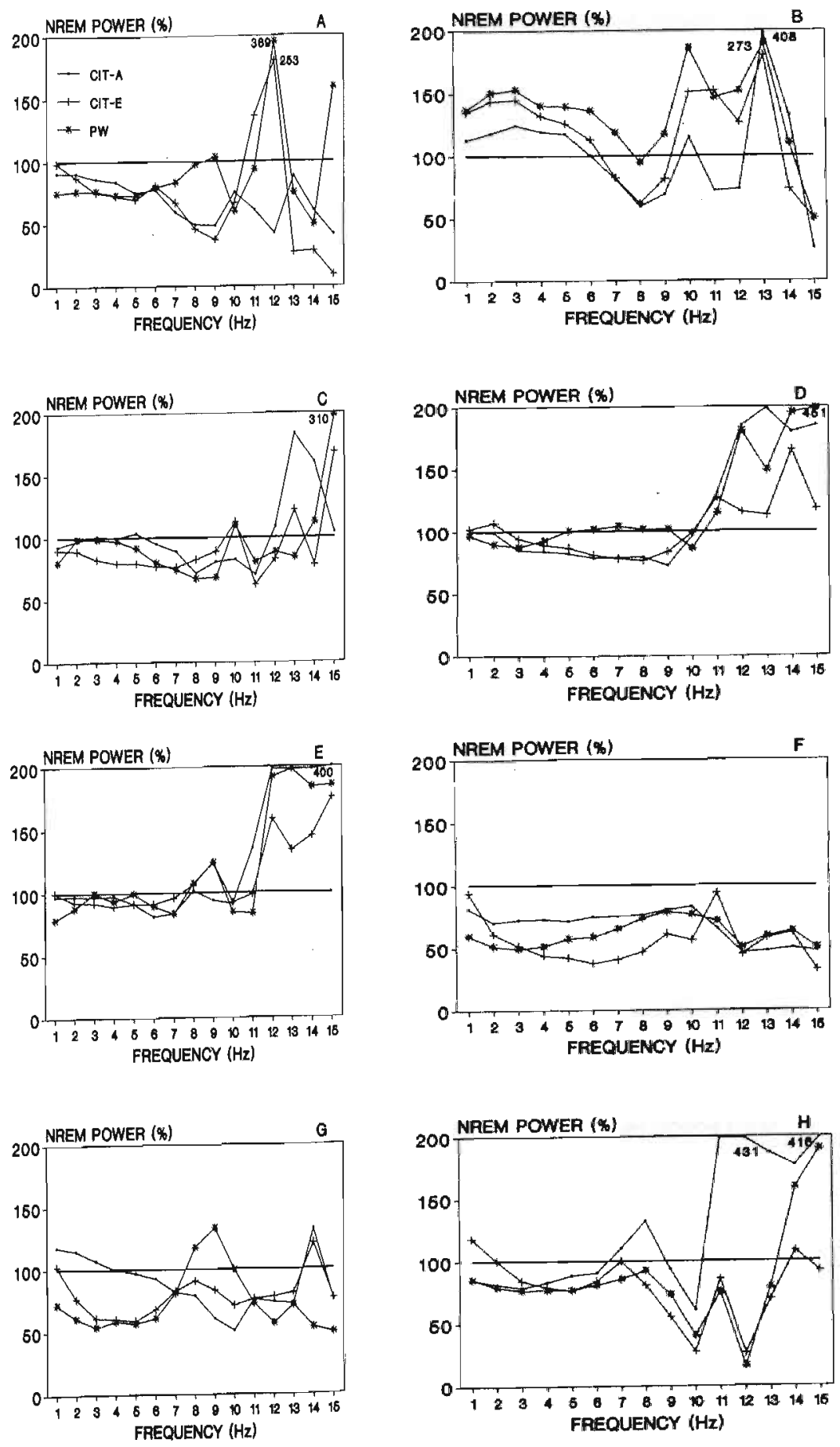

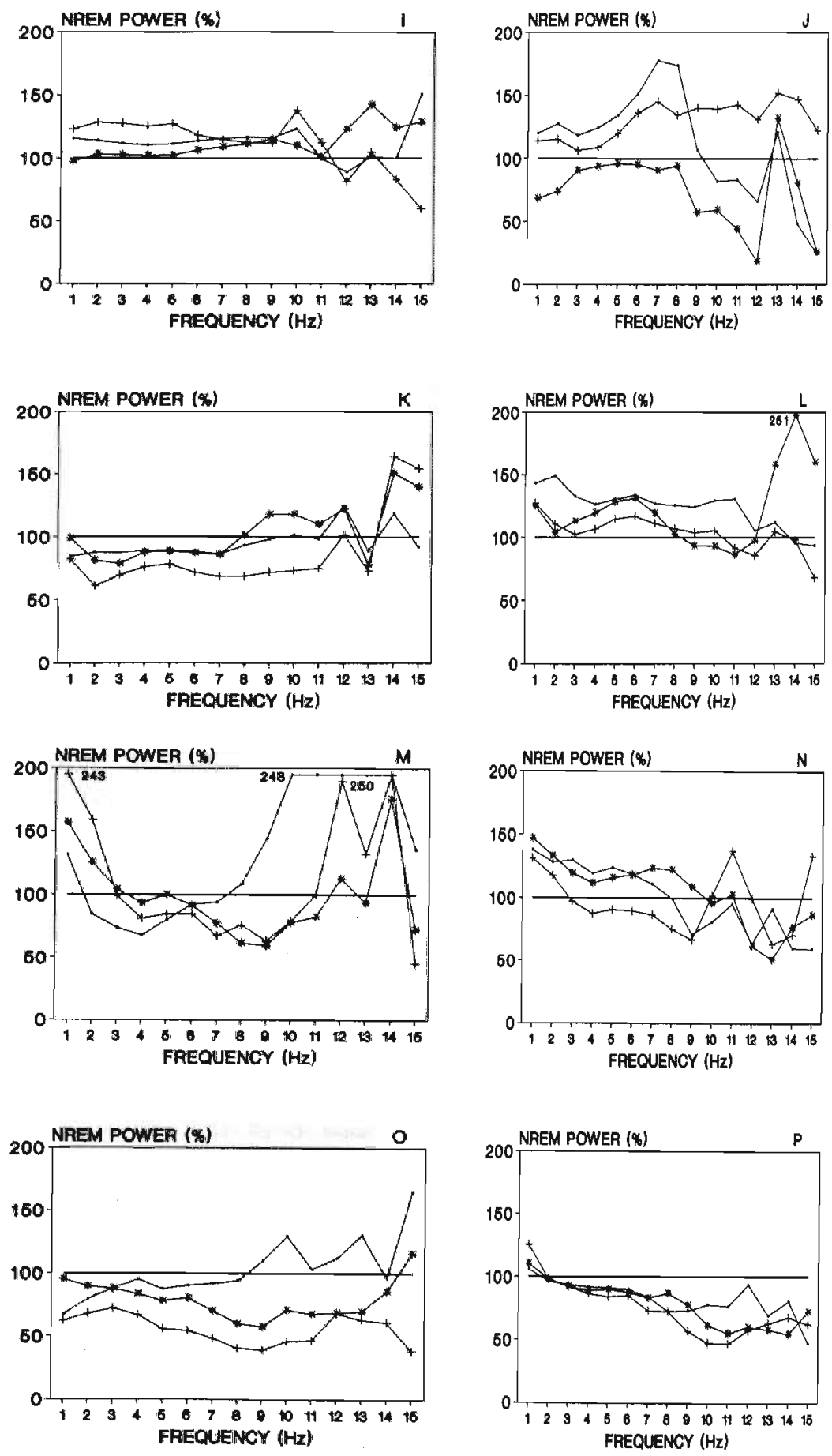


\section{LIST OF ABBREVIATIONS}

$\begin{array}{ll}\text { ACh } & \text { Acetylcholine } \\ \text { AD } & \text { Antidepressant drug } \\ \text { AMS } & \text { Adjective Mood scale } \\ \text { AT-RSD } & \text { Arousal-type REM sleep deprivation } \\ \text { CNS } & \text { Central Nervous System } \\ \text { EEG } & \text { Electroencephalography } \\ \text { EMG } & \text { Electromyography } \\ \text { EOG } & \text { Electrooculography } \\ \text { ES } & \text { End of sleep } \\ \text { FFT } & \text { Fast Fourier Transform } \\ \text { HRSD } & \text { Hamilton Rating scale for Depression } \\ \text { 5-HT } & \text { 5-Hydroxytryptamine; serotonin } \\ \text { Hz } & \text { Herz } \\ \text { MA } & \text { Monoamine } \\ \text { MANOVA } & \text { Multivariate Analysis of variance } \\ \text { MAOI } & \text { Monoamine Oxidase Inhibitor } \\ \text { MDE } & \text { Major Depressive Episode } \\ \text { NA } & \text { Noradrenaline } \\ \text { NOn-REM } & \text { Non-Rapid Eye Movement } \\ \text { PS } & \text { Paradoxical sleep } \\ \text { REM } & \text { Rapid Eye Movement } \\ \text { SL } & \text { Sleep Latency } \\ \text { SO } & \text { Sleep Onset } \\ \text { SQ } & \text { Subjective sleep Quality } \\ \text { SWA } & \text { Slow Wave Activity } \\ \text { SWS } & \text { slow Wave Sleep } \\ \text { TRT } & \text { Total Recording Time } \\ \text { TSA } & \text { Total time Spent Asleep } \\ & \end{array}$




\section{DANKWOORD}

Dit proefschrift kwam tot stand door de hulp en de steun van velen. Allereerst wil ik de patiënten bedanken die hun medewerking gaven aan het onderzoek. $\mathrm{Zij}$ deden dit in een periode van hun leven waarin ze gekweld werden door een kwaal die alleen mensen kan teisteren.

Professor Rutger van den Hoofdakker en dr. Domien Beersma, resp. eerste promotor en co-promotor, bedank it voor hun gedegen en kritische begeleiding. Ook dr. Netty Bouhuys wil ik bedanken voor haar vakkundige bijdrage aan en oprechte belangstelling voor het onderzoek. Aan hun 'groningse' supervisie voor dit proefschrift heb ik een belangrijk deel van mijn vorming tot wetenschappelijk onderzoeker te danken.

Met het intrigerende onderzoeksterrein 'slaap \& depressie' maakte ik voor het eerst aktief kennis tijdens mijn psychiatrie opleidingsjaar op de afdeling Biologische Psychiatrie van het Academisch Ziekenhuis in Groningen. Teruggekeerd in Maastricht vatte ik het plan op om op dit terrein onderzoek binnen de Vakgroep Klinische Psychiatrie van de RL te gaan opzetten. In de jaren die daar voor nodig bleken te zijn, hebben Rutger van den Hoofdakker en Domien Beersma hun niet-aflatende steun hieraan gegeven. De vele bezoeken aan het gastvrije 'huize van den Hoofdakker' en de afdeling Biologische Psychiatrie in Groningen waren voor mij steeds een 'hart onder de riem'. Ik hoop dat we onze vruchtbare samenwerking ook na dit promotie-onderzoek kunnen voortzetten.

De omstandigheden waaronder, vanaf 1981, de voorwaarden voor dit onderzoek moesten worden gecreëerd waren bijzonder en leerzaam. Er was nog geen traditie voor klinisch wetenschappelijk depressie-onderzoek aan de RL. Daarom was het nodig om daar zelf een infrastructuur voor te ontwikkelen. Hiervoor hebben de vakgroep Klinische Psychiatrie (0.l.v. professor Mark Richartz, tweede promotor), het Psychomedisch Streekcentrum Vijverdal, en later het "SIEP'-programma (o.l.w. professor Marten de Vries) mij de ruimte gegeven, waarvoor mijn dank. Drs. Aart-Jan Vrijlandt heeft, als directeur patiëntenzorg van Vijverdal mij door 'dik en dun' in deze ontwikkeling ondersteund. Voor de academisering van Vijverdal bestond toen geen 'blauwdruk'. De eerste jaren betekende dit de ontwikkeling van de Opname \& Crisis-afdeling van Vijverdal, wat ondermeer resulteerde in de Academische Afdeling voor de Behandeling van Stemmingsstoornissen (AABS) en een slaaplaboratorium. Hieraan hebben velen bijgedragen. In de eerste plaats de medewerkers en de arts-assistenten van de AABS. In deze ontwikkeling was het steeds zoeken naar een verantwoord evenwicht tussen de belangen van de patiëntenzorg en die van het onderzoek. Hoewel ik door het tijdrovende karakter van het onderzoek nogal heb moeten schipperen met mijn tijd voor de afdeling, hebben de verpleegkundigen van de 
AABS (m.n. Lidwie Krutzen, Tiny Gorissen, Petra Speetjens, Hennie Verhallen, Ger Dierx, Wim Huibers en Paul Linckens) mij steeds met grote betrokkenheid gesteund. Mijn dank voor het door hun in mij gestelde vertrouwen. Freddy Jans heeft als verpleegkundig-coördinator van deze complexe afdeling zijn noodzakelijk steentje bijgedragen; en dat was met het steeds rijpender tekort aan middelen geen gemakkelijke opgave. Als collega's van de staf zijn René Gitsels, Henk Milius, Arthur de Bie en als clusterleiders Paul Tans en later Olga Solet steeds een grote steun geweest. Rob van Diest heeft als grondig werkend psychofysioloog aan de inrichting van het slaaplaboratorium een cruciale bijdrage geleverd. Hij was ook altijd bereid om te helpen en nam primair de communicatie voor zijn rekening met electronici, computer-programmeurs enz. Mede door zijn eigen onderzoek hebben we menige discussie over slaapfysiologie gehad. Tevens mijn dank aan de medewerkers van de Technische Dienst van Vijverdal en van de Instrumentele Dienst van de RL voor hun noodzakelijk aandeel aan de totstandkoming van het slaaplaboratorium.

De uitvoering van het trazodone project ( $\left(88-^{\prime} 90\right)$ is het resultaat geweest van een samenwerking met het Instituut voor Geneesmiddelen Veiligheid en Gedrag, Rob Havermans, Els Schoenmakers en Henriëtte Swijgman hebben geholpen bij de slaapregistraties t.b.v. dit project. Rob Havermans heeft tevens een belangriijk aandeel gehad aan de eerste fase van het literatuuronderzoek. Tijdens de uitvoering van het citalopram project ('90-'92) heeft Gert Jan Mevius met grote inzer geholpen. Tevens mijn dank aan Karin Schols voor haar bijdrage aan de uitvoering van de slaapregistraties voor dit project. De klinischfarmaceuten Ton Beysens en Gert Beuman van het AZM, de apotheek en de prikdienst van Vijverdal hebben ervoor gezorgd dat de organisatie van de geneesmiddelen-verstrekking en de bloed-spiegelbepalingen zonder problemen verliepen. Erik Schouten heeft waardevolle adviezen gegeven voor de statistische analyses en Alan Ralston was behulpzaam bij het corrigeren van de engelse tekst.

En niet in de laatste plaats dank aan mijn thuisfront en onze vrienden. Annemiek, Rutger en Maarten hebben mijn werkzaamheden als slaaponderzoeker met grote interesse gevolgd, soms onder enig protest. Kortom, het tot stand komen van het slaaponderzoek van dit proefschrift was de resultante van de inspanning van velen; meer dan hier zijn genoemd. 


\section{CURRICULUM VITAE}

De schrijver van dit proefschrift werd geboren op 2 maart 1949 te Rotterdam. In 1966 behaalde hij het H.B.S.-B diploma aan het Johannes Calvijn Lyceum te Rotterdam; in 1973 het artsdiploma aan de Medische Faculteit van de Rijksuniversiteit Utrecht. Van 1974 tot 1976 was hij als wetenschappelijk medewerker verbonden aan de Medische Faculteit van de Rijksuniversiteit Limburg i.o.. Van 1976 tot 1980 volgde hij de opleiding tot psychiater; d.w.z. psychiatrie in het PMS Vijverdal te Maastricht en in het Academisch Ziekenhuis te Groningen; neurologie in het De Wever Ziekenhuis te Heerlen. Van 1974 tot 1984 volgde hij diverse psychotherapie opleidingen. Vanaf 1980 is hij als universitair docent verbonden aan de vakgroep Klinische Psychiatrie van de Rijksuniversiteit Limburg en tevens werkzaam als projectleider van de Opname \& Crisis-afdeling, resp. de Academische Afdeling voor de Behandeling van Stemmingsstoornissen van het Psychomedisch Streekcentrum Vijverdal. Tevens is hij plaatsvervangend hoofdopleider van de A-opleiding psychiatrie.

Werkadres: Vakgroep Psychiatrie, sectie klinische en biologische psychiatrie, Rijksuniversiteit Limburg, Postbus 616, 6200 MD Mastricht.

Tel.: 043-68 5444 Telefax: 043-685331 


\section{LIST OF PUBLICATIONS}

Bemmel, A.L. van and R.H. van den Hoofdakker. Maintenance of therapeutic effects of total sleep deprivation by limitation of subsequent sleep. Acta Psychiat, Scand. 63, 453-462, 1981.

Bemmel, A.L. van en J. Berkhout. Slaapklachten en slaapproblemen. Wet. Uitg. Bunge, Utrecht, 1982.

Bemmel, A.L. van en H.F. Kraan. De onbestanbare medaille van de sociobiologische psychiatrie, T. v. Psychiatric, 24: 75-79, 1982.

Bemmel, A.L. van. Biologische behandelingen van de depressieve mens, Organon Nederland: 157$169,1984$.

Bemmel, A.L. van en R. van Diest. Klinisch slaaponderzoek en depressie. Bul]. COBO, XV: 12-24, 1985.

Bemmel, A.L. van. Slaapstoornissen. Patient Care 12: 31-39, 1985.

Bemmel, A.L. van, E.H.J. Smeets and R. van Diest. 24-hour pattern of urinary MHPG excretion in depressives and normals. Acta Psychiat. Scand. 78: 298-303, 1988.

Bemmel, A.L. van, R. van Diest, E.H.J. Smeets, P. van Dongen and A.J.C. Hilgersom. Seasonal variation of cortisol plasma levels in depressives. J. Affect. Disord. 15: 191-193, 1988.

Bemmel, A.L. van. The link between sleep and depression: a pharmacological approach. In: A.M.L. Coenen (ed) Sleep-Wake Research in the Netherlands, Nijmegen :14, 1990.

Bemmel, A.L. van. De invloed van antidepressiva op de slanp: klinische en theoretische aspekten. In: Verhoeven (red) Slaap en depressie, symposium onder auspiciën van het Interdisciplinair Genootschap voor Biologische Psycliatrie. Searle/Maarssen: 31-38, 1990.

Bemmel, A.L. van. Biologische psychiatric: subspecialisme of benaderingswijze? Bull. $\mathrm{COBO}$, XXIV (1), 6-11, 1991.

Bemmel, A.L. van, G.J. Mevius and R. van Diest. The effects of trazodone on sleep stages and EEG power density in de pressed patients. In; A.M.L. Coenen (ed) Sleep-Wake Research in the Netherlands, Groningen: 23, 1991.

Bemmel, A.L. van, A.G. Havermans and R. van Diest. Effects of trazodone on EEG sleep and clinical state in major depression. Psychopharmacology 107: 569-574, 1992.

Bemmel, A.L. van, G.J. Mevius, and D.G.M. Beersma. EEG power density of NREM sleep in depression treated with trazodone. In: A.M.L. Coenen (ed) Sleep-W/ake Research in the Netherlands, Amsterdam: 17-18, 1992.

Bemmel, A. L. van, G.J. Mevius and R. van Diest. EEG power density of NREM sleep in depression during treatment with trazodone. J. Sleep Res. 1, Suppl. 1: 238, 1992.

Bemmel, A.L. van, D.G.M. Beersma, R.H. van den Hoofdakker and G.J. Mevius and. Changes in EEG power density of non-REM sleep in depressed patients during treatment with trazodone.

Submitted Psychiatry Res., 1993.

Bemmel, A.L. van, R.H. van den Hoofdakker, D.G. Beersma and A.L. Bouhuys. Changes in sleep polygraphic variables and clinical state in depressed patients during treatment with citalopram.

Psychopharmacology, accepted for publication, 1993.

Bemmel, A.L. van, D.G.M. Beersma and R.H. van den Hoofdakker. Changes in EEG power density of non-REM sleep in depressed parients during treatment with citalopram. Accepted for publication in J. Sleep Res., 1993.

Bemmel, A.L. van. The effects of anidepressants on sleep polygraphic variables in depressives and their clinical relevance. In: A.M.L. Coenen (ed) Sleep-Wake Research in the Netherlands, Elinkwijk, Utrecht, 1993.

Gerritsma, J.G.M. en A.L. van Bemmel. Acteursimulatie in het medisch onderwijs, Medisch Contact 29: 841-844, 1974. 
Gerritsma, J.G.M. und A.L.van Bemmel. Simulation durch Schauspieler in Medizinunterricht, Schweizerische Ärtzezeitung 57: 6\%9, 1976.

Bemmel, J.H. van, A.L. van Bemmel en R. van Djest. Staat de informatica model voor de psychiatrie? Bull. COBO XV:30-36, 1982.

Havermans, A.G. en A.L. van Bemmel. De inuloed van antidepressiva op de slaap: betekenis voor het therapeutisch werkingsmechanisme. T. v. Psychiatrie 33: 645-663, 1991.

\section{Abstracts}

Bemmel, A.L. van and R.H, van den Hoofdakker. Maintenance of therapeutic effects of total sleep deprivation by means of limitation of subsequent sleep. Abstr. 5th ESRS Congress, Amsterdam, 1980.

Smeets, E.H.J. and A.L. van Bemmel. Phase-advance of urinary MHPG excretion in normals and depressives. Abstr. 11th CINP Congress, Florence, 1984.

Bemmel, A.L. van, R. van Diest and J.H.M. Tulen. REM sleep and non-REM sleep characteristics and clinical state of endogenous depressives treated with placebo ormianserine. Abstr. 7th ESRS Congress, Munchen, 1984.

Tulen, J.H.M., A. Kumar, R. van Diest and A.L. van Bemmel. Ultradian thythmicity during nocturnal sleep of normal and depressed subjects. Abstr. 7th ESRS Congress, München, 1984.

Bemmel, A.L. van, E.H.J. Smeets and R. van Diest. 24-hour variation of urinary MHPG excretion in normals and depressives, measured at 3 -h intervals during 48 hours. Proceedings of the 27 th Dutch Federation of medical scientific societies. Groningen, 1986.

Bemmel, A.L. van, R. van Diest and E.H.J. Smeets. Circadianurinary MHPGexcretion: effects of total sleep deprivation. Abstr. Academic meeting, Biological measures, their theoretical and diagnostic value inpsychiatry. Noordwijk a.Z., 1986.

Bemnel, A.L. van, R. van Diest and E.H.J. Smeets. Circadian urinary MHPG excretion in normals and depressives: effects of total sleep deprivation. Abstr. 8th Eur Sleep Congress, Szeged, 1986.

Tulen, J.H.M., A. Kumar and A.L. van Bemmel. Eflects of mianserine on synchronized EEG activity during sleep ofdepressives. Abstr. 8th ESRS Congress, Szeged, 1986.

Bie, A.J.H.T. de, A.L. van Bemmel and R. van Diest. Seasonal variation of affective disorders: a pilot study in outparients. Abstr. XVIII Intern. Conf. on Chronobiology, Leiden, 1987.

Bie, A.J.H.T. de, A.L. van Bemmel and R. van Diest. Seasonal variation of depression: diagnostic aspects. Abstr. XVIth CINP Congress, München, 1988.

Bernmel, A.L. van, R. van Diest, E.H.J. Smeets and P.H.M. van Dongen. Seasonal variation of corrisol levels in depressives. Abstr. XVIth CINP Congress, Munchen, 1988.

Bemmel, A.L. van, A.G. Havermans, R. van Diest, E.A.J.M. Schoenmakers and J.F. O'Hanlon. Do trazodone"s effeets on REM sleep in depression contradict current theory. Abstr. World Congress of Psychiatry, Athens, 1989.

O'Hanlon, J.F., A.L. van Bemmel and E.A.J.M. Schoenmakers. Depression, insomnia and trazodone. Abstr. World Congress of Psychiatry, Athens, 1989.

Schoenmakers, E.A.J.M., A.L. van Bemmel, R. van Diest and J.F. O'Hanlon. Depressed patients' sleep and performance during trazodone therapy. Abstr. World Congress of Psychiatry, Athens, 1989.

Bemmel A.L. van, R. van Diest and A.G. Havermans. The effects of REM sleep suppression on non-REM sleep intensity in depressed patients treated with trazodone. Abstr. 10th Eur. Sleep Congress, Strasbourg, 1990. 
Havermans, A.G., A.L. van Bemmel and R. van Diest. The relationship between changes in REM sleep and clinical improvement in depressed patients treated with trazodone. Abstr. 100h Eur. Sleep Congress, Strasbourg, 1990.

Bemmel, A.L. van. The effects of trazodone on EEG power density of sleep in depressed paticnts. Abstr. Frühjahrstagung der Arbeits gemeinschaft Klinischer Schlafzentern: Congress on Normal and Abrormal REM sleep regulation. Freiburg, 1991.

Bemmel, A.L. van. The effects of trazodone on sleep stages and power densiry in depresscd patients. Abstr. 5th World Congress of Biological Psychiatry, Florence 1991.

Bemmel, A.L. van. The influence of antidepressant drugs on sleep polygraphic variables in man: a review of the literature. Abstr. 21ste Voorjaarscongres Ned. Ver. voor psychintrie. Lunteren, 1993.

Bemmel, A.L. van. Changes in EEG power density of non-REM sleep in depressed patients during treatment with antidepresants. Abstr. 21ste Voorjaarscongres Ned. Ver. voor psychiatrie. Lunteren, 1993.

Bemmel, A.L. van, D.G.M. Beersma, R.H. van den Hoofdakker and G.J. Mevius. Changes in EEG power density of non-REM sleep in depressed patients during treatment with trazodone. Abstr. in: Coenen (ed) Sleep-wake research in the Netherlands, Elinkwijk, Utrecht, 1993.

Bemmel, A.L. van, R.H. van den Hoofdakker, D.G.M. Beersma and A.L. Bouhuys. Changes in sleep polygraphic variables and clinical state in depressed patients during treatment with citalopram. Abstr. in: Coenen (ed) Sleep-wake research in the Netherlands, Elinkwijk, Utrecht, 1993.

Bemmel, A.L. van, D.G.M. Beersma and R.H. van den Hoofdakker. Changes in EEG power density of non-REM sleep in depressed patients during treatment with citalopram. Abstr. in: Coenen (ed) Sleep-wake research in the Netherlands, Elinkwijk, Utrecht, 1993. 



\section{COLOPHON}

SLEEP, DEPRESSION AND ANTIDEPRESSANTS werd typografisch vormgegeven door Bèr Crouzen van Scorpio bv te Maastricht en onder zijn leiding gedrukt in oktober 1993. De hier gebruikte letter is de Garamont Stempel.

Ontwerp omslag en afbeelding op frontispice naar een tekening Pale Mirror, 1993, (29,5×22cm.), zijn van de hand van Gèr Boosten, evenals de illustraties op de hoofdstuktitels. (@ Gèr Boosten, Maastricht) 



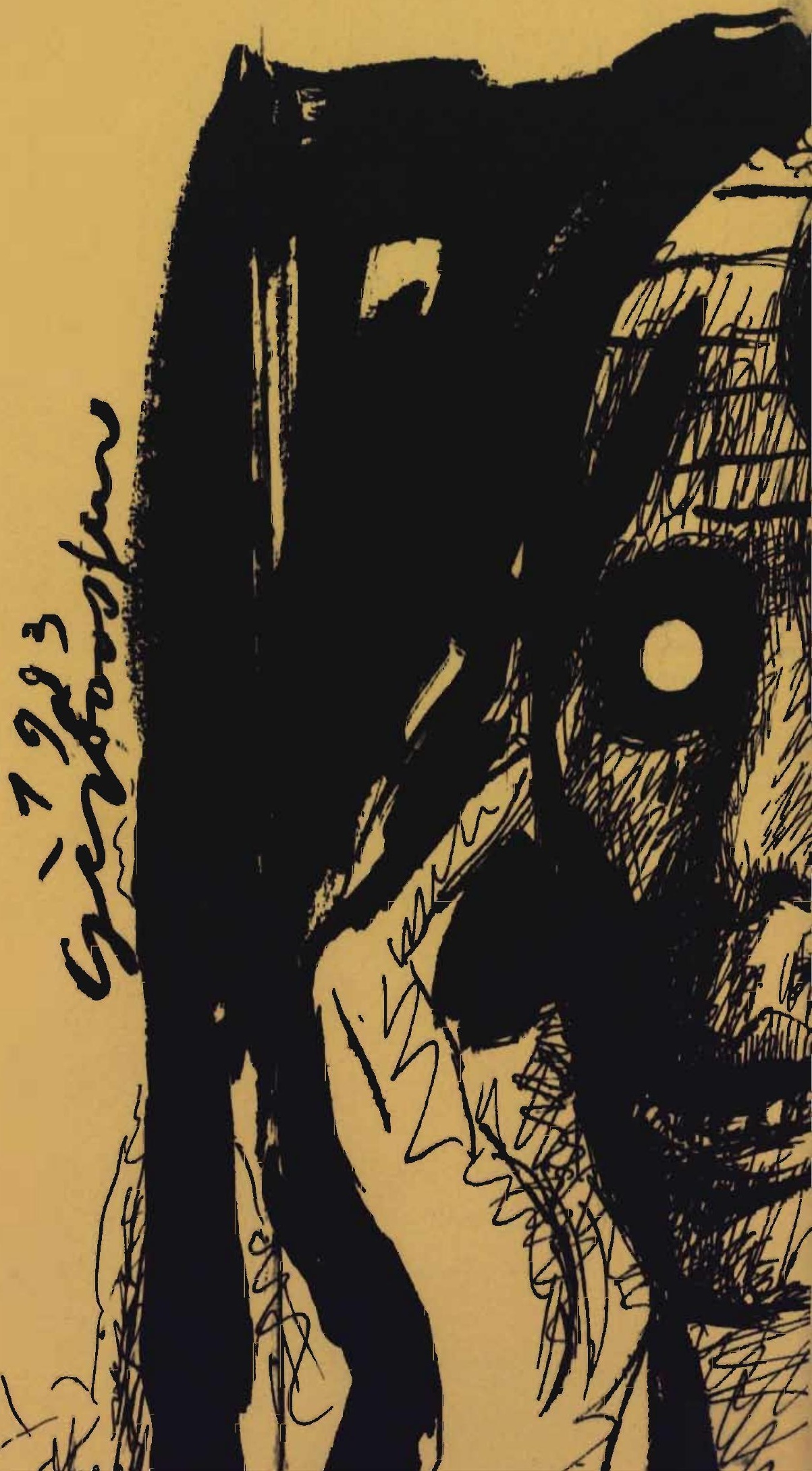

